\title{
IUCN
}

\section{Best Practice Guidelines for the Prevention and Mitigation of Conflict Between Humans and Great Apes}

Kimberley Hockings and Tatyana Humle Series Editor: E.A. Williamson

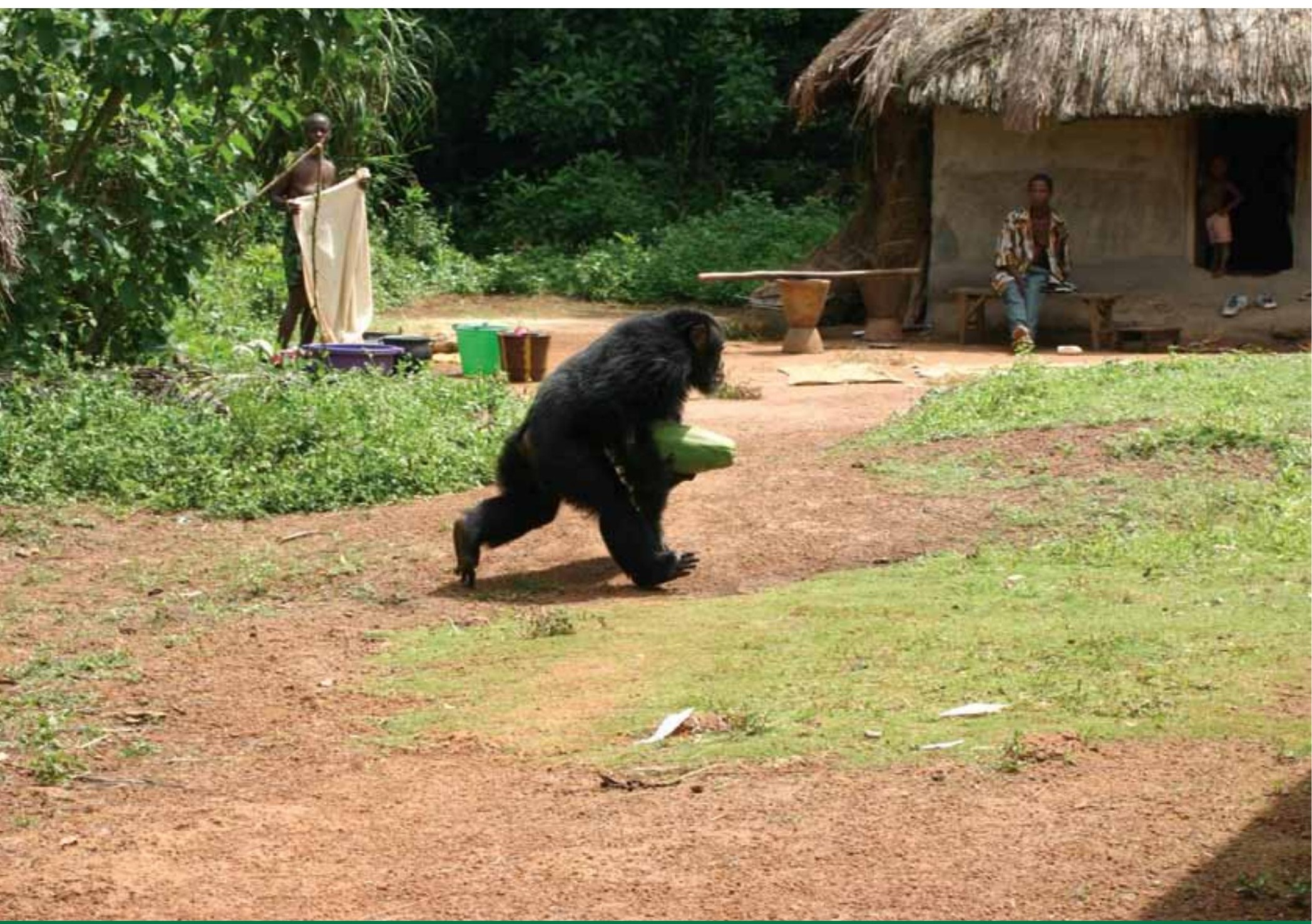




\section{IUCN}

Founded in 1948, IUCN (International Union for Conservation of Nature) brings together States, government agencies and a diverse range of non-governmental organizations in a unique world partnership: over 1000 members in all, spread across some 160 countries.

As a Union, IUCN seeks to influence, encourage and assist societies throughout the world to conserve the integrity and diversity of nature and to ensure that any use of natural resources is equitable and ecologically sustainable.

IUCN builds on the strengths of its members, networks and partners to enhance their capacity and to support global alliances to safeguard natural resources at local, regional and global levels.

\section{IUCN Species Survival Commission}

The Species Survival Commission (SSC) is the largest of IUCN's six volunteer commissions with a global membership of 8,000 experts. SSC advises IUCN and its members on the wide range of technical and scientific aspects of species conservation and is dedicated to securing a future for biodiversity. SSC has significant input into the international agreements dealing with biodiversity conservation. Web: www.iucn.org/themes/ssc

\section{IUCN Species Programme}

The IUCN Species Programme supports the activities of the IUCN Species Survival Commission and individual Specialist Groups, as well as implementing global species conservation initiatives. It is an integral part of the IUCN Secretariat and is managed from IUCN's international headquarters in Gland, Switzerland. The Species Programme includes a number of technical units covering Wildlife Trade, the Red List, Freshwater Biodiversity Assessments (all located in Cambridge, UK), and the Global Biodiversity Assessment Initiative (located in Washington DC, USA).

\section{IUCN SSC Primate Specialist Group}

The Primate Specialist Group (PSG) is concerned with the conservation of more than 630 species and subspecies of prosimians, monkeys, and apes. Its particular tasks include carrying out conservation status assessments, the compilation of action plans, making recommendations on taxonomic issues, and publishing information on primates to inform IUCN policy as a whole. The PSG facilitates the exchange of critical information among primatologists and the professional conservation community. The PSG Chairman is Dr. Russell A. Mittermeier, the Deputy Chair is Dr. Anthony B. Rylands, and the Coordinator for the Section on Great Apes is Dr. Liz Williamson. Web: www.primate-sg.org/ 


\section{Best Practice Guidelines for the Prevention and Mitigation of Conflict Between Humans and Great Apes}

Kimberley Hockings and Tatyana Humle

Series Editor: E.A. Williamson 


\section{IUCN}

The designation of geographical entities in this book, and the presentation of the material, do not imply the expression of any opinion whatsoever on the part of IUCN or other participating organizations concerning the legal status of any country, territory, or area, or of its authorities, or concerning the delimitation of its frontiers or boundaries. The views expressed in this publication do not necessarily reflect those of IUCN or other participating organizations.

Published by: IUCN, Gland, Switzerland in collaboration with the Center for Applied Biodiversity Science at Conservation International

Copyright: $\quad$ C 2009 International Union for Conservation of Nature and Natural Resources

Reproduction of this publication for educational or other non-commercial uses is authorized without prior written permission from the copyright holder(s) provided the source is fully acknowledged.

Reproduction of this publication for resale or other commercial purposes is prohibited without prior written permission of the copyright holder(s).

Citation: $\quad$ K. Hockings and T. Humle (2009). Best Practice Guidelines for the Prevention and Mitigation of Conflict Between Humans and Great Apes. Gland, Switzerland: IUCN/SSC Primate Specialist Group (PSG). 40 pp.

ISBN: $\quad 978-2-8317-1133-1$

Cover photo: Adult male chimpanzee runs through a village in Guinea. Photo @ Kimberley Hockings

Layout by: $\quad$ Center for Applied Biodiversity Science at Conservation International

Available from: [e-mail] j.lucena@conservation.org; [web] http://www.primate-sg.org/ 


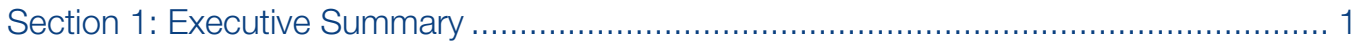

Section 2: Introduction, Review and Use of These Guidelines ..................................... 1

2.1 What is human-great ape conflict (HGAC)?

2.2 What are the causes of human-great ape conflict (HGAC)? …......................................... 2

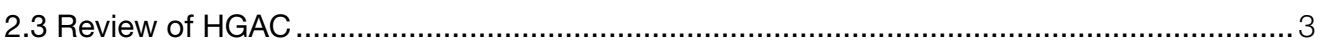

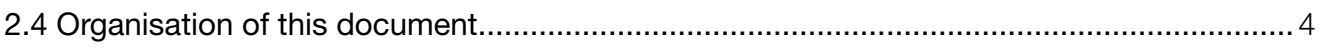

Section 3: Assessment of HGAC: Preparatory Issues ..................................................... 5

3.1 Sources and reliability of information about a HGAC issue................................................ 5

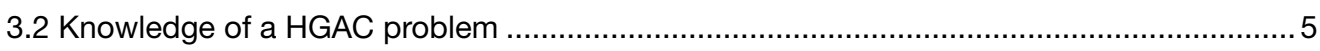

3.3 Who is affected by HGAC and what are their perceptions and attitudes? ........................ 6

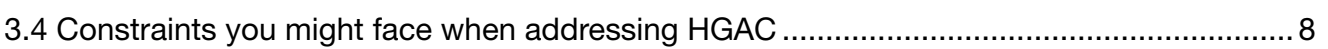

3.5 Others involved with the problem and how they can help you........................................... 8

Section 4: Review of Potential HGAC Counter-Measures and their Effectiveness ............. 9

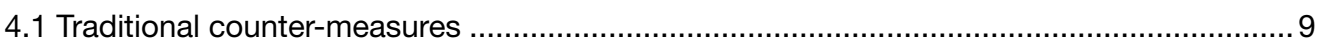

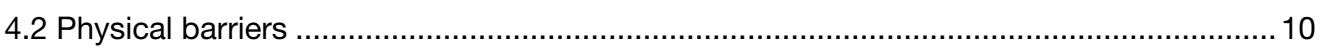

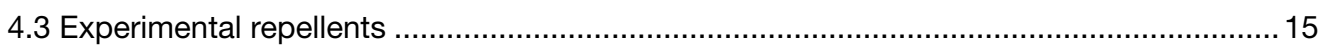

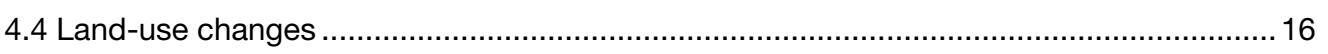

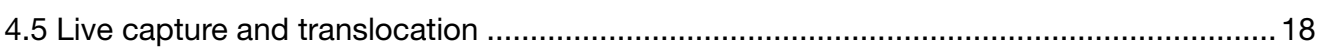

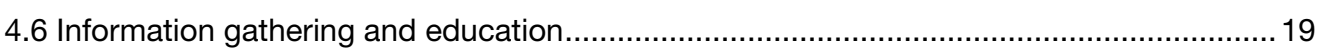

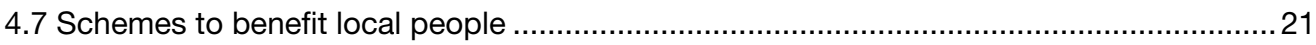

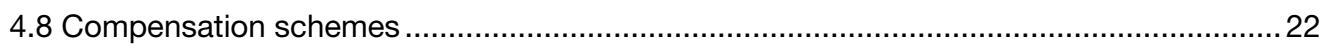

Section 5: Planning a HGAC Management Strategy .................................................. 24

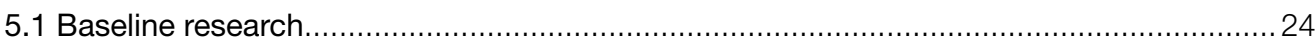

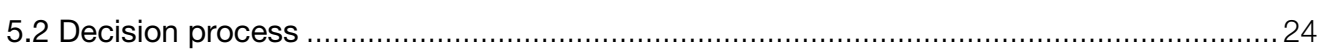

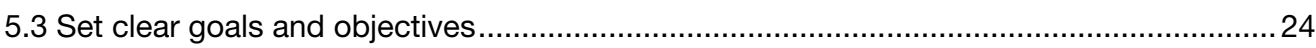

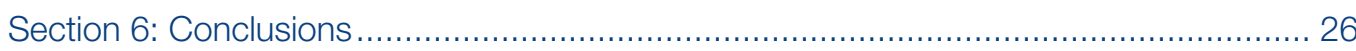

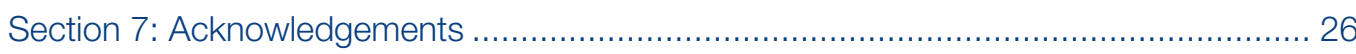

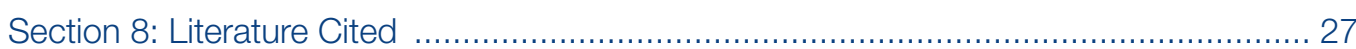

Appendix A: Species-specific reviews of crop-raiding and aggressive

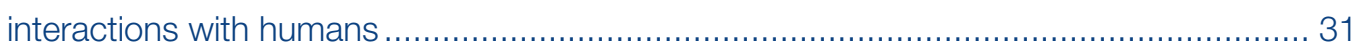

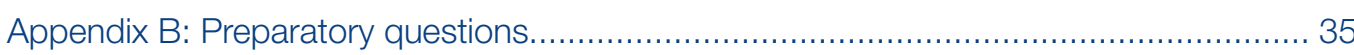

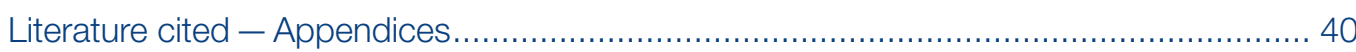

Note: Throughout these guidelines, we use 'great apes' to refer to the nonhuman great apes: bonobos, chimpanzees, gorillas and orangutans.

Certain information cited in these guidelines was provided by personal communications; the sources are not always given in the main body of the text, but all contributing authors are acknowledged in Section 7. 



\section{Section 1: Executive Summary}

One of the challenges facing great ape conservation is the rising level of interaction between humans and great apes, and the resulting conflicts that emerge. As human populations continue to grow and human development makes deeper incursions into forest habitats, such conflicts will become more widespread and prevalent in the natural ranges of great apes, especially considering that the majority of great apes live outside protected areas. It is essential that we develop a comprehensive understanding of existing and potential conflict situations, and their current or future impacts on both great apes and humans. This will require the integration of quantitative and qualitative data on multiple aspects of human and great ape behaviour and ecology, along with a good understanding of local people's perceptions of the situation. Such knowledge can then be used to develop effective, locally-adapted, management strategies to prevent or mitigate human-great ape conflicts, whilst respecting both conservation objectives and socio-cultural-economic contexts. These guidelines outline a sequence of logical steps that should be considered prior to any form of human-great ape conflict intervention, and propose possible counter-measures to be used in the management of human-great ape conflicts.

\section{Section 2: Introduction, Review and Use of These Guidelines}

\subsection{What is human-great ape conflict (HGAC)?}

Human-wildlife conflict is a well-known phenomenon. HGAC is a subset of human-wildlife conflict that can broadly be defined as 'any human-great ape interaction which results in negative effects on human social, economic or cultural life, great ape social, ecological or cultural life or the conservation of great apes and their environment' (adapted from the IUCN/SSC African Elephant Specialist Group). HGAC frequently involves conflict among people who have different goals, perceptions and levels of empowerment.

These guidelines will focus on conflicts over resources, especially food and water that humans perceive to be owned by them, and great ape attacks on humans. Given this narrow scope, these guidelines discuss aspects of HGAC that result in 'any threats to human safety or property by great apes and ensuing retaliatory responses by affected humans'. The HGAC guidelines

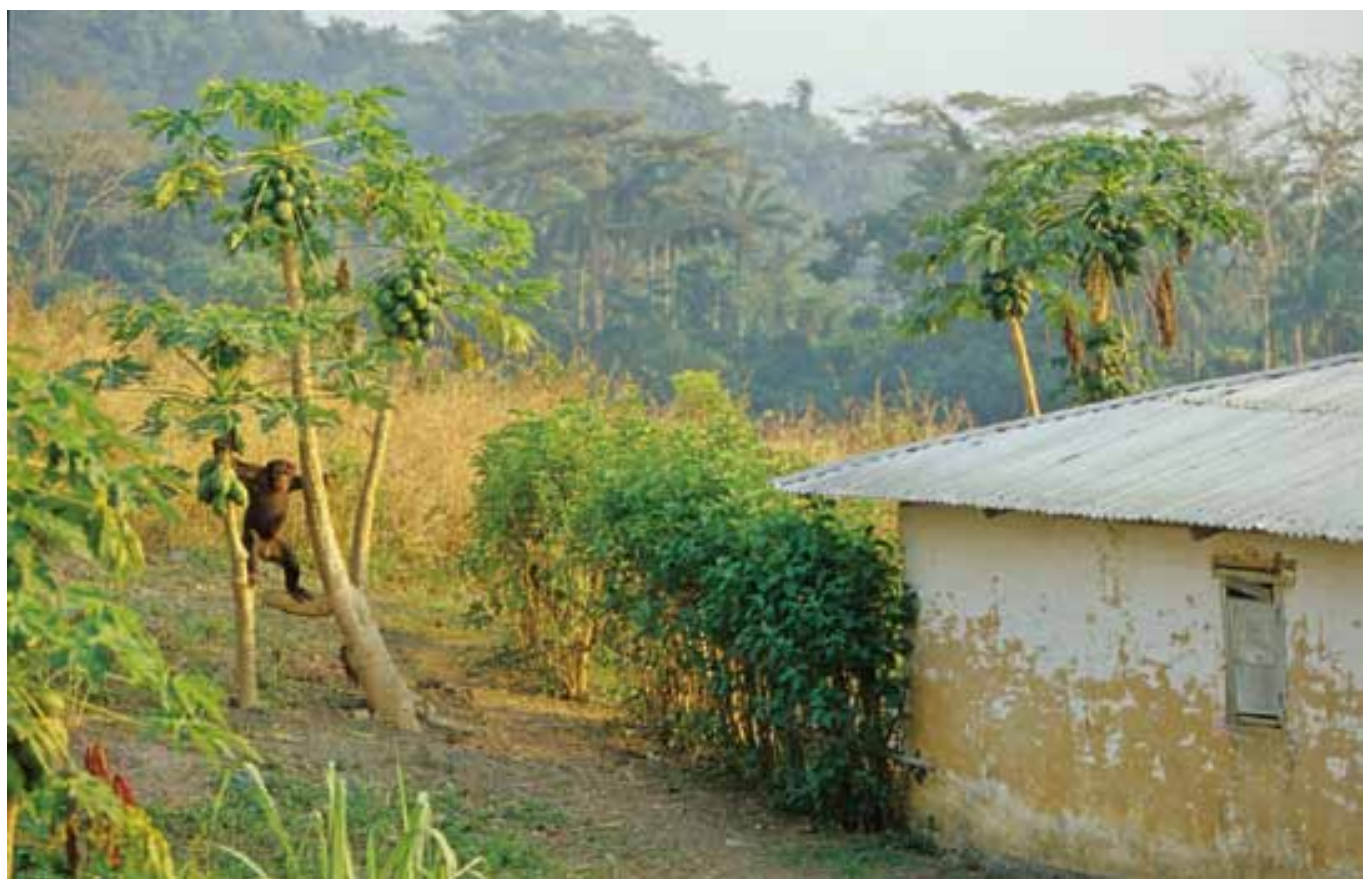

Chimpanzees in Bossou leave the forest to raid crops during periods of wild fruit scarcity.

Photo: () Tetsuro Matsuzawa 
intend to provide researchers and wildlife managers with (1) a sequential and logical framework to analyse and evaluate ongoing or foreseeable HGAC problems, and (2) a menu of possible counter-measures - categories of actions comprising a series of methods - that have the potential to be effective in the short- or long-term and which may be readily locally adapted to each site and HGAC situation. These guidelines are intended to help wildlife managers think about the nature of HGAC as it occurs in their area, what counter-measures they could consider and adopt to mitigate the problem, and how best to implement and evaluate these measures whilst considering the needs of both humans and great apes (inspired by Hoare 2001).

\subsection{What are the causes of human-great ape conflict (HGAC)?}

Across Africa and South-east Asia, as habitat destruction and fragmentation continue at an alarming rate, a growing number of great ape populations are increasingly forced into proximity with humans. The proximate mechanisms of forest disturbance vary, but subsistence and small- and large-scale commercial agriculture, plantations and extractive industries such as logging and mining are significant threats to tropical forests. The drive for economic growth through exploitation of natural resources and /or the establishment of large-scale agricultural projects aggravate the consequences of the human-primate interface. High rates of human population growth in great ape range countries contribute to the widespread conversion of natural habitats to agriculture and other human uses. Other factors such as poverty exacerbate the situation (Cowlishaw and Dunbar 2000). As a consequence, human and nonhuman species are increasingly coming into direct contact, competition, and conflict with each other (Lee et al. 1986). Using GLOBIO model analysis, Nelleman and Newton (2002) predicted that by 2030 more than $90 \%$ of African great ape habitats and more than $99 \%$ of orangutan habitats will suffer moderate to high impact from human activities.

There are many situations where great apes and humans come into conflict, and these vary greatly among sites. Conflicts resulting directly from human behaviour include: destruction and pollution of natural resources, habitat conversion to cultivate crops, competition over natural resources (e.g., fruit trees and water; Salafsky 1993; Pruetz 2006; Ancrenaz et al. 2007), incidental disease transmission (e.g., from faecal matter, discarded or stolen food; Kalema-Zikusoka et al. 2002), killing or wounding of great apes by traps and snares (Reynolds 2005), deliberate killing and capture of great apes for the bushmeat or pet trades, or for the protection of crops and plantations (Mittermeier 1987; Teleki 1989; Rijksen 1995, 2001; Rijksen and Meijaard 1999; Lackman-Ancrenaz et al. 2001; CITES/GRASP 2006). While contact between domestic animals and great apes can result in disease transmission, death of great apes due to disease transmission primarily results from close encounters between great apes and humans habituated for research or tourism purposes (e.g., Wallis and Lee, 1999; Dellatore 2007; Köndgen et al. 2008). Habitat loss, damage to natural resources, or resource competition may severely disrupt the activity budgets and ranging patterns of great apes, and result in greater overlap between the apes' home ranges. Higher rates of inter-ape encounter are likely to increase the spread of disease pathogens, aggravate competition for food or mates, and heighten levels of intra-specific aggression, potentially resulting in severe or lethal injuries, and even in the dissolution of an entire group or community (Wrangham et al. 2006; Pusey et al. 2007). Table 1 summarises human activities that provoke conflict with great apes, and their potential consequences for the apes.

As illustrated above, human behaviour often results in increased rates of encounter with great apes. Human activities may lead to increased levels of crop-raiding (Salafsky 1993; NaughtonTreves et al. 1998; Buckland 2005; Ancrenaz et al. 2007; Hockings 2007; Wilson et al. 2007), natural resource competition, domestic animal predation (e.g., Pan troglodytes; McLennan 2008), the restriction of peoples' movements' or attacks on humans by great apes (Yeager 1997; Macfie 2000; Wrangham et al. 2000; Butynski 2001; Wrangham 2001; Reynolds et al. 2003; Byamukama and Asuma 2006; Madden 2006; Dellatore 2007) that potentially escalate into situations of conflict. A sobering consequence of such conflicts is that people sometimes develop negative perceptions and come to fear great apes, retaliating by injuring or killing them to protect their resources, or for perceived personal safety (Campbell-Smith 2007; Pusey et al. 2007). Conflict might also occur when a person retaliates against the authorities that are responsible for conserving wildlife and the environment. Table 2 provides a summary of HGAC situations and their respective consequences for humans. 


\subsection{Review of HGAC}

Agricultural fields, and large plantations and orchards often border natural forests and protected areas; crop-raiding by wildlife is consequently a major cause of conflict with humans. Many nonhuman species have adapted their feeding repertoire to include crop-raiding, gaining access to an array of energy-rich foods (Salafsky 1993; Rijksen 1995, 2001; Muyambi 2004; Goldsmith 2005; Ancrenaz et al. 2007; King and Chamberlan 2007; Yuwono et al. 2007). Around some reserves in Africa and Asia, humans consider primates to be responsible for over $70 \%$ of damage events and $50 \%$ of the resulting area damaged (Naughton-Treves 1998; Hill 2000). This situation has

Table 1. Summary of main human activities in great ape habitats that may result in increased conflict with great apes and their respective consequences for great apes

\begin{tabular}{|c|c|c|c|c|c|c|c|c|}
\hline \multirow[b]{3}{*}{ Code } & \multirow[b]{3}{*}{ Activity in great ape habitat } & \multicolumn{7}{|c|}{ Consequences for great apes } \\
\hline & & \multicolumn{2}{|c|}{ Habitat } & \multirow{2}{*}{$\begin{array}{c}\text { Destruction } \\
\text { of key } \\
\text { natural } \\
\text { resources* }\end{array}$} & \multirow{2}{*}{$\begin{array}{c}\text { Pollution } \\
\text { of } \\
\text { natural } \\
\text { water } \\
\text { sources }\end{array}$} & \multirow[b]{2}{*}{$\begin{array}{c}\text { Behavioural } \\
\text { disruption }\end{array}$} & \multirow{2}{*}{$\begin{array}{c}\text { Disease } \\
\text { transmission } \\
\text { risk }\end{array}$} & \multirow{2}{*}{$\begin{array}{c}\text { Killing } \\
\text { or } \\
\text { capture }^{\star \star}\end{array}$} \\
\hline & & Destruction & $\begin{array}{l}\text { Fragmen- } \\
\text { tation }\end{array}$ & & & & & \\
\hline 1 & Traditional practices & $-/+$ & $-/+$ & $-/+$ & $-1+$ & $-/+$ & $-/+$ & $-/+$ \\
\hline 1.1 & Bushfires & + & + & $-/+$ & - & + & - & $-/+$ \\
\hline 1.2 & $\begin{array}{l}\text { Gathering of water from } \\
\text { natural sources }\end{array}$ & - & - & - & $-/+$ & $-/+$ & $-/+$ & - \\
\hline 1.3 & $\begin{array}{l}\text { Gathering of dead wood } \\
\text { for coal or cooking }\end{array}$ & - & - & - & - & $?$ & $-/+$ & - \\
\hline 1.4 & $\begin{array}{l}\text { Harvesting of natural } \\
\text { resources (e.g., food, } \\
\text { medicine, honey, dye) }\end{array}$ & $-/+$ & - & $-/+$ & - & $-/+$ & $-/+$ & - \\
\hline 1.5 & Snares & - & - & - & - & $-/+$ & - & $-/+$ \\
\hline 1.6 & Hunting with guns & - & - & - & - & + & + & $-/+$ \\
\hline 1.6 .1 & Great apes not targeted & - & - & - & - & + & + & - \\
\hline 1.6 .2 & Great apes targeted & - & - & - & - & + & + & + \\
\hline 2 & Agriculture & + & + & + & $-/+$ & + & $-/+$ & $-/+$ \\
\hline 2.1 & Slash and burn & + & + & + & - & + & $-1+$ & - \\
\hline 2.1 .1 & Snares: crop protection & - & - & - & - & $-/+$ & N/A & $-/+$ \\
\hline 2.2 & Commercial & + & $-/+$ & + & $-/+$ & + & $-/+$ & + \\
\hline 2.2 .1 & Eradication of forest & + & $-/+$ & + & - & + & N/A & $-/+$ \\
\hline 2.2 .2 & Influx of people & $-1+$ & - & - & $-1+$ & + & $-1+$ & + \\
\hline 3 & Logging & + & + & $-/+$ & $-/+$ & + & + & $-/+$ \\
\hline 3.1 & Small-scale & + & + & $-/+$ & - & + & + & - \\
\hline 3.2 & Commercial & + & + & + & $-/+$ & + & + & $-/+$ \\
\hline 3.2 .1 & 'Total' deforestation & + & + & + & - & + & + & $-/+$ \\
\hline 3.2 .2 & 'Selective' deforestation & + & $-/+$ & + & - & + & + & - \\
\hline 3.2 .3 & Road network & + & + & + & $-/+$ & + & + & $-/+$ \\
\hline 3.2 .4 & Influx of people & $-/+$ & $-/+$ & $-/+$ & $-/+$ & + & + & + \\
\hline 4 & Mining & + & + & $-/+$ & + & + & + & $-/+$ \\
\hline 4.1 & Small-scale & + & + & $-/+$ & + & + & + & $-/+$ \\
\hline 4.2 & Industrial & + & + & + & + & + & + & $-/+$ \\
\hline 4.2 .1 & Extraction & + & + & + & + & + & N/A & - \\
\hline 4.2 .2 & Erosion & + & + & + & + & + & $\mathrm{N} / \mathrm{A}$ & - \\
\hline 4.2 .3 & Influx of people & $-/+$ & $-/+$ & $-/+$ & $-/+$ & + & + & $-/+$ \\
\hline 5 & Tourism and Research & $-/+$ & - & $-/+$ & $-/+$ & $-/+$ & + & $-/+$ \\
\hline
\end{tabular}

* food and/or shelter (nesting/sleeping sites); ${ }^{* \star}$ for bushmeat, for the pet trade, or as pests; N/A = Not applicable; ? = unknown since never assessed or formally reported; $-=$ no risk; + = risk; $-/+=$ depending on circumstances and context either none or risk present 
Table 2. Summary of human-great ape conflict situations and their respective consequences for humans

\begin{tabular}{|c|c|c|c|c|c|c|c|c|}
\hline \multirow{3}{*}{ Code } & \multirow{3}{*}{ Situation } & \multicolumn{7}{|c|}{ Consequences for humans } \\
\hline & & \multicolumn{2}{|c|}{ Economic loss } & \multirow{2}{*}{$\begin{array}{c}\text { Travel } \\
\text { restrictions }\end{array}$} & \multirow{2}{*}{$\begin{array}{c}\text { Injury } \\
\text { or lethal } \\
\text { aggression }\end{array}$} & \multirow{2}{*}{$\begin{array}{c}\text { Disease } \\
\text { transmission } \\
\text { risk }\end{array}$} & \multirow{2}{*}{$\begin{array}{c}\text { Fear of } \\
\text { great apes }\end{array}$} & \multirow{2}{*}{$\begin{array}{c}\text { Negative } \\
\text { perception of } \\
\text { great apes }\end{array}$} \\
\hline & & Direct & Indirect* & & & & & \\
\hline 1 & Crop-raiding & + & + & $-/+$ & + & $-/+$ & $-/+$ & $-/+$ \\
\hline 1.1 & Field & + & + & $-/+$ & + & $-/+$ & $-/+$ & $-/+$ \\
\hline 1.2 & Plantation/concession & + & + & $-/+$ & + & $-/+$ & + & + \\
\hline 1.3 & Local orchard/garden & $-/+$ & $-/+$ & + & + & $-/+$ & $-/+$ & $-/+$ \\
\hline 2 & $\begin{array}{l}\text { Predation on } \\
\text { domestic animals }\end{array}$ & + & + & - & + & + & $-/+$ & $-/+$ \\
\hline 3 & Water-drinking** & - & - & + & + & + & $-/+$ & $-/+$ \\
\hline 4 & $\begin{array}{l}\text { Path travel or road } \\
\text { crossing }\end{array}$ & - & - & + & + & - & + & $-/+$ \\
\hline
\end{tabular}

* increased crop supervision, construction of physical barriers; ** at natural water sources also used by humans; - = no risk; + = risk;

$-/+=$ depending on circumstances and context either none or risk present

resulted in some primates being viewed as a serious menace to agriculture in many tropical countries (Mascarenas 1971; Lackman-Ancrenaz et al. 2001; Rijksen 2001; Marchal 2005; Yuwono et al. 2007) and has in some cases led to the development of primate control or eradication programmes. Furthermore, crop damage can contribute indirectly to land clearance and habitat change; for example, forest remnants near fields may be cleared by farmers to eliminate potential 'islands' and discourage crop-raiders (Osborn and Hill 2005). Although less frequently reported than crop-raiding by monkeys, crop-raiding by great apes is on the increase (Naughton-Treves et al. 1998; Biryahwaho 2002; Marchal 2005; Ancrenaz et al. 2007; Yuwono et al. 2007; CampbellSmith and Linkie 2008).

In addition to crop loss, people often feel threatened by great apes due to fears for their personal safety (Gorilla beringei: Macfie 2000; Madden 2006; Pan troglodytes: Wrangham 2001; Hockings et al. 2006a; Webber 2006; McLennan 2008; Pongo pygmaeus and P. abelii: Salafsky, 1993; Rijksen, 2001; Campbell-Smith 2007). Most great apes are actually fearful of humans, and attacks on humans by great apes are therefore uncommon. Reported incidents, however, do suggest that chimpanzees (Pan troglodytes) exhibit a higher propensity to attack than do the other great apes. Although poorly understood, attacks tend to occur when an animal is directly provoked by humans (e.g., by stick or stone throwing, shouting, gunshot, or slingshot) and then retaliates in response to a perceived threat or exhibits protective behaviour towards other more vulnerable members of their party, especially mothers in defence of infants. Dominant males in particular may act to protect group members. Accidental attacks may also result from surprise encounters between humans and great apes on roads or paths, as well as ill-managed tourism activities (McLennan 2008). At some sites, chimpanzees have made unprovoked attacks on human children; these rare incidents appear to represent examples of predation (Wrangham et al. 2000; Kamenya 2002). Please see Appendix A for species-specific reviews.

Situations where HGAC occurs are complex, diverse, and often multifaceted (Mittermeier et al. 2007), whilst also being specific to the species and locality. Nevertheless similarities between conflict situations do exist. Mitigating such conflicts is challenging as certain sectors of society want to preserve great apes, whilst others who are negatively affected by the conflict may want them eliminated (Osborn and Hill 2005).

\subsection{Organisation of this document}

So far these guidelines have provided a general overview of past research and reports pertaining to human-great ape conflicts. Section 3 will look at preliminary issues to consider in conflicts (see also Appendix B), and Section 4 discusses possible HGAC counter-measures that can be applied to specific situations, their potential effectiveness, as well as their disadvantages. Section 5 then provides an overview of how to design a HGAC Management Strategy. 


\section{Section 3: Assessment of HGAC: Preparatory Issues}

It is important not to assume that conflict always results when great apes and humans compete for resources (Siex and Struhsaker 1999). The term 'conflict', which is regularly used to describe these associations, may in fact unnecessarily provoke the situation into one of hostility (Lee 2004). It is necessary to determine whether human-wildlife relationships actually lead to conflict before making negative assumptions ${ }^{1}$ (Priston 2005). Cultural attitudes and practices vary greatly between regions and the perception of conflicts between humans and great apes will differ accordingly.

Hill et al. (2002, p.9) stated that 'it is important that anyone responsible for assessing or managing a human-wildlife conflict situation knows exactly what the important issues are locally, how far they extend geographically and temporally, and what portion or group in the local population is affected, or consider themselves to be at risk'. More specifically, to highlight issues related to HGAC, the following types of information should be assessed prior to implementing any mitigation strategy (see Appendix B for section-related questions to help assess HGAC in a specific area):

\subsection{Sources and reliability of information about a HGAC issue}

The perspectives and opinions of those involved in HGAC situations (e.g., researchers, human communities suffering threats or damage from wildlife, or agencies responsible for alleviating the problem such as non-governmental organizations) will vary in relation to the seriousness of the problem and what might be done. Persons researching or managing HGAC need to be aware that, given issues of social exclusion and empowerment, information from key informants may not accurately reflect the situation of those people most affected by interactions with great apes. It is therefore extremely important to track who is providing information about the problem, and to compare information from different sources to assess reliability (See Appendix B1 for guidance on this matter).

In assessing and evaluating local perceptions and attitudes towards HGAC, Treves (2008, p.265) cautioned that 'perceptions and attitudes are influenced by testimonials and entertaining stories that may reflect (a) extreme events and imagination, (b) long memories and a history of human-animal interactions, and (c) experiences from a broad region. By contrast, systematic field data on human-wildlife conflict events and losses tend to emphasize variation around averages and shorter time periods in smaller regions.' Regional averages may thus conceal the individuals, households, or communities that are the most affected (Oli et al. 1994; Naughton-Treves 1997, 1998; Treves and Naughton-Treves 1999; Karanth and Madhusudan 2002). Finally, although interpreting local perceptions and systematic, quantitative data on HGAC may each present their own limitations and challenges, both are essential and complementary in acquiring a comprehensive picture of HGAC (Treves et al. 2006).

See Appendix B1 for questions designed to help assess the HGAC situation in a specific area.

\subsection{Knowledge of a HGAC problem}

For any conflict, whether crop-raiding, travel restriction, competition for water or other natural resources, or instances of attack on humans by great apes, it is important to acquire an understanding of the spatial and temporal patterns of such events. It is also necessary to evaluate the seriousness of each conflict and assess whenever possible which individuals or age-sex classes of great apes are involved.

Crop-raiding by great apes can be seasonal as it is influenced by availability of both crops and wild food resources. Raiding intensity may vary as a function of local crop assemblages, planting

\footnotetext{
1 It has been argued that referring to wildlife feeding on human crops as 'crop-raiding' may elicit or exacerbate negative perceptions, and that 'resource competition' may be more appropriate. However, the term resource competition is ambiguous, as humans and wildlife share and compete for different resources in various ways. For consistency with existing publications and for the sake of clarity, the expression crop-raiding is used to describe crop-feeding forays.
} 
patterns, growth stage or ripening periods, with certain crops and developmental stages being consumed preferentially (Salafsky 1993; Naughton-Treves et al. 1998; Hockings 2007). Availability and fluctuations in preferred forest foods may affect crop-raiding incidence, as certain species have been observed to forage on crops as a temporary alternative in times of fruit scarcity (Salafsky 1993; Hill 1997; Naughton-Treves et al. 1998; Saj et al. 2001; Humle 2003; Reynolds 2005; Hockings et al. 2006b; Hockings 2007; Campbell-Smith and Linkie 2008). Although evidence suggests that forest fruit availability may affect crop-raiding levels, crop consumption may also be a preferential means of accessing a high-energy food to optimize foraging strategies (Naughton-Treves et al. 1998; Hockings 2007). By predicting temporal and spatial variations in HGAC, farmers might be able to direct their resources more effectively. For example, mitigation strategies could target a few choice crops during specific periods when great ape raiding levels are elevated. HGAC incidents may also show inter-annual variation in both distribution and severity; long-term data collected consistently are sometimes required, therefore, to fully understand the prevalence and extent of the problem.

Population and species differences in the intensity of crop-raiding are likely to reflect the relative costs and benefits of feeding on cultivated versus non-cultivated foods. Great apes that are habituated to human observers or have been reared by humans, such as ex-captive (rehabilitant), former-sanctuary great apes, and great apes habituated for tourism, may feel less threatened by humans (e.g., Madden 2006; Dellatore 2007). The frequency with which these individuals crop-raid may be high compared with non-habituated individuals, groups, communities, or populations. Great caution should therefore be exercised when attempting to habituate great apes that live in proximity to human settlements and cultivated areas, especially if habituation is likely to aggravate HGAC issues. The management of HGAC will be easier if 'problem' individual apes can be identified. Adult male chimpanzees are, for example, more likely than other group members to raid crops, especially in risky and exposed environments that present increased likelihood of human confrontation (Hockings et al. 2007). The risk takers among Bornean orangutans, whether excaptive or wild, also appear to be adolescent and subadult males. Finally, given differences in the social systems of great apes, patterns may vary between orangutans, chimpanzees, bonobos, and gorillas. Understanding species-typical patterns across age-sex classes in ranging, diet and foraging, adjustments to seasonality, social dynamics, and in cultural transmission are important when assessing current and future risks of crop-raiding.

Regarding attacks on humans, it is important to gather information on the age-sex class of individuals concerned and attackers, as well as the context prior to and during such events. When characterising wildlife attacks on humans, Quigley and Herrero (2005) used two broad categories: (1) Provoked and (2) Unprovoked. They argued that a 'provoked attack' may take many forms. The definition we use is when a person enters an animal's space or purposely tries to touch, capture, injure or kill the animal and the animal attacks, or the person has food or garbage attractants that draw the animal to his or her personal space. This personal space can be defined as the area around an animal where it reacts to the presence of a human (and vice versa). Despite the obvious difficulties when attempting to define a 'provoked' attack, it is important to consider the characteristics of any attack, and these will be determined by the species' ecology and behaviour. An 'unprovoked attack' is defined as one in which an animal approaches and attacks and whereby the principal attraction was the person, not the person's food or any other attractant. Unprovoked attacks might be predatory (person is attacked as prey, e.g., Wrangham 2001) or involve the great ape's right of way (person uses the same space as the ape, and the ape attacks when it is not given right of way. No food or attractant is involved).

See Appendix B2 for questions designed to help assess HGAC in a specific area.

\subsection{Who is affected by HGAC and what are their perceptions and attitudes?}

In many parts of Africa and Asia, great apes have complex relationships with humans, and might be afforded protection as a function of local customs. Consideration of the cognitive, aesthetic and spiritual influences on human behaviour, attitudes and perceptions are major factors in human-wildlife interactions (Hill 2000; Fuentes and Wolfe 2002; Cormier 2003). These human perceptions of great apes are important because the choices and actions of rural people who live in daily contact with wildlife will ultimately determine its survival. 
The human social unit which is most affected by the HGAC issue is the level at which you should direct most of your efforts to address the problem (Hoare 2001; Webber et al. 2007). However, the social unit must be considered in relation to the administrative context. In the case of aggressive attacks on humans, Quigley and Herrero (2005, p.28) stated that 'reducing attacks has the potential not only to reduce injury and loss of lives in human populations, but to conserve wildlife populations, promote good will toward wildlife, minimize economic loss and improve quality of life for humans'. Madden (2004) emphasized that conflicts can escalate when local people feel that the needs or values of wildlife are given priority over their own needs, especially when they feel they have little to gain and much to lose by sharing land with great apes. For example, certain communities living near mountain gorilla habitat perceive themselves to be powerless against economic losses caused by crop-raiding and the threat of attack by gorillas, especially as the species is protected by law and because no easy solution is available to the authorities. Living in proximity to great apes may be associated with subtle and difficult-to-quantify social problems or 'opportunity costs' (Naughton-Treves and Treves 2005; Treves et al. 2006).

The attitude of a person affected by HGAC may differ if they speak to a researcher or wildlife manager alone rather than in the presence of other members of their community. HGAC issues easily become exaggerated or politicized, particularly in meetings where complainants have an audience and may be speaking to outsiders perceived to have political or other influence (Naughton-Treves and Treves 2005). Perceptions may be exaggerated or reality distorted for economic, social or political reasons (Salafsky 1993; Macfie 2000; Marchal 2005; Naughton-Treves and Treves 2005; Newton-Fisher et al. 2006; Webber 2006; Yuwono et al. 2007). It is essential, therefore, to gain the trust of an affected community and maintain cultural sensitivity when discussing issues connected with HGAC in order to acquire a comprehensive and fair understanding of how great apes and HGAC issues are perceived in a particular locality. However, when collecting, analysing, and reporting data on perceptions, a cynical approach is also inappropriate. Instead of examining the exactness of people's risk perception, finding explanations for why people are disproportionately concerned about some species is more constructive (see Treves et al. 2006 for discussion of this issue).

Contrasting values between affected local people and households, wildlife managers, and wildlife protection interests are the most common causes of political disagreements over human-wildlife conflict (Richards 2000; Treves 2008). It is therefore necessary to establish whether the HGAC problem is politically linked to other issues, such as local hostility towards conservation authorities, or disagreements among people related to empowerment and resource access (Treves et al. 2006). For example, when the Ugandan Wildlife Authority started to earn significant revenue

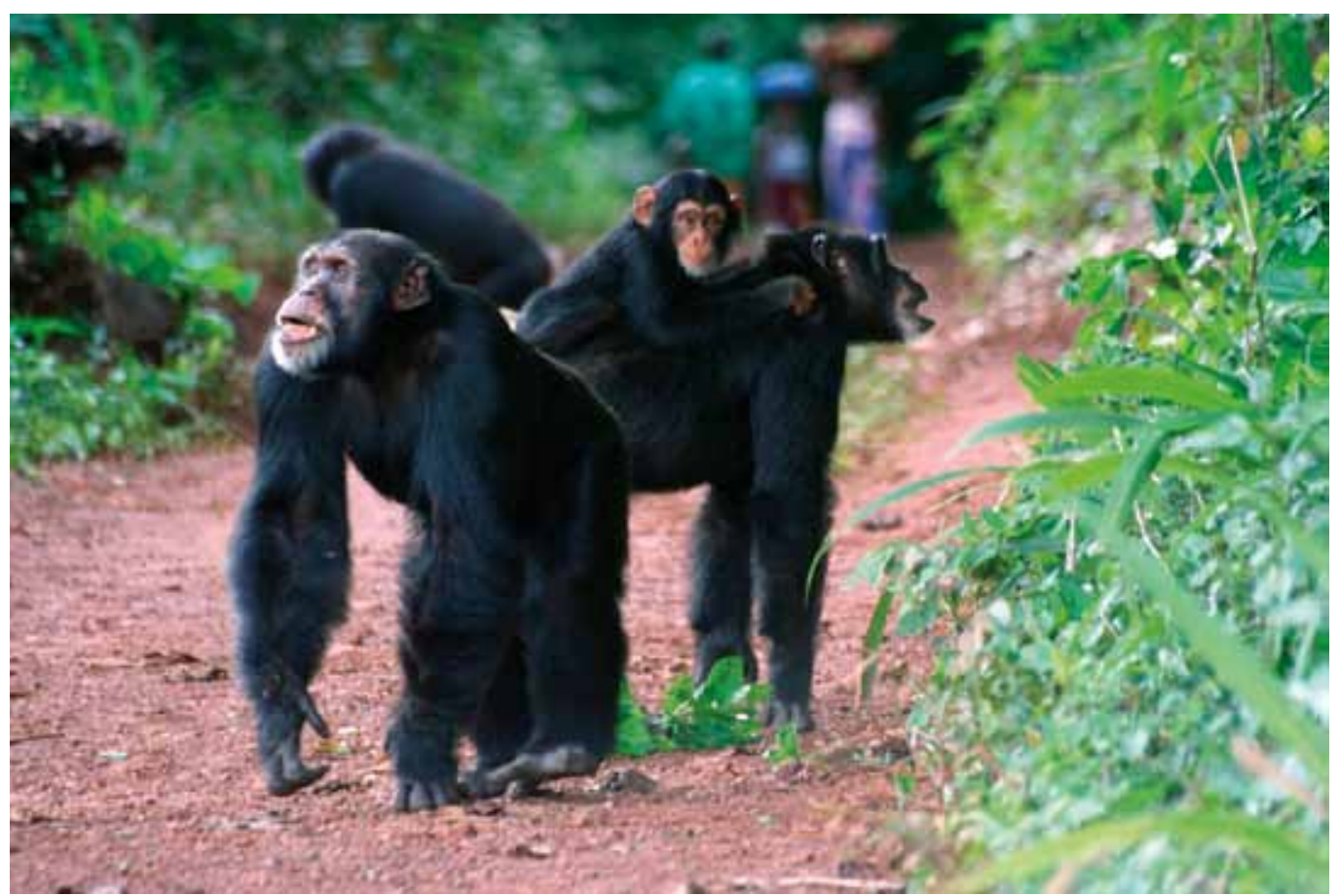

Chimpanzees cross roads and paths, which brings them into contact with people.

Photo: (C) Tatyana Humle 
from mountain gorilla tourism, resentment towards the gorillas increased in areas that experienced crop-raiding (Macfie 2000). Evidence suggests that centralized approaches, where decisions are taken from outside the affected area by unknown individuals, are less successful than decentralized strategies developed with the involvement of affected communities (Hill et al. 2002).

See Appendix B3 to guide your assessment of a HGAC problem.

\subsection{Constraints you might face when addressing HGAC}

The level of detail and the amount of data to be collected will depend on the scale of the problem and a number of other factors, including the objectives and time-scale, and the financial, human and technical resources available to implement a strategy or solution. Although researchers and managers need to prioritise the types of data to be collected, past research suggests that a solely economic or solely ecological evaluation of a conflict situation is inadequate (Hill et al. 2002). As highlighted above, how local people perceive a conflict determines their responses and their willingness to participate in and contribute to a mitigation strategy. It is therefore crucial to comprehend and take into account people's perceptions of HGAC problems when designing and implementing mitigation strategies (Hill 1997, 1998, 2005; Macfie 2000; Priston 2005; Ancrenaz et al. 2007; Webber et al. 2007). It may also be useful to establish how people dealt with the problem in the past, to highlight why the situation degenerated into conflict. One should also consider that programmes dependent on external funding are unlikely to be sustainable in the long-term (Webber et al. 2007). Finally, it is important to devise a strategy to address the HGAC problem, a method to measure success of the strategy, and a means of modifying the strategy if it is unsuccessful.

See Appendix B4 to evaluate your constraints.

\subsection{Others involved with the problem and how they can help you}

HGAC situations can escalate when local people or institutions are unable to deal with the conflict effectively. Where possible, people assigned to resolving a conflict situation should already have, or be trained to acquire, the necessary expertise. Furthermore simply arriving at a site and taking an interest in HGAC can lead to problems in itself, since it immediately raises expectations that a solution will be forthcoming (e.g., capture and relocation, compensation), and can lead to repercussions if it is not (Naughton-Treves and Treves 2005; Treves et al. 2006). In certain cases, and depending on the research objectives, data might be collected without leading farmers to think that the HGAC is the main point of investigation (e.g., a survey of general rural agricultural problems for farmers). Addressing complex problems within Protected Areas requires a level of training and expertise that is rarely met by the authorities. Management decisions intended to mitigate HGAC require consultation with great ape experts whenever and wherever appropriate. For example, Nishida (2008) suggested that the Tanzanian National Park authority's decision to remove

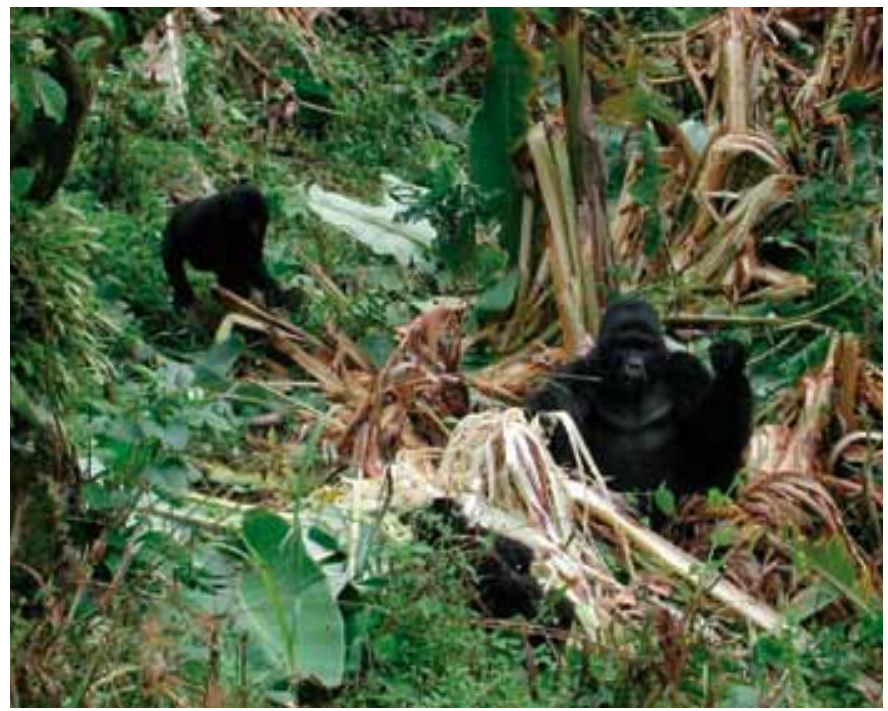

Mountain gorillas devastate a banana grove in Uganda.

Photo: @ Fortunate Muyambi introduced plant species, including guava, mango, oil palm, and lemon trees, from Mahale Mountains National Park, may be negatively impacting the survival of chimpanzees within the park. Although introduced by humans, these species are regularly consumed by the Mahale chimpanzees, especially during times of natural fruit scarcity. Mahale chimpanzees have promoted the dispersal of these species within the forest, but there is no evidence to suggest that they are invasive or putting other forest species at risk. The capacity constraints of many park management programmes include a lack of general information on HGAC, insufficiently trained staff, inadequate coordination between stakeholders, non-involvement of local communities in decisions about resource management, lack of staff motivation and incentives, and inadequate funding at park level. If the needs of the local people are not addressed, conflict levels may increase both between humans and wildlife, and among humans about the value of wildlife. 
See Appendix B5 to help you assess your constraints and how others concerned by the HGAC problem can help you.

In conclusion to Section 3, it is crucial to understand the issues related to HGAC in your area, and to assess how you are equipped to address the problem to avoid careless action when implementing any HGAC mitigation strategy. The issues surrounding HGAC will sometimes be site-specific and not all aspects mentioned so far will apply. However, Madden (2004, p.251) emphasised that a 'fully-integrated view - complete with a full understanding of the similarities across a wide spectrum, as well as the local distinctions - is critical in successfully designing and implementing any conflict mitigation programme'.

\section{Section 4: Review of Potential HGAC Counter-Measures and their Effectiveness}

In general, great apes can achieve more sophisticated cognitive abilities than many other mammals, including advanced abilities for social learning, solving problems innovatively, and behaving flexibly. Such cognitive capacities must be considered when assessing how great apes perceive and adapt to human-induced habitat changes, what counter-measures are likely to be effective, and for how long.

Given the protected status of all great apes, a problem individual should only be repelled, removed or tolerated. In this section we draw on experience from other human-wildlife conflict programmes, and suggest measures to reduce HGAC. These measures are either direct, by reducing the severity or frequency of interactions with great apes, or indirect by raising tolerance for great ape threats (Treves 2008). Generally we distinguish between measures that are appropriate for communities neighbouring protected areas and those where the great apes are found outside protected areas on private or state land. In accordance with the IUCN/SSC African Elephant Specialist Group (Hoare 2001), HGAC mitigation measures are listed as counter-measures, which are subdivided into methods. Methods are merely different actions within each category of counter-measure.

\subsection{Traditional counter-measures}

Guarding crops against damage by wildlife is common practice across the agriculture-wildlife interface (Salafsky 1993; Hill 2005; Byamukama and Asuma 2006); however, quantitative data specific to great apes are lacking. As crop-raiding incidents are sometimes opportunistic and occur in poorly defended fields, crop loss is often inversely correlated with the farmers' vigilance (Osborn and Hill 2005). The guarding measures preferred by different groups of people vary in effectiveness and practicality (Chalise and Johnson 2005). There are considerable social implications to guarding crops, such as increased risk of injury and significant time commitment. The effectiveness of methods, such as patrolling fields and shouting, banging objects and throwing stones, sticks or spears, is difficult to quantify; although Naughton-Treves (2001) suggests that in Uganda intensive guarding is at least partially effective because primates avoid farms that are heavily guarded. Although the use of domestic animals to guard crops might reduce some of the social costs, they could introduce health hazards or safety risks to great apes (see Smith et al. 2000a for a review of guard animal use).

In Sumatra, rural farmers generally shout and throw sticks or stones in attempts to displace orangutans feeding in cultivated durian trees. This provokes orangutans to display, sometimes breaking branches, and results in far greater damage to both tree and fruit crop than would have occurred had the farmer not reacted. In contrast, gorilla monitoring response teams (comprised of volunteers from local communities who are trained and supervised by a park ranger) chase gorillas that come into cultivated or residential areas, and shouting is most effective for encouraging gorillas to retreat to the Bwindi Impenetrable National Park (Byamukama and Asuma 2006). Although response teams can be effective in situations where crop-raiding is localized or occurs over an extended period, response times are often slow (12 to $48 \mathrm{hr}$ ) and consequently crop damage is extensive (Musaasizi 2006). Tactics must be varied over time if a group becomes desensitized to 
a particular deterrent, but not all gorillas habituate to chasing methods (Macfie 2000). Different gorilla groups have different responses to chasing and noisemaking tactics: in Bwindi, M group quickly left cultivated areas when rangers made chasing gestures towards them, $\mathrm{K}$ group tolerated days of shouting and bush-beating before finally retreating to the forest, whilst gorillas in the Virunga National Park changed their behaviour and avoided park staff by making evening visits to fields and orchards (Madden 1999). The long-term employment of gorilla monitoring response teams requires funding to compensate team members for time spent guarding and chasing gorillas from cultivated areas (Musaasizi 2006), so financial support must be secured if such activities are to be sustained.

Guardians are effective when they actively threaten raiding animals with, for example, spears or slingshots (King and Lee 1987; Priston 2005); however, adult male apes sometimes challenge a human aggressor, which can result in injury or death of either protagonist (Reynolds 2005). Throwing objects is therefore strongly discouraged. Men are more successful at guarding against raiding primates than are women or children (Osborn and Hill 2005), but whether the raiding individual assesses the sex, physical size or fear reactions of the guardian is unknown. The intelligence and adaptability of great apes often make both traditional and more sophisticated disturbance devices (such as flares) ineffective in the long-term (Chalise and Johnson 2005). Problem individuals habituate to most deterrence techniques after some exposure or may adjust their crop-raiding activities to periods when fields are left unguarded. Campbell-Smith (2007) highlights the immediate effectiveness of homemade fire-crackers in deterring crop-raiding orangutans, but the effectiveness of the use of fires in fields or their periphery has not been evaluated. Fires are also problematic as uncontrolled bushfires endanger people and great apes, and may damage homes, cultivated fields and great ape habitat.

Traditional fencing has proven ineffective for excluding great apes from fields. In some regions, fencing is combined with wire snares set between pickets to capture raiding rodents, and these snares constitute a danger to great apes. In Uganda, one quarter of chimpanzees in two habituated communities (Budongo and Kibale) have snare related injuries (Wrangham and Mugume 2000; Plumptre et al. 2003; Reynolds 2005). Although chimpanzees can escape by dislodging a wire from the release mechanism, the wire often remains tight around the trapped limb, resulting in severe short- or long-term handicap, limb loss or even in some cases the death of the individual. Remarkably at Bossou in Guinea, chimpanzees have learned to dismantle wire snares by triggering the release mechanism without contacting the snare (Ohashi 2005). Clearing an area of 2-5 m around fences to enhance visibility may help great apes to avoid snares while aiding human guards to more effectively monitor their fields. Clearing around fences may also discourage shyer individ-

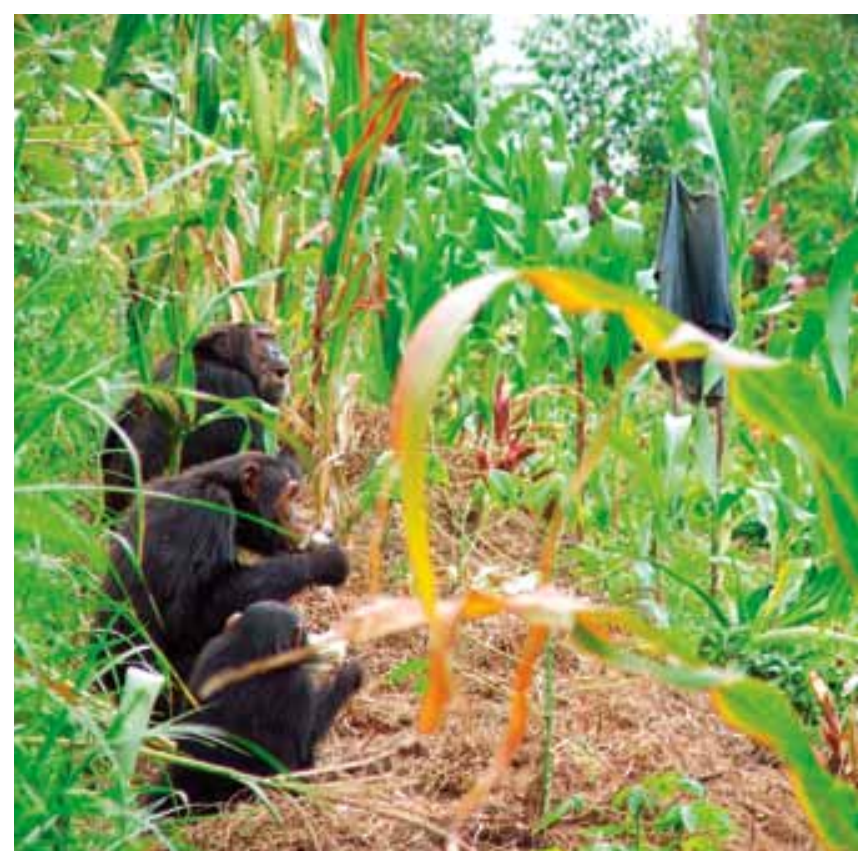

Chimpanzees in a maize field where local people have placed a simple scarecrow. Photo: @ Paco Bertolani ual great apes from raiding thus minimising damage to crops and offsetting economical losses. Regular small scale cutting back of vegetation along fields, paths and trails frequented by humans and great apes can also help reduce the incidence of great ape attacks on humans if these are linked to issues of travel restriction and surprise encounters.

\subsection{Physical barriers}

Modification of the landscape around ape habitat might significantly improve a HGAC situation by creating new buffers and barriers to influence great ape behaviour and discourage them from coming into contact with local people. Fencing and barriers are widely used to keep animals out of agricultural areas (Osborn and Hill 2005; Yuwono et al. 2007). However, studies of orangutans suggest that even electric fences can become ineffective due to the great apes' ability to learn to overcome the problem; once an ape realizes that shocks from electric fences are not harmful, their effectiveness decreases (Agoramoorthy 2002; Yuwono et al. 2007). Nevertheless, electric fences are used in sanctuaries (e.g., Tacugama Chimpanzee Sanctuary, Sierra Leone) to keep great apes inside enclosures. Electric fences have also been 
Table 4.1. Traditional methods used to deter crop-raiding by great apes

\begin{tabular}{|c|c|c|c|c|c|}
\hline \multirow{2}{*}{ Direct - Traditional method } & \multirow{2}{*}{ Effectiveness } & \multicolumn{3}{|c|}{ Cost } & \multirow{2}{*}{ Side-effects/Considerations } \\
\hline & & Financial & Time & Labour & \\
\hline Guardians & Variable & Variable & High & High & \\
\hline (Crop guards in or patrolling fields/gardens) & & & & & Risk of great ape and human injury \\
\hline (Farmers guarding with the aid of dogs) & & & & & Risk of great ape and human injury \\
\hline \multicolumn{6}{|l|}{ (Scarecrows) } \\
\hline Noise in presence of problem great apes & Brief & Variable & High & High & Risk of great ape and human injury \\
\hline \multicolumn{6}{|l|}{ (Shouting and whistling) } \\
\hline \multicolumn{6}{|l|}{ (Banging noisy objects) } \\
\hline \multicolumn{6}{|l|}{ (Cracking whips) } \\
\hline \multicolumn{6}{|l|}{ (Shooting guns in the air) } \\
\hline \multicolumn{6}{|l|}{ (Use of thunder flashes/firecrackers) } \\
\hline Fire & Brief & Low & High & High & $\begin{array}{l}\text { May cause bushfires/Risk of great } \\
\text { ape and human injury }\end{array}$ \\
\hline \multicolumn{6}{|l|}{ (Fires lit on periphery of fields and in fields) } \\
\hline \multicolumn{6}{|l|}{ (Farmers carry burning sticks) } \\
\hline $\begin{array}{l}\text { Missiles thrown at great apes (e.g., stones, } \\
\text { sticks or spears) }\end{array}$ & High & Low & High & High & Risk of great ape and human injury \\
\hline Clearing around fields, paths or trails & Brief/High & Low & Medium & High & $\begin{array}{l}\text { Increase visibility/Reduce surprise } \\
\text { encounters/Require maintenance }\end{array}$ \\
\hline Simple fenced barriers around fields & Low & Low & Medium & Variable & $\begin{array}{l}\text { Require maintenance/May } \\
\text { contribute to habitat degradation, } \\
\text { depending on materials used }\end{array}$ \\
\hline
\end{tabular}

employed to contain orangutans at the BOS Foundation's orangutan re-introduction centre in Central Kalimantan, although again effectiveness is not ensured. Orangutans also learn to detect when electricity is off, or invent methods of disabling or bypassing the electrical cables. Although not always effective with great apes, electric fences may have the additional benefit of blocking out other problem species, such as wild boar and deer (Yuwono et al. 2007); the same effect could constitute a cost, however, if beneficial or innocuous species are excluded. The careful design and installation of an electric fence is crucial to its success and should therefore be carried out by someone experienced in using electric fences with great apes. In some regions, fences can be powered with solar panels to reduce ongoing costs. It should, however, be noted that when the cleared soil beneath and around the fence is dry, conductivity is reduced. Therefore in dry regions or during the peak of the dry season, such a system may require regular wetting of the soil to remain effective. Overall, the cost of materials, installation and maintenance, as well as the theft of materials, make electric fencing often unaffordable, impractical and unsustainable for large-scale application in developing countries.

Water-filled boundary canals could be useful barriers (Yuwono et al. 2007), but alone are unlikely to yield effective results. Not all great apes are afraid of water, and canals have to be deep and wide enough to deter them from crossing. Wild-born chimpanzees living on island sanctuaries have become habituated to living in water-surrounded environments and when water levels allow, individuals cross to adjacent islands (Farmer 2002). However, deep, wide canals can create a drowning risk for great apes and for humans. Canals and their banks must be kept devoid of items that great apes might use as tools to get across (e.g., trees, branches, boats). In addition, canals may pose disease risks if water becomes stagnant, and could become ineffective if problems develop with maintaining water levels. When located close to a water source, it may be possible to flood canals for use in combination with other deterrence mechanisms, such as an electric fence and patrol units.

At Kinabatangan in Malaysia, and in the former orangutan rehabilitation centre at Bohorok, North Sumatra, corrugated zinc sheets placed around individual fruit trees that do not have canopy 


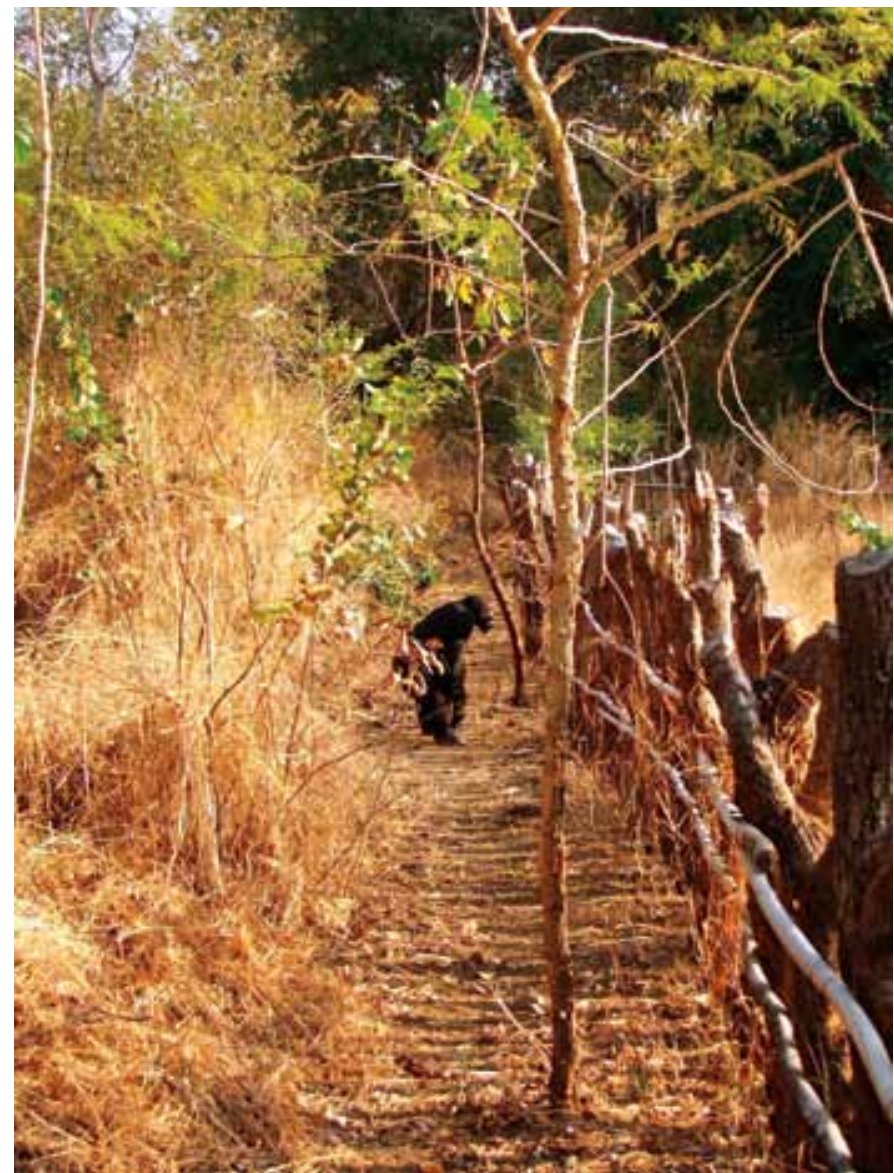

Traditional fence in Senegal. Photo: @ Paco Bertolani connectivity have been effective in deterring orangutans from raiding fruit (Marchal 2005). Corrugated sheeting is also being used in rubber plantations, where orangutans de-bark branches as well as the main trunk of rubber trees, which affects flow of the latex. Under certain conditions, fishing nets covering important fruiting trees or crop areas form effective barriers to crop-raiding orangutans (Campbell-Smith 2007). Netting is cheap to install but can be labour intensive for subsistence farmers; it is, however, a method that warrants further trials, especially in large-scale commercial plantations.

'Live hedges' comprised of the Mauritius thorn (Caesalpinia decapetala) have been used to prevent primate-human conflicts in Uganda (Fortunate 2004). However, it has transpired that the Mauritius thorn is a highly invasive species that spreads rapidly and, if not managed properly, prevents the regeneration of natural species and farmlands (Plumptre et al. 2007). 'Live hedges' of carefully chosen and locally available species known to be unattractive to great apes could be an effective means of isolating vulnerable crops from the forest edge, particularly when interspersed with unpalatable crops such as chilli, sisal, and tea. Such preventive measures require testing to assess labour requirements, practicality, cost, effectiveness, and impacts on local fauna and flora.

Buffer zones are blocks of land located between natural forests and cultivated areas that are intended to discourage wildlife from crossing between them. In its broadest sense, a buffer zone should be an area where land-use practises and land management are designed to reduce or prevent human-wildlife conflict; this does not predetermine ownership or control of the buffer zone, but implies a need to choose carefully the structures and processes to be put in place. Buffer zones can be used for economic gain, and care should be taken that buffer zones do not contain plant species that attract foraging great apes (Salafsky 1993; Goldsmith 2005; Byamukama and Asuma 2006). In Rwanda (Nyungwe) and Uganda (Kibale), large stretches of national park boundary are bordered by tea plantations. Although quantitative data are lacking, these plantations appear to provide effective barriers that chimpanzees do not cross. Furthermore chimpanzees show no interest in and do not destroy the tea plants, therefore where economically viable, the effectiveness of tea plantations in reducing HGAC warrants further research. Around Budongo, chilli peppers have been planted in buffer zones with some success as a deterrent.

Tobacco is not recommended as a buffer crop. Aside from the fact that other wildlife species, such as baboons, appear to destroy it, tobacco is a nutrient-hungry crop that rapidly degrades soil quality. In Hoima District, Uganda, tobacco farmers are among the groups clearing forest for fertile ground, aggravating habitat fragmentation and HGAC issues (McLennan 2008). Tobacco has been highlighted as a potentially disastrous crop for conservation, because poles and raphia are needed in the drying and curing process. Further, where people prefer smoke-dried to air-cured tobacco, fuel wood is also required, which may incite people to collect wood from protected forests.

The establishment of buffer zones around protected areas and other key sites must be designed in line with site-specific conditions. Their effectiveness will also depend on the level of habituation and risk-taking behaviour of great apes in the region. Before land-use changes were implemented at Nkuringo (southern Bwindi), buffer zones were no deterrent to habituated gorillas, which typically ranged up to $1 \mathrm{~km}$ beyond the park boundaries (Goldsmith 2005). Further trials and monitoring are required, but there are indications that manipulating buffer strips at Nkuringo has reduced crop-raiding and thus improved economic stability for local farmers. Small-scale research is currently focusing on determining which plants (including wheat, pasture grass and lemon grass) can effectively deter crop-raiders from entering or crossing the buffer, whether local climatic and soil 
conditions favour the growth of these buffer plants, and whether locals will successfully adopt the proposed intervention. A management plan for Nkuringo identified the following as important attributes of a buffer zone: (1) it directly borders both park and community land and is one continuous strip of accessible terrain, (2) it is wide enough to minimize HGAC, (3) the inner zone has abundant and suitable food for gorillas, and (4) the area has plants and animals that are economically important and can support tourism. The Nkuringo buffer has been divided into a 'community exclusive use sub-zone', which is the outermost $12 \mathrm{~km}$ by $150 \mathrm{~km}$, and an 'actively managed subzone' which borders the park $(12 \mathrm{~km}$ by $200 \mathrm{~km})$. Activities in the former include problem animal control interventions, research and monitoring, community conservation education, and livelihood improvement initiatives (crop and animal husbandry and community tourism). In the latter subzone, activities include gorilla tracking, research and monitoring, and manipulation of the ecosystem to prevent it from developing into mature forest (Nkuringo Buffer Zone Management Plan 2007, pp.13-20).

Table 4.2. Physical barriers

\begin{tabular}{|c|c|c|c|c|c|}
\hline \multirow{2}{*}{ Direct - Physical barrier } & \multirow{2}{*}{ Effectiveness } & \multicolumn{3}{|c|}{ Cost } & \multirow{2}{*}{ Side-effects/Considerations } \\
\hline & & Financial & Time & Labour & \\
\hline Fencing & Variable & Variable & Medium & $\begin{array}{l}\text { Medium / } \\
\text { High }\end{array}$ & $\begin{array}{l}\text { Requires maintenance and } \\
\text { knowledge of great ape habitat use }\end{array}$ \\
\hline $\begin{array}{l}\text { Traditional (non-electrical) fencing (see also } \\
\text { Counter-measure 4.1) }\end{array}$ & & & & & $\begin{array}{l}\text { May contribute to habitat degrada- } \\
\text { tion, depending on materials used }\end{array}$ \\
\hline \multicolumn{6}{|l|}{ Netting } \\
\hline Electric fencing & & & & & $\begin{array}{l}\text { Requires technical support and } \\
\text { reliable electrical supply }\end{array}$ \\
\hline \multicolumn{6}{|l|}{ (Using mains electricity) } \\
\hline \multicolumn{6}{|l|}{ (Using solar panels and 12 volt batteries) } \\
\hline \multicolumn{6}{|l|}{ Fencing layout } \\
\hline \multicolumn{6}{|l|}{$\begin{array}{l}\text { (Fencing encircles great ape range or } \\
\text { human settlement) }\end{array}$} \\
\hline \multicolumn{6}{|l|}{ (Fencing a protected area boundary) } \\
\hline \multicolumn{6}{|l|}{$\begin{array}{l}\text { (Open-ended fencing protecting the } \\
\text { edge of an area) }\end{array}$} \\
\hline \multicolumn{6}{|l|}{ Fencing scale } \\
\hline \multicolumn{6}{|l|}{ (Single household scale) } \\
\hline \multicolumn{6}{|l|}{ (Group of households scale) } \\
\hline \multicolumn{6}{|l|}{ (Village or community scale) } \\
\hline Barriers & Variable & $\begin{array}{l}\text { Medium/ } \\
\text { High }\end{array}$ & Medium & High & Maintenance required \\
\hline Boundary canal & & & & & $\begin{array}{l}\text { Water level maintenance required/ } \\
\text { Risk of disease transmission }\end{array}$ \\
\hline $\begin{array}{l}\text { Individual tree protection (e.g., zinc sheets, } \\
\text { electrical) }\end{array}$ & & & & & Risk of great ape and human injury \\
\hline \multicolumn{6}{|l|}{ Trench } \\
\hline Moat & & & & & $\begin{array}{l}\text { Risk of great ape and human injury } \\
\text { and disease transmission }\end{array}$ \\
\hline \multicolumn{6}{|l|}{ Stone wall } \\
\hline 'Live hedge' & & & & & $\begin{array}{l}\text { Avoids use of invasive non-locally } \\
\text { available species }\end{array}$ \\
\hline Buffer zones & Variable & High & Low & Low & $\begin{array}{l}\text { Requires careful design, planning } \\
\text { and management/Effectiveness } \\
\text { dependent on habituation level } \\
\text { and risk taking behaviour of great } \\
\text { ape/Risk of exacerbating clearing } \\
\text { practises }\end{array}$ \\
\hline
\end{tabular}


Mountain gorillas in Rwanda de-bark Eucalyptus trees planted outside the national park. Photo: (C) Prosper Uwingeli

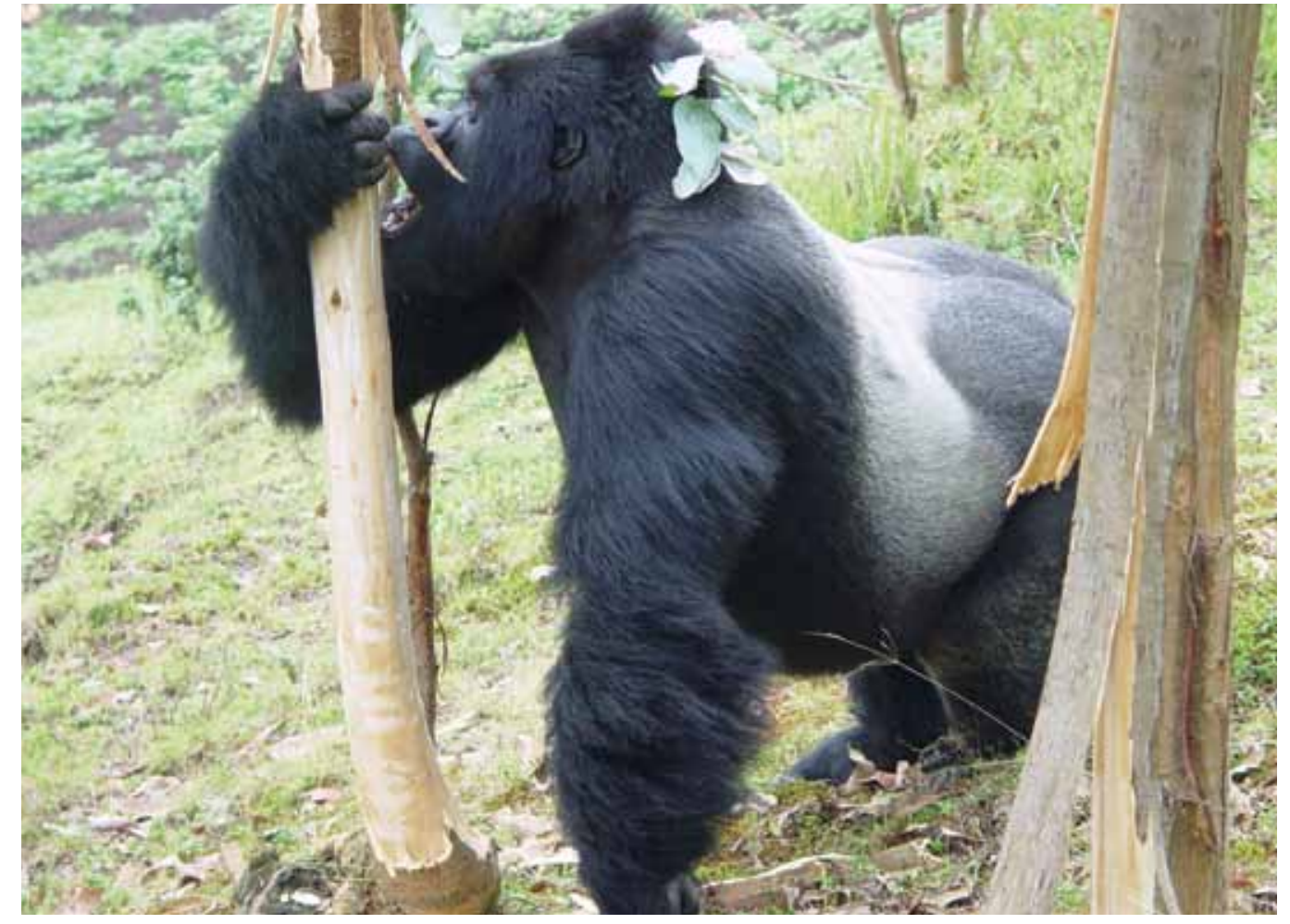

Harrison (1992) proposed that the ideal minimum width of a buffer zone at the edge of large protected areas, such as parks or biosphere reserves, is equal to the diameter of the home-range of the species it is designed to contain. Naughton-Treves (1998) recommended a 500m buffer zone between forest and fields to reduce crop-raiding by chimpanzees. However, these ideals are not always possible, especially in fragmented areas and where farmers practise swidden (slash-and-burn) agriculture (Hockings 2007). If considered a viable measure for other reasons, a buffer zone should be as wide as possible and regularly cleared of vegetation that could provide cover for the great apes. At Budongo, a $20 \mathrm{~m}$ buffer has shown some success at restricting cropraiding by animals. For orangutans, Yuwono et al. (2007) recommend buffers around plantations of $20-30 \mathrm{~m}$, in combination with other barriers (such as fences), and monitored by patrol units. The authors propose that a well-maintained buffer zone will discourage orangutans from crossing because these apes feel insecure and uncomfortable in exposed areas. However, even wild orangutans will cross cleared areas to reach target food plants, so cleared buffer areas may not deter them and may instead encourage them to be more terrestrial (Russon et al. 2001). Yuwono et al. (2007) also suggested that a buffer planted with an abundance of fruit trees would remove incentives for orangutans to venture further into plantations. However, this contradicts the 'exposure' element of a buffer zone and may encourage orangutans to frequent and penetrate the buffer, effectively drawing them closer to the crops that humans aim to protect. Thus an ape-exploitable buffer zone may not be an effective management tool. Salafsky (1993) has argued that a buffer zone that is exploited by orangutans will not prevent human-orangutan conflicts, and Goldsmith (2005) suggested that allowing great apes to use a buffer will actually promote forays and may actually increase the chances of crop-raiding once the buffer zone has been depleted. This is in line with other measures taken with mountain gorillas to make buffer zones as unattractive as possible, and discourage apes from frequenting the area (see details above). Whether an exploitable buffer is or is not an effective measure seems to depend on the great ape species concerned. Further studies are required to investigate the effectiveness of different types of buffer for each species of great ape.

Ideally buffer zones neither carve into great ape habitat nor attract wildlife to areas of potential conflict. However, if vegetation clearance is used in creating a buffer zone, it is vital to ensure beforehand that the area to be cleared does not harbour key natural resources used by the great apes or constitute core area(s) of their home range(s), as clearance would then exacerbate HGAC (see Section 4.4). The creation and maintenance of buffer zones should also be well managed, as there is a risk that such activities may be used as a pretext for forest clearance. 


\subsection{Experimental Repellents}

There are three basic types of repellent: (1) visual, (2) acoustic and (3) chemical (for reviews see Smith et al. 2000b; Osborn and Hill 2005). It is unknown if inanimate visual repellents are effective against crop-raiding primates although it is likely that primates readily habituate to them (also see Section 4.1). Research on the impact of acoustic repellents on the raiding behaviours of primates is lacking; however, given their ready habituation to visual stimuli, it is likely that they also readily habituate to sound if it becomes predictable (e.g., stationary noisemakers such as bells). To conduct a pilot study, for instance, it might be necessary to install several speakers, so that the playback stimuli come from various locations. As technology advances and the costs of equipment go down, there may be opportunities to test and use such forms of deterrent in the future. The playback of predator vocalisations could be tested, but in many regions, humans are now the only natural predator of great apes. For chimpanzees, playback of loud and unusual noises might be effective, but again it is unknown how quickly habituation would occur without systematic testing. Species-specific acoustics such as 'playbacks' should be used with caution so as not to disrupt the apes' normal communications or social systems, and to incite approach rather than retreat. Methods used in playback research may offer useful pointers, because they too must consider habituation and disruption of normal behaviour (Slocombe et al. 2009). Chemical raiding-repellents have been tested against primates with limited success. Some have tried to encourage taste aversion in monkeys with the use of an emetic, such as lithium chloride (Papio anubis: Forthman et al. 2005) or cyclophosphamide (Macaca fuscata: Matsuzawa et al. 1983). However, taste aversion interventions need to be designed very carefully for practical and ethical reasons, and should not be implemented by farmers without technical support. Crop palatability can be reduced by applying capsicum solution to crops (Strum 1994; Chalise 2001), and capsicum grease has been applied to netting with some success against orangutans (Campbell-Smith 2007). However, generally capsicum derivatives have been used as primate deterrents with mixed results. Systematic research is needed to determine appropriate concentrations and means of implementation. If effectively developed, capsicum could be applied in other sites where conflicts occur, for example specific paths or high-risk areas. Finally, great caution is needed when considering any visual, acoustic and chemical repellents, as they may displace target wildlife to new locations, disrupting social networks or resulting in damage to additional properties, and may impact non-target wildlife (Treves 2008).

Table 4.3. Non-traditional repellent methods

\begin{tabular}{|c|c|c|c|c|c|}
\hline \multirow{2}{*}{ Direct - Repellent method } & \multirow{2}{*}{ Effectiveness } & \multicolumn{3}{|c|}{ Cost } & \multirow{2}{*}{ Side-effects/Considerations } \\
\hline & & Financial & Time & Labour & \\
\hline Visual & Unknown & Low & Low & Low & May be more effective if varied \\
\hline Acoustic & Unknown & Medium & Low & $\begin{array}{l}\text { Low/ } \\
\text { Medium }\end{array}$ & $\begin{array}{l}\text { May be more effective if varied/Risk } \\
\text { of disrupting great ape behaviour/ } \\
\text { Risk of affecting non-target wildlife }\end{array}$ \\
\hline \multicolumn{6}{|l|}{ (Alarm calls broadcast in conflict area) } \\
\hline \multicolumn{6}{|l|}{ (Broadcasting noises of people or dogs) } \\
\hline Chemical & Unknown & Medium & Medium & Medium & $\begin{array}{l}\text { Requires technical advice/Risk of } \\
\text { great ape and human injury/Risk of } \\
\text { affecting non-target wildlife }\end{array}$ \\
\hline \multicolumn{6}{|l|}{$\begin{array}{l}\text { (Capsicum/chilli grease sprays and } \\
\text { bombs, available commercially) }\end{array}$} \\
\hline \multicolumn{6}{|l|}{ (Smoke from burning capsicum seeds) } \\
\hline $\begin{array}{l}\text { (Capsicum-based grease applied to simple } \\
\text { barriers) }\end{array}$ & & & & & \\
\hline
\end{tabular}




\subsection{Land-use changes}

The size of farms, and the type and quantity of crops that farmers and their neighbours grow, can influence crop-raiding behaviour (Campbell-Smith 2007). Proximity of farms or plantations to the forest boundary and the existence of neighbouring farms on the intervening land are also predictors of vulnerability to crop-raiding. Greater distance from the forest and the presence of neighbouring farms reduce the susceptibility of any one farm (Salafsky 1993; Hill 1997, 2000; Naughton-Treves 1997; Priston 2005; Ross and Warren 2006). Furthermore, the effect of proximity to the forest boundary can be reduced by establishing buffer zones (see Section 4.2).

When assessing the suitability of different types of land-use in preventing HGAC, it is important to consider whether the great apes inhabit a protected or non-protected area. Clearance of non-protected areas may destroy forest remnants, and lead to local great ape extinction. The Fongoli chimpanzees in Senegal are exclusively reliant on small forest patches that provide food and shelter, so these forested areas should be protected from cultivation (Pruetz 2006). Also, before establishing a new commercial plantation or extractive industry (e.g., logging or mining), potential HGAC should be anticipated (see Morgan and Sanz 2007; Yuwono et al. 2007). Additionally, a critical component in land-use planning should be the learning abilities of local great apes and the potential for behaviours that lead to conflict.

When choosing buffer crops to plant on the forest boundary (see Section 4.2), it is important to consider whether they will be for subsistence or cash generating, and dependent on external markets. For example, in addition to the environmental destruction caused by tobacco farming, the depreciation of international prices has caused Ugandan tobacco farmers to leave their crop to rot because the costs of harvesting and drying are too high to allow any profit. Such cash crops cannot be eaten or used for animal fodder, thus propelling vulnerable farmers into a debt that is difficult to escape. Tobacco, of course, is not the only potentially problematic cash crop - coffee and cocoa growers are susceptible to fluctuations in international markets.

Increasing connectivity between forest sites, specifically via corridors, can prevent the decline of genetic diversity in great apes by reducing isolation of subpopulations and providing additional food resources. However, establishing corridors is a complicated process and could create population sinks if the apes move into areas frequented by humans. The expertise of primatologists, ecologists, sociologists and economists should be sought prior to developing corridors for great apes. Corridors require the collaboration of neighbouring concession holders, and ideally, strong support from local communities and government. Areas that can be developed as potential corridors include forests that have been degraded, as they can be replanted with local tree species (e.g., Bossou-Nimba corridor; Hirata et al. 1998; Humle 2004). Experts on local botany, reforestation practices in tropical forests, and great ape ecology should be consulted when planning and implementing such projects. Increased connectivity between groups, communities or subpopulations of great apes might also exacerbate the risks of disease transmission. It is therefore vital to carry out a health risk assessment prior to establishing a corridor. Long-term planning and monitoring systems need to be developed to manage corridors. The ideal minimum width of corridors should equal the home-range diameter of the species they are designed for, plus a margin for edge effects (Harrison 1992). However, like buffer zones, the design and management of corridors depends on adjacent land-uses.

Conflicts resulting from great ape activity occur primarily at the forest edge - the interface with humans. Although the designation of protected areas depends largely on their conservation goals (Newmark 1986; Burkey 1989), large and regularly shaped protected areas will have fewer edge effects (Wrangham 2001). Wrangham (2001) demonstrated that even in protected areas as large as $3,000 \mathrm{~km}^{2}, 50 \%$ of chimpanzees might visit edges. In smaller and irregularly shaped protected areas, the proportion of chimpanzees potentially visiting the edges rises sharply, up to $100 \%$, even for areas greater than $500 \mathrm{~km}^{2}$. Thus the shape of a protected area is a key factor in HGAC. If the establishment of a protected area or the expansion of an existing protected area's boundaries requires the relocation of human populations or agricultural activities, such relocation should take into account great ape ecology and habitat use, the risks of HGAC, and local people's perceptions of the issue, to avoid negative attitudes developing towards conservation initiatives and HGAC issues. For example, human relocation close to great ape habitat can generate new 
conflict situations, as witnessed at the boundary of the Kouroufing National Park, Mali. The translocation of people is prohibitively expensive, but more likely to succeed if combined with direct or indirect benefit-sharing schemes (see Section 4.7).

Along these lines, another means of reducing conflict is a 'Land Purchase Programme', whereby local people affected by HGAC voluntarily sell their land to conservation and development organisations (Macfie 2000; Nkuringo Buffer Zone Management Plan 2007, see Sections 4.2 and 4.7). Land Purchase Programmes should concentrate on acquiring existing gorilla habitat outside the park, in particular areas where gorillas already forage. Such programmes also provide an opportunity to conduct research and methodology trials and testing of suitable buffer crops. Land purchase is not an option in most HGAC situations due to lack of finance. Furthermore, a 'Land Purchase Program' may not provide a satisfactory long-term solution if local people depend on the land for their livelihoods. As previously mentioned, the main incentive for a community in Uganda to sell their land was the anticipated benefits of gorilla tourism. This example demonstrates that conflict mitigation needs the collaboration of local communities. To consolidate community support, it is important that local people rapidly experience benefits from such programmes and that these benefits outweigh any costs incurred. A non-coercive approach to establishing a buffer zone outside of great ape habitat could involve subsidies for the growing of certain crops or of desig-

Table 4.4. Land-use change methods that might reduce spatial competition between people and great apes

\begin{tabular}{|c|c|c|c|c|c|}
\hline \multirow{2}{*}{ Direct - Land-use change methods } & \multirow{2}{*}{ Effectiveness } & \multicolumn{3}{|c|}{ Cost } & \multirow{2}{*}{ Side-effects/Considerations } \\
\hline & & Financial & Time & Labour & \\
\hline $\begin{array}{l}\text { Reduce human settlement/encroachment } \\
\text { into great ape range }\end{array}$ & High & Variable & Variable & Variable & $\begin{array}{l}\text { Requires careful design and local } \\
\text { support }\end{array}$ \\
\hline $\begin{array}{l}\text { Relocate agricultural activity out of great } \\
\text { ape range }\end{array}$ & High & Variable & Variable & Variable & $\begin{array}{l}\text { Requires careful design and local } \\
\text { support }\end{array}$ \\
\hline $\begin{array}{l}\text { Consolidate human settlement patterns } \\
\text { near great ape range }\end{array}$ & High & Variable & Variable & Variable & $\begin{array}{l}\text { Requires careful design and local } \\
\text { support }\end{array}$ \\
\hline Change location of crops/fields & Variable & Variable & Variable & Variable & $\begin{array}{l}\text { Requires careful design and local } \\
\text { support }\end{array}$ \\
\hline Change cropping regime & High & Low & NA & Variable & $\begin{array}{l}\text { Requires careful design, local } \\
\text { support and technical advice }\end{array}$ \\
\hline \multicolumn{6}{|l|}{ (Change to crops not used by great apes) } \\
\hline \multicolumn{6}{|l|}{$\begin{array}{l}\text { (Use inter-cropping layout e.g., inedible } \\
\text { crops on forest boundary) }\end{array}$} \\
\hline $\begin{array}{l}\text { Develop improved sustainable agricultural } \\
\text { techniques }\end{array}$ & Variable & High & Variable & Variable & Benefits local human communities \\
\hline \multicolumn{6}{|l|}{$\begin{array}{l}\text { (Increase yield of crops to minimise land } \\
\text { use) }\end{array}$} \\
\hline Create/Secure corridors for great apes & Unknown & High & High & $\begin{array}{l}\text { High/ } \\
\text { Low }\end{array}$ & $\begin{array}{l}\text { Benefits local fauna and flora/ } \\
\text { Requires careful design and local } \\
\text { support }\end{array}$ \\
\hline $\begin{array}{l}\text { Secure great ape and human access to } \\
\text { different water points }\end{array}$ & High & Variable & Low & Low & $\begin{array}{l}\text { Reduces risk of encounters and } \\
\text { disease transmission }\end{array}$ \\
\hline Expand protected areas & High & High & Variable & High & $\begin{array}{l}\text { Benefits local fauna and flora/ } \\
\text { Requires careful design and local } \\
\text { support }\end{array}$ \\
\hline Designate new protected areas & High & High & High & High & $\begin{array}{l}\text { Benefits local fauna and flora/ } \\
\text { Requires local and national support }\end{array}$ \\
\hline \multicolumn{6}{|l|}{ (Reduce edge-effect of protected area) } \\
\hline Habitat enrichment & Medium/High & Variable & High & Variable & $\begin{array}{l}\text { Benefits local fauna and flora/ } \\
\text { Requires careful design }\end{array}$ \\
\hline Buffer zones (see Counter-measure 4.2) & Variable & High & Low & Low & $\begin{array}{l}\text { Requires careful design, planning } \\
\text { and management/Effectiveness } \\
\text { dependent on habituation level and } \\
\text { risk taking behaviour of great ape / } \\
\text { Risk of excessive clearing practises }\end{array}$ \\
\hline
\end{tabular}


nated land-use practices. Subsidies can take many forms, from direct payments to individuals or households, to the provision of production and marketing infrastructure for buffer zone crops.

Where conflict between humans and great apes is caused by a shortage of natural resources, one solution, especially in unprotected areas, might be to provide alternative resources through habitat enrichment. Hockings (2007) proposes management strategies that conserve and encourage recovery or growth of key species in specific areas and corridors. If crop-raiding is related to periods of wild food scarcity, increasing the presence and availability of natural fallback foods (mostly foods of low preference but high seasonal importance sensu Marshall and Wrangham 2007) that are not consumed by humans may constitute a means of reducing cropraiding at these times. Habitat enrichment could reduce conflict between plantation owners and orangutans, as orangutans often raid plantations when availability of natural food resources in their forest habitat is low. However, habitat enrichment may require maintenance and monitoring to prevent human encroachment into these areas and to preserve the water resources therein.

\subsection{Live capture and translocation}

Translocation of 'problem' great apes should be considered only as a last resort. The ethics of translocation are highly questionable - translocation is stressful, dangerous, and potentially life-threatening, besides being expensive and labour-intensive (Goossens et al. 2005; Beck et al. 2007). The cost of translocating one orangutan is around US $\$ 3,000$ (Yuwono et al. 2007), not including the costs involved in identifying areas appropriate for release (the identification of habitat suitable for orangutans, considering such aspects as protected status, carrying capacity, and the levels of human threat), site preparation (surveying, establishing support infrastructure), and post-release monitoring of individuals to evaluate success. Finally, translocation does nothing to induce humans to alter their practices so as to reduce conflict. Despite these issues, it has become increasingly common to remove orangutans from conflict zones to provide immediate relief from crisis situations. According to Yuwono et al. (2007), only skilled employees from sanctuaries or rehabilitation centres, working in coordination with relevant authorities, should carry out such procedures. Individuals to be relocated must be anaesthetised, secured with a net (to avoid dangerous falls) and placed in a cage. It is essential that health checks be conducted prior to release to avoid transmission of diseases to the release site. In addition, orangutans must be translocated to an area of suitable habitat with adequate natural resources and a low probability of future conflict developing; individuals that have previously crop-raided might seek out cultivated areas. The social and resource requirements of the particular species of great ape need to be carefully considered before introducing individuals to a new area, but translocation to a site harbouring a resident ape population is not recommended (Beck et al. 2007). Across all great ape habitats, if HGAC involves raiding of large-scale plantations or industrial activity (e.g., mining), the companies concerned should be advised and preferably required by law to take corporate responsibility to mitigate the conflict. Finally, translocation should only be used under extraordinary conditions when no other option for the survival of the individual apes exists.

Table 4.5. Live capture methods and translocation of great apes

\begin{tabular}{|c|c|c|c|c|c|}
\hline \multirow{2}{*}{ Direct - Translocation method } & \multirow{2}{*}{ Effectiveness } & \multicolumn{3}{|c|}{ Cost } & \multirow{2}{*}{ Side-effects/Considerations } \\
\hline & & Financial & Time & Labour & \\
\hline Removal of selected individual great apes & Unknown & High & High & High & $\begin{array}{l}\text { Ethical issues/Logistically complex/ } \\
\text { Interference with great ape social } \\
\text { organization/Requires extensive } \\
\text { research, monitoring and technical } \\
\text { support and expertise/High risk of } \\
\text { diseased transmission }\end{array}$ \\
\hline \multicolumn{6}{|l|}{ (Identified problem individuals only) } \\
\hline \multicolumn{6}{|l|}{ (Age-sex class of problem individuals) } \\
\hline Capture and removal of entire population & High & High & High & High & $\begin{array}{l}\text { Logistically highly } \\
\text { complex/Requires extensive } \\
\text { research, monitoring, planning and } \\
\text { technical support and expertise/ } \\
\text { High risk of disease transmission }\end{array}$ \\
\hline
\end{tabular}




\subsection{Information gathering and education}

Although research on HGAC does not directly prevent or mitigate conflicts, it forms an integral part of almost any 'package' of counter-measures, actions or schemes, and should be one of the first courses of action. Furthermore, research and long-term monitoring of habituated communities provides knowledge of 'lessons learnt' that can be applied to other situations. If the ultimate goal is to design and develop mitigation measures or solutions that will be effective and sustainable in the long term, it is essential to fully understand the nature of the problem (see Section 3). Baseline data should be recorded to monitor long-term HGAC problems, such as recurring competition for water, repeated or serious damage to human resources (and the true economic losses incurred), killing of great apes, and human injuries or deaths caused by great apes (also Section 3). Detailed information is needed on the age-sex classes and behaviour of the great apes involved, in addition to an exhaustive list of ecological, sociological, political, behavioural, and anthropological research questions (see Macfie 2000, p.16). In all circumstances, researchers should avoid habituating great apes that live near human settlements and cultivated areas, especially if increased habituation could aggravate the problem. Where apes are already habituated, researchers should be aware that their presence may potentially increase the boldness of crop-raiding individuals.

As part of a Human-Gorilla conflict resolution programme (HuGo), the International Gorilla Conservation Programme (IGCP) has worked with the Uganda Wildlife Authority (UWA) and local communities to evaluate conflict situations and intervention measures (Byamukama et al. 2006). Global Positioning System (GPS) data are collected by rangers during routine patrols and whilst guiding, on illegal activities, animal presence, gorilla presence and their health status based on clinical signs and behaviour, using standardized checksheets. Gorilla monitoring response teams also take GPS points and collect additional data on crops destroyed and extent of damage, chasing methods used on standardized checksheets whenever they move gorillas back to the park. Byamukama et al. (2006) found that geo-spatial information has made conflict situations more tangible to the conflicting parties, especially the local communities involved, easing negotiations and the reaching of agreements. GIS data also helped pinpoint sites where interventions are most needed and most likely to be effective.

Although education and awareness-raising programmes do not resolve conflicts, they may promote a better understanding of great ape behaviour and appreciation of their conservation value. This may in turn lead to greater tolerance on the part of affected communities. An education programme should serve to inform local people about the goal and aims of a HGAC mitigation programme, also addressing the health risks that exist when great apes and humans share the same area. Such initiatives may help people better comprehend some of the underlying causes of HGAC, rendering them more open to discussion, better equipped to alter their own practices in

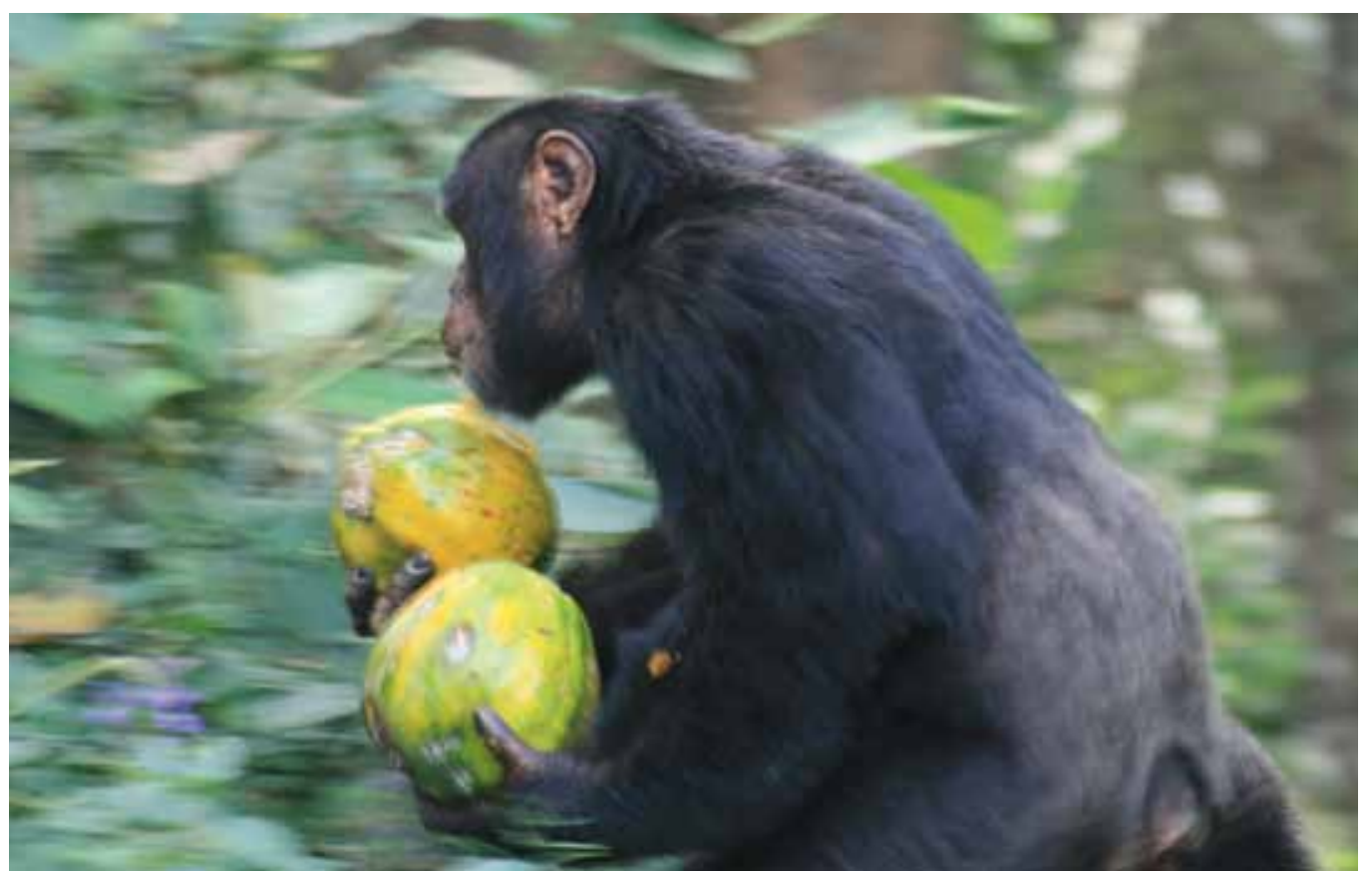

Chimpanzee carries fruit back to the forest.

Photo: @ Jiles Dore 
Table 4.6. Information needs and education to increase knowledge of great apes

\begin{tabular}{|c|c|c|c|c|c|}
\hline \multirow{2}{*}{$\begin{array}{l}\text { Indirect - Research/Data } \\
\text { collection and Education }\end{array}$} & \multirow{2}{*}{ Effectiveness } & \multicolumn{3}{|c|}{ Cost } & \multirow{2}{*}{ Side-effects/Considerations } \\
\hline & & Financial & Time & Labour & \\
\hline $\begin{array}{l}\text { Data collection/research } \\
\text { With wildlife authority resources } \\
\text { only or in collaboration with wildlife } \\
\text { authority and NGO(s) }\end{array}$ & Not Applicable & High & High & High & $\begin{array}{l}\text { Required to help mitigate and resolve } \\
\text { human-great ape conflicts and identify } \\
\text { appropriate counter-measure(s)/Promotes } \\
\text { involvement of wildlife authorities and local } \\
\text { employment/Promotes law enforcement } \\
\text { and great ape conservation/Requires careful } \\
\text { design, long-term commitment and good } \\
\text { communication between parties involved }\end{array}$ \\
\hline \multicolumn{6}{|l|}{$\begin{array}{l}\text { (Involve affected local people } \\
\text { reporting only) }\end{array}$} \\
\hline \multicolumn{6}{|l|}{$\begin{array}{l}\text { (Use qualified researchers and } \\
\text { data collection design) }\end{array}$} \\
\hline \multicolumn{6}{|l|}{$\begin{array}{l}\text { (Using trained human/great ape } \\
\text { conflict enumerators in the field) }\end{array}$} \\
\hline $\begin{array}{l}\text { Education and awareness-raising } \\
\text { campaigns }\end{array}$ & Variable & Variable & High & High & $\begin{array}{l}\text { Helps promote understanding of human- } \\
\text { great ape conflict issues and increase } \\
\text { tolerance towards great apes/Most } \\
\text { effective if long-term and involving locally } \\
\text { or nationally trained educators/Encourages } \\
\text { participatory approach to resolving human- } \\
\text { great ape conflict issues/Promotes great ape } \\
\text { conservation/Requires adapted design and } \\
\text { approach sensitive to audience }\end{array}$ \\
\hline \multicolumn{6}{|l|}{ (Village or community-based) } \\
\hline \multicolumn{6}{|l|}{ (Schools/universities) } \\
\hline (Authorities) & & & & & \\
\hline
\end{tabular}

ways that reduce rather than aggravate conflict, and more open to negotiation of concerted solutions. In addition, showing genuine interest in the problem and the people affected by HGAC and making efforts to address the issue may provide an effective short-term means of reducing conflict, effectively buying time for longer-term measures to be developed (Macfie 2000; Madden 2004).

If people are more informed on how to behave or not to behave when encountering great apes, education programmes may also help reduce the incidence of attacks on humans. Some basic tips on body movement, eye contact and other behaviours can reduce the likelihood that an ape will attack (Madden 2006); however, species- and even subspecies-specific differences are likely. For example, orangutans, which are predominantly arboreal, can be particularly unpredictable when encountered on the ground (Campbell-Smith 2007, 2008). In general, people should keep calm, try not to scream, and avoid running away and scattering, especially when in groups. Human infants are sometimes left behind by fleeing adults, increasing the likelihood of serious injury. In continuation of this point, children should not be left alone near the forest boundary nor venture alone into the forest. Observations suggest that adult male chimpanzees are less likely to confront men than women and children (supported by Wrangham 2001), so where possible, adult men should take a lead position. Gorillas can be dangerous during the habituation process, but standing up if in a seated position and holding one's ground whilst avoiding eye contact often stops a charge. The worst possible reaction is for a person to run away, as this often provokes a gorilla to charge, ending with a grab or a bite (Macfie 2000, p.7). Doran-Sheehy et al. (2007) suggest that the best way to prevent an attack is to stand in a group and hold onto another person (or a tree) to avoid being pulled to the ground. Education programmes may also provide advice on how to reduce the incidence of surprise encounters, such as increasing visibility on paths and trails that are also used by great apes. Finally, awareness-raising programmes can be designed for both villages and schools, and adapted to the local socio-cultural context, depending on the materials and logistics available. Materials are most likely to be effective if developed over time with the participation of locally-trained educators, and translated into an appropriate language. In schools especially, seminars should be annual events as new pupils start each year. 


\subsection{Schemes to benefit local people}

The implications of resource-ownership security are obvious. The argument made in conservation that long-term gains can be made despite short-term losses is a weak incentive for people to assist in local or national conservation (Cowlishaw and Dunbar 2000). There are three basic types of community-based conservation project: (1) direct benefit-sharing schemes: local people gain directly from conservation-oriented activities, for example, employment opportunities; (2) indirect benefit-sharing schemes: local people gain indirectly if conservation income contributes to local development projects, such as building hospitals and schools; and (3) local empowerment schemes: local people are given responsibility for managing a resource. An important prerequisite for the success of these projects is that the goals of the local community are the same as those of the conservationists. Wildlife utilisation schemes attempt to give local communities some control over the wildlife resources with which they coexist. However, before implementing or even proposing this type of project, one must consider the commodification ${ }^{2}$ of nature and its considerable costs. IGCP has supported the development of 'community conservation enterprises' in local communities around Bwindi, in recognition of the negative impacts of living close to a protected area. These initiatives include financial assistance for the production of handicrafts, beekeeping, growing of unpalatable crops that are of commercial value, support for campgrounds and ecolodges for tourists. Local communities that have benefited from these enterprises showed reduced levels of illegal activities and quicker responses to fire incidents compared to communities that were not in the scheme. Community conservation enterprises could be considered as indirect compensation schemes. Additionally, in an effort to provide long-term sustainable solutions, the HuGo conflict resolution programme has promoted the use of savings and credit schemes. The gorilla monitoring response teams have formed accumulated saving associations and are now able to use these savings to boost the enterprises started with IGCP grants. However, interviews carried out by an evaluation team suggest that the benefits from grants and savings do not compensate fully for the added responsibilities of cooperative law enforcement and gorilla monitoring (Musaasizi 2006). In Tanzania, community-focussed conservation programmes have been assisting villagers by building classrooms, but they also increase awareness and promote positive attitudes towards conservation issues (Anderson et al. 2004; Pusey et al. 2007). More recently, to restore and protect habitat around Gombe, conservation strategies have become more focussed and strategic. These include creating a GIS database that integrates satellite imagery, long-term data from chimpanzee observations, developing land-use plans in collaboration with local communities, and establishing a network of interconnected forest reserves (Pusey et al. 2007).

Great apes can be central to such schemes. Depending on the locality, great apes may have a value that can be turned into human benefit. Local people must be involved throughout the process of developing solutions, so that they understand the potential costs and benefits of the situation and the long-term value of great apes and their habitat, and have an incentive to treat natural resources sustainably. Some argue that this can be achieved either by establishing new programmes, such as sustainable harvesting of natural plant resources or tourism, or by distributing more effectively the economic benefits of existing programmes. Some research (e.g., Archabald and Naughton-Treves 2001) suggests that when revenue from wildlife is distributed to local communities, negative perceptions towards crop-raiding species can be improved (e.g., HuGo, tourism revenue sharing, and community benefits from running tourism businesses).

There are important and well-known risks associated with commodifying nature (McCauley 2006) that should be recognized and taken into consideration before promoting economically-motivated schemes for mitigating HGAC. Schemes that achieve successes in the short-term may cause serious problems in the long-term, especially for great apes, which are long-lived and exceptionally intelligent. For example, tourism can have negative consequences for great apes and requires careful management of disease risks (e.g., Homsy 1999; Hanamura et al. 2007). In addition, revenue-sharing schemes, if not managed appropriately, may destabilize local communities

\footnotetext{
${ }^{2}$ Commodification refers to the expansion of market trade to previously non-market areas, and to the treatment of things as if they were a tradable commodity.
} 
Table 4.7. Schemes that provide benefits to local people

\begin{tabular}{|c|c|c|c|c|c|}
\hline \multirow{2}{*}{ Schemes benefiting local people } & \multirow{2}{*}{ Effectiveness } & \multicolumn{3}{|c|}{ Cost } & \multirow{2}{*}{ Side-effects/Considerations } \\
\hline & & Financial & Time & Labour & \\
\hline $\begin{array}{l}\text { Direct benefit-sharing schemes } \\
\text { through local employment }\end{array}$ & Variable & High & High & High & $\begin{array}{l}\text { Risks associated with great ape habitua- } \\
\text { tion/Provides local employment and im- } \\
\text { proves local economy/Could help increase } \\
\text { tolerance towards great apes/Requires } \\
\text { long-term commitment, effective manage- } \\
\text { ment and institutional support/Wide local } \\
\text { support and benefit }\end{array}$ \\
\hline \multicolumn{6}{|l|}{ (Research) } \\
\hline \multicolumn{6}{|l|}{ (Ecoguards/rangers) } \\
\hline \multicolumn{6}{|l|}{ (Tourism) } \\
\hline $\begin{array}{l}\text { Indirect benefit-sharing schemes - } \\
\text { Local development projects }\end{array}$ & Variable & High & High & High & $\begin{array}{l}\text { Same as above/Needs to be compatible } \\
\text { with conservation goals/Transparency and } \\
\text { accountability/Risk of influx of people in } \\
\text { locality }\end{array}$ \\
\hline Local empowerment schemes & Variable & High & High & High & $\begin{array}{l}\text { Requires wide local support/Effective } \\
\text { management/Transparency and account- } \\
\text { ability/Needs to be compatible with con- } \\
\text { servation goals }\end{array}$ \\
\hline
\end{tabular}

and attract an unsustainable influx of people to the area which could ultimately negatively affect conservation goals; further, in areas with high human density, individual gain from tourism schemes might be negligible. However with firm institutional support and realistic expectations, revenuesharing from tourism could play an important role in improving local attitudes towards conservation without overlooking, trivializing, or discounting the great apes' intrinsic value. Archabald and Naughton-Treves (2001) suggest four key components of successful revenue-sharing programmes: (1) appropriate identification of the target community and project type, (2) transparency and accountability, (3) adequate long-term funding, and (4) long-term institutional support. We might add (5) a professionally-informed understanding of the key human, great ape, and programmatic factors involved and (6) continued consultation with relevant experts.

It is important that the benefits accruing from conservation are shared with local land-users and not solely absorbed by higher-level administrative structures. Care must be taken to ensure that any measures implemented really do target the most affected households. Community conservation efforts often fail because community-level interventions are steered towards elite groups who tend to have a stronger influence over the management of resources, leaving poorer more marginalized households with few real benefits (Gillingham and Lee 1999; Naughton-Treves and Treves 2005). It is crucial to clearly define which households are most impacted, and the use of participatory research methods to identify community priorities could be useful in this respect (FAO 2004). Successful programmes require long-term partnerships between the wildlife authorities, local authorities, private sector and local people, including the key stakeholders, which are often difficult to achieve. Throughout these negotiations, the affects on great apes must not be forgotten or such schemes risk causing them more harm than good.

\subsection{Compensation schemes}

Anyone managing a HGAC situation is likely to be confronted with demands for compensation for damaged property and/or lost revenues. Issues of compensation should not overshadow discussions of the many other measures that can be used to prevent and mitigate HGAC. Few data exist on HGAC compensation schemes, so we judge the likelihood of this counter-measure being effective via an examination of the human-elephant conflict compensation issue undertaken by the AfESG (Hoare 2001). Although monetary compensation can provide short-term alleviation of conflict, cases evaluated by the AfESG showed that compensation schemes suffer from degrees or combinations of the following:

- Inability to decrease the level of the problem, as the problem is not being addressed;

- less incentive for self-defence by farmers, which may even exacerbate the problem; 
- expensive and slow administration due to stringent financial controls;

- potential for abuse or corruption through false or inflated claims;

- absence of sufficient funds to cover all claims;

- the scheme potentially having no end point;

- unequal payment to victims, causing social problems and disputes;

- inability to compensate for unquantifiable opportunity costs for those people who are affected by the threat of problem individuals; and

- conflict with regulations or principles of the national protected areas authority.

Unlike most other counter-measures, the major conceptual flaw in a monetary compensation process is that unless compensation is made dependent on farmers undertaking measures to protect themselves in the future, it addresses only the symptoms and not the causes of the problem (Hoare 2001; Nyhus et al. 2005). In addition, schemes tend to be perceived as providing unequal benefits, which can exacerbate negative attitudes towards wildlife and protected areas (Gillingham and Lee 1999). However, the AfESG does not reject the idea of compensation under all circumstances. For example, situations of competition over water sources, already noted among chimpanzees living in arid zones, can potentially be resolved by a non-monetary compensation scheme involving the construction of wells. Such a scheme requires a commitment from local people to abandon use of the water points of conflict and to maintain the new wells. This measure constitutes not only a compensation scheme, but also a tolerance-increasing scheme for alleviating conflict. The location of new wells must be carefully chosen so as not to create further HGAC concerns by attracting people to an area frequented by apes, or by exacerbating travel restriction issues between humans and great apes. A systematic study of human-elephant conflict revealed that usually only a few people in a community are seriously affected; accordingly, Hoare (2001) suggested that if it is possible to identify these people and make fair assessments of their situation, locally-administered relief systems that involve foodstuffs rather than money might be more appropriate. Schemes developed to offset the economic losses incurred by local farmers and to engage local farmers in great ape conservation may, in combination, constitute a successful mitigation strategy.

After administering surveys to experts in large mammal conservation, and reviewing relevant publications, Nyhus et al. (2005, p.120) concluded that the 'key determinants of success for compensation schemes typically include the accurate and rapid verification of damage, prompt and fair payment embedded in a transparent process, a long-term source of funding capable of responding to variations in damage over time, clear rules and guidelines that link payment to sound management practices, an appreciation of the cultural and socio-economic context, and an ability to actively monitor the wildlife population of interest'. Without quantitative research to accurately estimate the true economic costs of HGAC, a project may not compensate for the true costs, and is bound to fail. The sustainability of a monetary compensation scheme will also be of key concern, especially in resource-constrained economies where human-wildlife conflict is widespread and involves a range of different species. For example, once compensation is awarded to farmers for crop damage by great apes, it becomes morally difficult to refuse compensation claims for damage by other species. Nyhus et al. (2005) emphasise that compensation schemes will be most effective as part of a more comprehensive approach actually dealing with the causes of the problem.

Table 4.8. Compensation schemes for crop damage by great apes

\begin{tabular}{|c|c|c|c|c|c|}
\hline \multirow{2}{*}{ Indirect - Compensation scheme } & \multirow{2}{*}{ Effectiveness } & \multicolumn{3}{|c|}{ Cost } & \multirow{2}{*}{ Side-effects/Considerations } \\
\hline & & Financial & Time & Labour & \\
\hline $\begin{array}{l}\text { Monetary - linked to damage by } \\
\text { great apes }\end{array}$ & Brief & High & High & Variable & $\begin{array}{l}\text { Often unsustainable/Requires local } \\
\text { commitment and accurate damage report }\end{array}$ \\
\hline $\begin{array}{l}\text { Non-monetary (e.g., food aid linked to } \\
\text { ape damage, construction of wells) }\end{array}$ & Variable & $\begin{array}{l}\text { Medium/ } \\
\text { High }\end{array}$ & Variable & Variable & $\begin{array}{l}\text { Requires local commitment and when } \\
\text { relevant, accurate damage report }\end{array}$ \\
\hline
\end{tabular}




\section{Section 5: Planning a HGAC Management Strategy}

A management plan may vary in its complexity, depending on your assessment of a HGAC situation (Hoare 2001). You may choose to incorporate other problem animal species into a mitigation strategy, which may alleviate intolerance to great apes and decrease levels of conflict perceived by local farmers. It is also important to work closely with all relevant stakeholders, as well as with the national and regional authorities, as independent action that pays insufficient respect to appropriate institutions or personnel can lead to resentment or backfire with negative consequences for conservation.

The following basic steps should be followed in the production and operation of any wildlife management plan (Treves et al. 2006): (1) baseline research to identify the humans, great apes and locations most at risk, (2) facilitate a participatory decision-making process about which intervention to deploy, and (3) experimental deployment with monitoring of outcomes.

\subsection{Baseline research}

See Section 3 for the information required to determine which humans, great apes and locations are most at risk based on past and present patterns of interaction.

\subsection{Decision process}

It is important to consider your position in the chain of responsibility when making decisions about HGAC. A major factor in the decision-making process is whether a person works near the HGAC area. People living in close geographical range (such as wildlife managers, villagers, researchers) should be able to consult regularly, and ideally decisions will be consensus-based. In contrast, when stakeholders live further away (such as government officials), the process is more hierarchical and decisions are more likely to be passed down in the form of instructions. Such differences in decision-making processes can create management problems or setbacks if there is a lack of agreement between those working in the locality concerned (i.e., in situ) and those not on site (e.g., government ministers or officials).

\subsubsection{Set clear goals and objectives}

Once a conflict site has been identified and local people agree that intervention is necessary, the specific goal and intervention objectives for conflict resolution must be established and the necessary resources secured. For example, if elimination of HGAC is unrealistic, your goal may be to 'reduce HGAC by accommodating both human and great ape needs'. The goal of the Nkuringo Buffer Zone Management Plan (2007) is to 'reduce human-wildlife conflict while protecting the Critically Endangered mountain gorilla and contributing to improved community livelihoods'. It is, however, important to be conscious of the priorities and to recognise positions that are potentially adversarial. Some, for instance, consider that the priority of any intervention should be to improve the livelihood security of the farmers concerned or the economy through the careful development of exploitation industries such as mining or logging or large scale agricultural projects (Hill et al. 2002); others might consider this position untenable if their aim is to protect great apes from extinction. Whatever one's standpoint, people are part of the problem of wildlife decline and therefore must be part of the solution. In cases of crop-raiding, if an objective of intervention is to 'reduce crop damage', then increasing human tolerance of crop damage is as important as reducing the damage itself. Examples of specific objectives might include:

- Reduce the level of crop losses to great apes;

- improve tolerance (i.e., local people's attitudes towards great apes and habitat); and

- help local farmers to improve agricultural production.

Major constraints relating to policy and the practical application of a HGAC mitigation plan may be technical, ethical, political, economical, environmental or social. Hoare (2001, p.79) stated that 'theoretically, the dilemma is that [great apes] have both benefits and costs and what you are trying to do as a manager is balance these in some sort of compromise, using the limited resources at your disposal'. 
We recommend that people at all levels of the decision-making process appreciate that HGAC mitigation is not an isolated issue (cf. Hoare 2001). Other obligations might include: (1) censusing great apes, (2) law enforcement and measuring the impact of law enforcement efforts on great apes, (3) compiling data on the bushmeat and pet trades, (4) research on great ape behaviour, (5) the management of important habitats (6) recognition of obligations of land owners to provide for their families, and (7) accounting for the needs of governments and industry to obtain revenue from agriculture (e.g., plantations) or other activities. Active integration of HGAC into an overall plan that deals with other aspects of great apes management will help decision makers gain a practical perspective.

\subsubsection{Describe and evaluate feasible counter-measure options that meet the objectives}

See Section 4 for a review of possible counter-measures. You will probably need to combine actions, counter-measures or schemes over variable time scales as a 'package'; it is important to outline the measures that you might employ at all stages. Madden (2004, p.252) highlighted that 'rarely, if ever, can a single tactic address the full range of social, economic, biological, and other aspects of a conflict scenario. By combining a number of tactics, tools and techniques, we can strengthen and improve the chances of overall success in mitigation efforts'. Specific interventions may be applicable to specific areas of a multifaceted HGAC situation. The AfESG recommends the use of two-way matrices to facilitate the organisation of possible actions and mitigation options (Hoare 2001). Initially, it is recommended that a small selection of intervention actions be implemented and their effectiveness monitored; it is always possible to return to the original list and invoke another intervention. It is also important to conduct a 'time-scale assessment' by considering whether interventions were chosen as short- or long-term solutions (see summary tables of counter-measures in Section 4). An 'objective-action matrix' will help to set objectives against these short- and long-term actions (Table 5; for further information see Hoare 2001, p.88); objectives do not have to be mutually exclusive as there is much overlap between HGAC issues. Another important step is to establish the feasibility of the mitigation packages in your area. A 'pay-off matrix' might be useful as it includes a control option where no interventions are used (in situations with no available resources this might be an unavoidable reality), and the control is ranked against the outcomes of the interventions (Table 6; for further information see Hoare 2001, p.90). Different packages of interventions can be applied to different levels of the HGAC problem and likely outcomes compared. Hoare (2001) stated that 'using simple aids like these [matrices] to organize one's thoughts in advance of taking any management action can actually make the difference between success and failure of a whole strategy'.

\subsection{Experimental deployment - monitoring, evaluation and revision}

Monitoring of outcomes should be conducted at three levels: (1) was the intervention implemented as planned? (2) did encounters leading to HGAC diminish? (3) were people and great apes protected? (Treves et al. 2006).

The performance of any management plan should be monitored and evaluated with respect to the impacts (i.e., the real effects of intervention), goals and objectives, even if circumstances change over time (see Nkuringo Buffer Zone Management Plan 2007, pp.22-23 for Monitoring and Evaluation Framework). One simple way to measure whether an action or package has the desired result is to compare 'before and during/after' situations. These measurements may range from numbers of households reporting damage to methods requiring research input, such as attitude assessments and levels of great ape damage. It may be difficult to establish what constitutes the 'before action' scenario, especially if prevention had already been attempted before investigation began, but trends over specific intervals from when data gathering started should be examined (e.g., per month, per season, per year). For results to be comparable, the effort put into recording information must be standardized, continuous, and of consistent quality (Hoare 2001). This 'adaptive management' approach integrates data collection with management action and constantly evaluates progress through lessons learnt. This approach rarely allows for experimental control as mentioned in relation to the 'pay-off matrix' above.

An evaluation of the Human-Gorilla conflict resolution programme (HuGo) indicated that efforts had mostly been relevant, effective, and efficient (Byamukama and Asuma 2006). Gorilla monitoring 


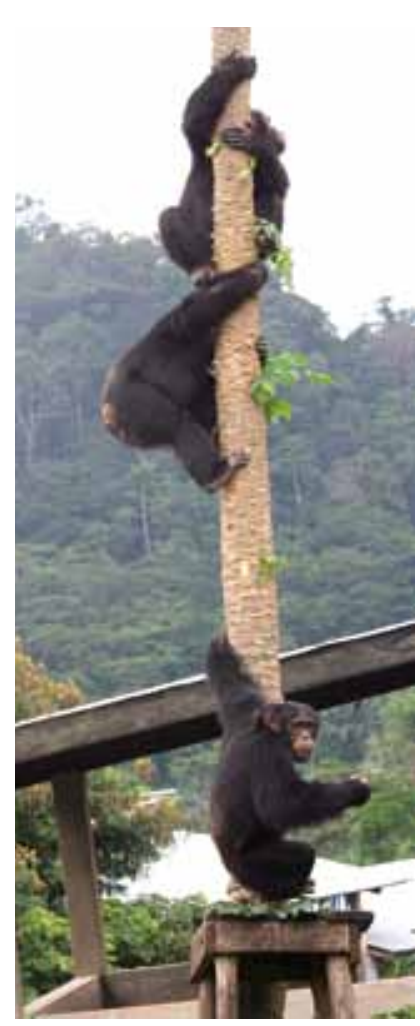

Adult male chimpanzees feeding on papaya in a village. Photo: () Tatyana Humle response teams greatly reduced crop loss by chasing and guarding; however, as touched upon throughout these guidelines, the need for a reward system is the main factor that might undermine the long-term sustainability of the HuGo programme. Education and sensitisation, and involvement of local communities from the beginning, have improved understanding of the conflict resolution process and the long-term aims of gorilla conservation. Communities now understand that the Uganda Wildlife Authority is willing to respond to their concerns and that joint park-community solutions are most effective. However, one of the main concerns about HuGo is that park managers are handicapped by the absence of policy relevant to the human-gorilla conflict (e.g., regulations governing conduct of the gorilla monitoring research teams and supervisors; written guidelines for responding to gorilla excursions). Musaasizi (2006, p.12) highlighted that 'it is imperative that guidelines and policy for responding to human-gorilla conflicts be developed from the lessons learned so far and the current collaborative approach be institutionalized through a Memorandum of Understanding with the concerned community groups and local governments.' Following evaluation, the HuGO programme was extended to cover other problem animals. To date, teams have been formed to cover four more problem animals - namely baboons, bush pigs, monkeys, and elephants (Musaasizi 2006).

\section{Section 6: Conclusions}

It is clear that HGAC issues must be viewed from a range of perspectives, and placed in the context of local community and individual needs, as well as conservation objectives and those of the government and industry involved (Hill et al. 2002). What might seem like an appropriate intervention strategy to researchers may not necessarily be acceptable or practical to a community or individual. HGAC is complex and unlikely to be resolved quickly or by technical means, and often requires adopting a series of strategies; steps that can solve one type of conflict are not always applicable to others. Caution is needed when implementing mitigation methods as few have been tested thoroughly with great apes. There is no ideal solution for managing HGAC, and no human-great ape mitigation strategy will work without knowledge of what is possible, practical or acceptable in any particular area. Cost-benefit analyses are also required to identify the most effective short- and long-term options for reducing conflict.

Programmes that are dependent on external funding are unlikely to be sustainable in the long-term. Intervention methods will therefore be more successful if they are financially and technologically within the capacity of the people, organisations, institutions or bodies who will implement them (Kangwana, 1995, cited in Osborn and Hill, 2005). Farmers need to take responsibility for protecting their own crops, which requires assisting them to develop locally-appropriate schemes to successfully reduce loss (Osborn and Hill 2005).

\section{Section 7: Acknowledgements}

We thank the many contributors to these guidelines. It is our opinion that as our understanding of global human-wildlife conflict situations increases, guidelines such as these should be added to and updated. We have taken lessons from previous guidelines and adopted a similar approach to that of the IUCN/SSC African Elephant Specialist Group (AfESG). We would therefore like to strongly acknowledge R.E. Hoare, author of 'A decision support system for managing human-elephant conflict situations in Africa', published in 2001. We would also like to acknowledge specific conflict mitigation documents we have referred to, in particular:

Yuwono et al. 2007. Guidelines for Better Management Practices on Avoidance, Mitigation and Management of Human-Orangutan Conflict In and Around Oil Palm Plantations. WWF-Indonesia.

Hill et al. 2002. Human-wildlife conflict: Identifying the problem and possible solutions. Albertine Rift Technical Report Series Vol.1. Wildlife Conservation Society, New York.

Macfie, L. 2000. Human-gorilla conflict resolution. Report to the International Gorilla Conservation Programme, Nairobi. 
Many thanks to all who have written similarly important documents about human-wildlife conflict. Furthermore, we are thankful to those who answered our questionnaire on HGAC at their field site, namely Marc Ancrenaz, Paco Bertolani, Gail Campbell-Smith, Janis Carter, Diane Doran, Andrew Dunn, Chris Duvall, Albert Ekinde, Nicolas Granier, llka Herbinger, Cleve Hicks, Tony King, Matt McLennan, Bethan Morgan, Aaron Nicholas, Toshida Nishida, Ndiaye Souleye, and Jo Thompson.

We thank Liz Williamson for her immense support and time dedicated to these guidelines. Special thanks to Kathelijne Koops who helped with initial ideas, and the following, who shared their experience of great ape behaviour: Takeshi Furuichi, Alexander Georgiev, Michelle Klailova, Francine Madden, Michio Nakamura, Hannah Parathian, Diane Sheehy-Doran, Katie Slocombe, Klaus Zuberbühler. Lastly thanks to the reviewers who generously gave their time and expertise to improve this document: Marc Ancrenaz, Stephen Asuma, Paco Bertolani, Glenn Bush, James Byamukama, Gail Campbell-Smith, Christelle Colin, Chris Duvall, Kay Farmer, Maryke Gray, Kate Hill, Annette Lanjouw, Phyllis Lee, Liz Macfie, Arthur Mugisha, Vernon Reynolds, Anne Russon, lan Singleton, Joshua Smith, Claudia Sousa, Adrian Treves, Janette Wallis, Ymke Warren, Mike Wilson, Richard Wrangham, and Juichi Yamagiwa.

\section{Section 8: Literature cited}

Agoramoorthy, G. 2002. Exhibiting orang-utans on a natural island in Malaysia. International Zoo News 49:260-266.

Ancrenaz, M., Dabek, L. and O'Neil, S. 2007. The costs of exclusion: recognizing a role for local communities in biodiversity conservation. PLoS Biol 5:e289.

Anderson, G.W., Gaffikin, L., Pintea, L., Kajembe, Yeboah, K. and Humplick, B.J. 2004. Assessment of the Lake Tanganyika Catchment, Reforestation and Education (TACARE) project. Report to USAID and Jane Goodall Institute, Washington, DC.

Archabald, K. and Naughton-Treves, L. 2001. Tourism revenue-sharing around national parks in western Uganda: early efforts to identify and reward local communities. Environmental Conservation 28:135-149.

Beck, B., Walkup, K., Rodrigues, M., Unwin, S., Travis, D. and Stoinski, T. 2007. Best Practice Guidelines for the Re-introduction of Great Apes. IUCN/SSC Primate Specialist Group, Gland, Switzerland. 48pp. www.primate-sg.org/BP.reintro.htm

Biryahwaho, B. 2002. Community perspectives towards management of crop-raiding animals: Experiences of Care-DTC with communities living adjacent to Bwindi Impenetrable and Mgahinga Gorilla National Parks, Southwest Uganda. In: Albertine Rift Technical Report Series Vol. 1. Wildlife Conservation Society, New York.

Buckland, H. 2005. The oil for ape scandal: How palm oil is threatening orang-utan survival. Friends of the Earth Trust, London.

Burkey, T.V. 1989. Extinction in nature reserves: the effect of fragmentation and importance of migration between reserve fragments. Oikos 55:75-81.

Butynski, T.M. 2001. Africa's great apes. In: B.B. Beck, T.S. Stoinski, M. Hutchins, T.L. Maple, B. Norton, A. Rowan, E.F. Stevens and A. Arluke (eds.), Great Apes and Humans: The Ethics of Coexistence, pp.3-56. Smithsonian Institution Press, Washington, DC.

Byamukama, J. and Asuma, S. 2006. Human-gorilla conflict resolution (HuGo) - the Uganda experience. Gorilla Journal 32:10-12.

Byamukama, J., Gray, M. and Kagoda, E. 2006. GIS as a Tool in Human-Gorilla Conflict Management in Bwindi Impenetrable National Park-Uganda. International Gorilla Conservation Programme, Nairobi.

Campbell-Smith, G.A. 2007. Bittersweet knowledge: Can people and orangutans live in harmony? Unpublished Report to the Great Apes Conservation Fund, US Fish and Wildlife Service, Arlington, Virginia.

Campbell-Smith, G.A. 2008. Bittersweet knowledge: Can people and orangutans live in harmony? Unpublished Report to the Great Apes Conservation Fund, US Fish and Wildlife Service, Arlington, Virginia.

Campbell-Smith, G.A. and Linkie, M. 2008. Bittersweet knowledge: Can farmers and orangutans live in harmony? International Journal of Primatology $N(S 1): 82$. (Abstract).

Chalise, M.K. 2001. Crop-raiding by wildlife, especially primates, and indigenous practices for crop protection in Lakwuna area, east Nepal. Asian Primates 7:4-9.

Chalise, M.K. and Johnson, R.L. 2005. Farmer attitudes toward the conservation of 'pest' monkeys: The view from Nepal. In: J.D. Paterson and J. Wallis (eds.), Commensalism and Conflict: the Human-Primate Interface, pp.222-239. American Society of Primatologists, Norman, Oklahoma.

CITES/GRASP. 2006. CITES/GRASP Orang-Utan Technical Mission: Indonesia, 8-12 May 2006. CITES Secretariat, Geneva.

Cormier, L.A. 2003. Kinship with Monkeys. The Guaja Foragers of Eastern Amazonia. Columbia University Press, New York.

Cowlishaw, G. and Dunbar, R. 2000. Primate Conservation Biology. University of Chicago Press, Chicago.

Dellatore, D.F. 2007. "Behavioural health of reintroduced orangutans (Pongo abelii) in Bukit Lawang, Sumatra Indonesia". MSc thesis, Oxford Brookes University, Oxford.

Doran-Sheehy, D.M., Derby, A.M., Greer, D. and Mongo, P. 2007. Habituation of western gorillas: The process and factors that influence it. American Journal of Primatology 69:1-16.

FAO. 2004. Rural Households and Resources: A pocket guide for extension workers. Socio-Economic and Gender Analysis Programme. Food and Agriculture Organization of the United Nations, Rome. Website: www.fao.org/sd/seaga/4_en.htm

Farmer, K.H. 2002. "The behaviour and adaption of chimpanzees (Pan troglodytes troglodytes) in the Republic of Congo". PhD thesis, University of Stirling, Stirling.

Forthman, D.L., Strum, S.C. and Muchemi, G.M. 2005. Applied conditioned taste aversion and the management and conservation of crop-raiding primates. In: J.D. Paterson and J. Wallis (eds.), Commensalism and Conflict: the Human-Primate Interface, pp.421-443. American Society of Primatologists, Norman, Oklahoma.

Fortunate, M. 2004. Implementation of Mauritius thorn 'live hedge' as a tool to mitigate primate-human conflicts around Bwindi Impenetrable National Park. Report to the Conservation and Research Small Grants Projects, Cleveland Metroparks Zoo/Cleveland Zoological Society, Cleveland, Ohio. Website: www.clemetzoo.com/conservation/grants/small/2004/fortunate.asp

Fuentes, A. and Wolfe, L.D. 2002. Primates Face to Face: the Conservation Implications of Human-Nonhuman Primate Interconnections. Cambridge University Press, Cambridge. 
Gillingham, S. and Lee, P.C. 1999. The impact of wildlife-related benefits on the conservation attitudes of local people around the Selous Game Reserve, Tanzania. Environmental Conservation 26:218-228.

Goldsmith, M. 2005. Impacts of habituation for ecotourism on the gorillas of Nkuringo. Gorilla Journal 30:11-14.

Goossens, B., Setchell, J.M., Tchidongo, E., Dilambaka, E., Vidal, C., Ancrenaz, M. and Jamart, A. 2005. Survival, interactions with wild conspecifics and reproduction in wild-born orphan chimpanzees following release into Conkouati-Douli National Park, Republic of Congo. Biological Conservation 123:461-475.

Hanamura, S., Kiyono, M, Lukasik-Braum, M., Mlengeya, T., Fijimoto, M., Nakamura, M. and Nishida, T. 2007. Chimpanzee deaths at Mahale caused by flu-like disease. Primates 49:77-80.

Harrison, R.L. 1992. Toward a theory of inter-refuge corridor design. Biological Conservation 6:293-295.

Hill, C.M. 1997. Crop-raiding by wild vertebrates: the farmer's perspective in an agricultural community in western Uganda. International Journal of Pest Management 43:77-84.

Hill, C.M. 1998. Conflicting attitudes towards elephants and conservation around the Budongo Forest, Western Uganda. Environmental Conservation 25:244-250.

Hill, C.M. 2000. Conflict of interest between people and baboons: Crop raiding in Uganda. International Journal of Primatology 21:299-315.

Hill, C.M. 2005. People, crops and primates: A conflict of interests. In: J.D. Paterson and J. Wallis (eds.), Commensalism and Conflict, pp.40-59. American Society of Primatologists, Norman, Oklahoma.

Hill, C.M., Osborn, F.V. and Plumptre, A.J. 2002. Human-wildlife conflict: Identifying the problem and possible solutions. Albertine Rift Technical Report Series Vol.1. Wildlife Conservation Society, New York.

Hirata, S., Morimura, N. and Matsuzawa, T. 1998. Green passage plan (Tree planting project and environmental education using documentary videos at Bossou): A progress report. Pan Africa News 5:9-11.

Hoare, R. 2001. A decision Support System (DSS) for managing human-elephant conflict situations in Africa. AfESG (IUCN/SSC African Elephant Specialist Group), Nairobi.

Hockings, K.J. 2007. "Human-Chimpanzee Coexistence at Bossou, the Republic of Guinea: A Chimpanzee Perspective”. PhD thesis, University of Stirling, Stirling.

Hockings, K.J., Anderson, J.R. and Matsuzawa, T. 2006a. Road-crossing in chimpanzees: A risky business. Current Biology 16:668-670.

Hockings, K.J., Anderson, J.R. and Matsuzawa, T. 2006b. Temporal patterns of crop-raiding in the Bossou chimpanzees, Guinea, West Africa (Pan troglodytes verus): Relation to wild food availability. International Journal of Primatology 27(S1):304. (Abstract).

Hockings, K.J., Humle, T., Anderson, J.R., Biro, D., Sousa, C., Ohashi, G. and Matsuzawa, T. 2007. Chimpanzees share forbidden fruit. PLoS ONE 2:e88.

Homsy, J. 1999. Ape Tourism and Human Diseases: How Close Should We Get? International Gorilla Conservation Programme (IGCP), Nairobi. Website: www.igcp.org/files/ourwork/Homsy_rev.pdf

Humle, T. 2003. Chimpanzees and crop raiding in West Africa. In: R. Kormos, C. Boesch, M.I. Bakarr and T.M. Butynski (eds.), West African Chimpanzees. Status Survey and Conservation Action Plan, pp.147-155. IUCN, Gland, Switzerland.

Humle, T. 2004. Chimpanzee Conservation at Bossou and in the Nimba Mountains Region, West Africa: Environmental Education and the Green Corridor Project. Unpublished Report to the Great Apes Conservation Fund, US Fish and Wildlife Service, Arlington, Virginia.

Kalema-Zikusoka, G., Kock, R.A. and Macfie, E.J. 2002. Scabies in free ranging gorilla (Gorilla beringei beringei) in Bwindi Impenetrable National Park, Uganda. The Veterinary Record 150:12-15.

Kamenya, S. 2002. Human baby killed by Gombe chimpanzee. Pan Africa News 9:26.

Karanth, K.U. and Madhusudan, M.D. 2002. Mitigating human-wildlife conflicts in southern Asia. In J. Terborgh, C.P. van Schaik, M. Rao and L.C. Davenport (eds.), Making Parks Work: Identifying Key Factors to Implementing Parks in the Tropics, pp.250-264). Island Press, Covelo.

King, F.A. and Lee, P.C. 1987. A brief survey of human attitudes to a pest species of primate-Cercopithecus aethiops. Primate Conservation 8:82-84.

King, T. and Chamberlan, C. 2007. Orphan gorilla management and reintroduction: Progress and perspectives. Gorilla Journal 34:21-25.

Köndgen, S., Kühl, H., N'Goran, P.K., Walsh, P.D., Schenk, S., Ernst, N., Biek, R., Formenty, P., Mätz-Rensing, K., Schweiger, B., Junglen, S., Ellerbrok, H., Nitsche, A., Briese, T., Lipkin, W.I., Pauli, G., Boesch, C. and Leendertz, F.H. 2008. Pandemic human viruses cause decline of endangered great apes. Current Biology 18:260-264.

Lackman-Ancrenaz, I., Ancrenaz, M. and Saburi, R. 2001. The Kinabatangan Orangutan Conservation Project. In: B. Zoo (ed.), The Apes: Challenges for the 21st Century, pp.262-265. Brookfield Zoo, Chicago.

Lee, P.C. 2004. Who wins? Human-primate conflict in the context of conservation, development and gender. Primate Eye 84:15-16.

Lee, P.C., Brennan, E.J., Else, J.G. and Altmann, J. 1986. Ecology and behaviour of vervet monkeys in a tourist lodge habitat. In: J.G. Else and P.C. Lee (eds.), Primate Ecology and Conservation, pp.229-235. Cambridge University Press, Cambridge, UK.

Macfie, L. 2000. Human-Gorilla Conflict Resolution: Recommendations for Component within IGCP Uganda Programming. International Gorilla Conservation Programme, Nairobi.

Madden, F. 1999. The Human-Gorilla conflict resolution project (HuGo): a problem analysis and project design. International Gorilla Conservation Programme, Nairobi.

Madden, F. 2004. Creating coexistence between humans and wildlife: global perspectives on local efforts to address human-wildlife conflict. Human Dimensions of Wildlife 9:247-257.

Madden, F. 2006. Gorillas in the garden - Human-wildlife conflict at Bwindi Impenetrable National Park. Policy Matters 14:180-190.

Marchal, V. 2005. "Primate crop-raiding: A study of local perceptions in four villages in North Sumatra, Indonesia". MSc thesis, Oxford Brookes University, Oxford.

Marshall, A.J. and Wrangham, R.W. 2007. Evolutionary consequences of fallback foods. International Journal of Primatology 28:1219-1235.

Mascarenas, A. 1971. Agricultural vermin in Tanzania. In: S.H. Ominds (ed.), Studies in East African Geography and Development, pp.259-267. Heinemann Educational Books Ltd, Oxford.

Matsuzawa, T., Hasegawa, S., Gotoh, S. and Wada, K. 1983. One-trial long-lasting food-aversion learning in wild Japanese monkeys (Macaca fuscata). Behavioural and Neural Biology 39:155-159.

McCauley, D.J. 2006. Selling out on nature. Nature, London 443:27-28.

McLennan, M.R. 2008. Beleaguered chimpanzees in the agricultural district of Hoima, western Uganda. Primate Conservation (23):45-54.

Mittermeier, R.A. 1987. Effects of hunting on rainforest primates. In: C.W. Marsh and R.A. Mittermeier (eds.), Primate Conservation in the Tropical Rain Forest, pp.109-146. Alan R. Liss, New York. 
Mittermeier, R.A., Ratsimbazafy, J., Rylands, A.B., Williamson, E.A., Oates, J.F., Mbora, D., Ganzhorn, J.U., Rodriguez-Luna, E., Palacios, E., Heymann, E.W., Cecilia, M., Kierulff, M., Yongcheng, L., Supriatna, J., Roos, C., Walker, S. and Aguiar, J.M. 2007. Primates in peril: The world's 25 most endangered primates, 2006-2008. Primate Conservation (22):1-40.

Morgan, D. and Sanz, C. 2007. Best Practice Guidelines for Reducing the Impact of Commercial Logging on Great Apes in Western Equatorial Africa. IUCN/SSC Primate Specialist Group. Gland, Switzerland. 32pp. Website: www.primate-sg.org/BP.logging.htm

Musaasizi, J. 2006. Evaluation of human gorilla conflict resolution programme, Bwindi Impenetrable National Park. Report compiled for the African Wildlife Foundation/International Gorilla Conservation Programme, Nairobi.

Muyambi, F. 2004. Crop raiding: Human-gorilla conflicts and its implication on conservation around Bwindi Impenetrable National Park. Institute of Tropical Forest Conservation, Bwindi Impenetrable National Park, Uganda.

Naughton-Treves, L. 1997. Farming the forest edge: Vulnerable places and people around Kibale National Park, Uganda. The Geographical Review 87:27-46.

Naughton-Treves, L. 1998. Predicting patterns of crop damage by wildlife around Kibale National Park, Uganda. Conservation Biology 12:156-168.

Naughton-Treves, L. 2001. Farmers, wildlife and the forest fringe. In: W. Weber, L.J.T. White, A. Vedder and L. Naughton-Treves (eds.), African Rainforest Ecology and Conservation, pp.369-384. Yale University Press, New Haven.

Naughton-Treves, L. and Treves, A. 2005. Socio-ecological factors shaping local support for wildlife: crop-raiding by elephants and other wildlife in Africa. In: R. Woodroffe, S. Thirgood and A. Rabinowitz (eds.), People and Wildlife: Conflict and Coexistence?, pp.252-277. Cambridge University Press, Cambridge.

Naughton-Treves, L., Treves, A., Chapman, C. and Wrangham, R. 1998. Temporal patterns of crop-raiding by primates: Linking food availability in croplands and adjacent forest. Journal of Applied Ecology 35:596-606.

Nelleman, C. and Newton, A. 2002. Great Apes - the Road Ahead. An analysis of great ape habitat, using GLOBIO methodology. United Nations Environment Programme (UNEP), Nairobi.

Newmark, W.D. 1986. Species-area relationship and its determinants for mammals in western North American national parks. Biological Journal of Linnean Society 28:83-98.

Newton-Fisher, N.E., Notman, H., Paterson, J.D. and Reynolds, V. 2006. Primates of Western Uganda. Kluwer Academic Publishers, Dordrecht, The Netherlands.

Nishida, T. 2008. Why were guava trees cut down in Mahale park? The question of exterminating all introduced plants. Pan Africa News 15:12-14.

Nkuringo Buffer Zone Management Plan 2007 to 2012. 2007. Nkuringo Conservation and Development Foundation and Uganda Wildlife Authority, Kampala.

Nyhus, P.J., Osofsky, S.A., Ferraro, P., Madden, F. and Fischer, H. 2005. Bearing the costs of human-wildlife conflict: the challenges of compensation schemes. In: R. Woodroffe, S. Thirgood and A. Rabinowitz (eds.), People and Wildlife: Conflict and Coexistence?, pp.107-121. Cambridge University Press, Cambridge.

Ohashi, G. 2005. Trap-breaking chimpanzees found in Guinea. PHYSORG news release. http://www.physorg.com/news6340.html

Oli, M.K., Taylor, I.R. and Rogers, M.E. 1994. Snow leopard Panthera uncia predation on livestock: An assessment of local perceptions in the Annapurna Conservation Area, Nepal. Biological Conservation 68:63-68.

Osborn, F.V. and Hill, C.M. 2005. Techniques to reduce crop loss to elephants and primates in Africa; the human and technical dimension. In: R. Woodroffe, S. Thirgood and A. Rabinowitz (eds.), People and Wildlife: Conflict and Coexistence?, pp.72-85. Cambridge University Press, Cambridge.

Plumptre, A.J., Cox, D. and Mugume, S. 2003. The Status of Chimpanzees in Uganda, Albertine Rift Technical Report Series 2. Wildlife Conservation Society, New York.

Plumptre, A.J., Davenport, T.R.V., Behangana, M., Kityo, R., Eilu, G., Ssegawa, P., Ewango, C., Meirte, D., Kahindo, C., Herremans, M., Kerbis Peterhans, J., Pilgrim, J.D., Wilson, M. Languy, M. and Mover, D. 2007. The biodiversity of the Albertine Rift. Biological Conservation 134:178-194.

Priston, N. 2005. "Crop-raiding by Macaca ochreata brunnescens in Sulawesi: Reality, Perceptions and Outcomes for Conservation." PhD thesis, University of Cambridge, Cambridge.

Pruetz, J.D. 2006. Feeding ecology of savanna chimpanzees (Pan troglodytes verus) at Fongoli, Senegal. In: G. Hohmann, M. Robbins and C. Boesch (eds.), Feeding Ecology in Apes and Other Primates, pp.326-364. Cambridge University Press, Cambridge.

Pusey, A.E., Pintea, L., Wilson, M.L., Kamenya, S. and Goodall, J. 2007. The contribution of long-term research at Gombe National Park to chimpanzee conservation. Conservation Biology 21:623-634.

Quigley, H. and Herrero, S. 2005. Characterization and prevention of attacks on humans. In: R. Woodroffe, S. Thirgood and A. Rabinowitz (eds.), People and Wildlife: Conflict and Coexistence?, pp.27-48. Cambridge University Press, Cambridge.

Reynolds, V., Wallis, J. and Kyamanywa, R. 2003. Fragments, sugar and chimpanzees in Masindi District, western Uganda. In: L. Marsh (ed.), Primates in Fragments: ecology and conservation, pp.309-320. Kluwer Academic Publishers, New York.

Reynolds, V. 2005. The Chimpanzees of the Budongo Forest: Ecology, Behaviour, and Conservation. Oxford University Press, Oxford.

Richards, P. 2000. Chimpanzees as political animals in Sierra Leone. In: J. Knight (ed.), Natural Enemies: People-wildlife Conflicts in Anthropological Perspective, pp.78-193. Routledge, London

Rijksen, H.D. 1995. The neglected ape? NATO and the imminent extinction of our close relative. In: R.D. Nadler, B.M.F. Galdikas, L.K. Sheeran and N. Rosen (eds.), The Neglected Ape, pp.13-21. Plenum Press, New York.

Rijksen, H.D. 2001. The orangutan and the conservation battle in Indonesia. In: B.B. Beck, T.S. Stoinski, M. Hutchins, T.L. Maple, B. Norton, A. Rowan, E.F. Stevens and A. Arluke (eds.), Great Apes and Humans: The Ethics of Coexistence, pp.57-70. Smithsonian Institution Press, Washington, DC.

Rijksen, H.D. and Meijaard, E. 1999. Our Vanishing Relative: The Status of Wild Orang-utans at the Close of the Twentieth Century. Dordrecht: Kluwer Academic Publishers, Dordrecht, The Netherlands.

Ross, C. and Warren, Y. 2006. Primate and other mammalian maize pests in Gashaka, Nigeria. International Journal of Primatology 27(S1):403. (Abstract)

Russon, A.E., Erman, A. and Dennis, R. 2001. The population and distribution of orangutans (Pongo pygmaeus pygmaeus) in and around the Danau Sentarum Wildlife Reserve, W. Kalimantan, Indonesia. Biological Conservation 97:21-28.

Saj, T., Sicotte, P. and Paterson, J.D. 2001. The conflict between vervet monkeys and farmers at the forest edge in Entebbe, Uganda. African Journal of Ecology 39:195-199.

Salafsky, N. 1993. Mammalian use of a buffer zone agroforestry system bordering Gunung Palung National Park, West Kalimantan, Indonesia. Conservation Biology 7:928-933. 
Siex, K.S. and Struhsaker, T.T. 1999. Colobus monkeys and coconuts: a study of perceived human-wildlife conflicts. Journal of Applied Ecology 36:1009-1020.

Slocombe, K., Townsend, S. and Zuberbühler, K. 2009. Wild chimpanzees (Pan troglodytes schweinfurthii) distinguish between different scream types: evidence from a playback study. Animal Cognition. In press.

Smith, M.E., Linnell, J.D.C., Odden, J. and Swenson, J.E. 2000a. Review of methods to reduce livestock depredation: I. Guardian animals. Acta Agriculturae Scandinavica, Section A Animal Science 50:279-290.

Smith, M.E., Linnell, J.D.C., Odden, J. and Swenson, J.E. 2000b. Review of methods to reduce livestock depredation II. Aversive conditioning, deterrents and repellents. Acta Agriculturae Scandinavica, Section A Animal Science 50:304-315.

Strum, S.C. 1994. Prospects for management of primate pests. Revue d'Ecologie: La Terre et la Vie 49:295-306.

Teleki, G. 1989. Population status of wild chimpanzees (Pan troglodytes) and threats to survival. In: P.G. Heltne and L.A. Marquardt (eds.), Understanding Chimpanzees, pp.312-353. Harvard University Press: Cambridge, MA.

Treves, A. and Naughton-Treves, L. 1999. Risk and opportunity for humans coexisting with large carnivores. Journal of Human Evolution 36:275-282.

Treves, A., Wallace, R.B., Naughton-Treves, L. and Morales, A. 2006. Co-managing human-wildlife conflicts - a review. Human Dimensions of Wildlife 11:383-396.

Treves, A. 2008. The human dimensions of conflicts with wildlife around protected areas. In: D.J., Manfredo, J.J., Vaske, P. Brown and D.J. Decker (eds.), Wildlife and Society: The Science of Human Dimensions, pp.262-278. Island Press, New York.

Wallis, J. and Lee, D.R. 1999. Primate conservation: The prevention of disease transmission. International Journal of Primatology 20:803-826.

Webber, A.D. 2006 How people's perceptions of primates can help us design more effective conflict mitigation strategies: crop-raiding in Uganda. International Journal of Primatology 27(S1):402. (Abstract).

Webber, A.D., Hill, C.M. and Reynolds, V. 2007. Assessing the failure of a community-based human-wildlife conflict mitigation project in Budongo Forest Reserve, Uganda. Oryx 41:177-184.

Wilson, M.L., Hauser, M.D. and Wrangham, R.W. 2007. Chimpanzees (Pan troglodytes) modify grouping and vocal behaviour in response to location-specific risk. Behaviour 144:1621-1653.

Wrangham, R.W. and Mugume, S. 2000. Snare Removal Program in Kibale National Park: a preliminary report. Pan Africa News 7:18-20.

Wrangham, R.W., Wilson, M.L., Hare, B.A. and Wolfe, N.D. 2000. Chimpanzee predation and the ecology of microbial exchange. Microbial Ecology in Health and Disease 12:186-188.

Wrangham, R. 2001. Moral decisions about wild chimpanzees. In: B.B. Beck, T.S. Stoinski, M. Hutchins, T.L. Maple, B. Norton, A. Rowan, E.F. Stevens and A. Arluke (eds.), Great Apes and Humans: The Ethics of Coexistence, pp.230-244. Smithsonian Institutional Press, Washington, DC.

Wrangham, R.W., Wilson, M.L. and Muller, M.N. 2006. Comparative rates of aggression in chimpanzees and humans. Primates 47:14-26 Yeager, C.P. 1997. Orangutan rehabilitation in Tanjung Puting National Park, Indonesia. Conservation Biology 11:802-805.

Yuwono, E.H., Susanto, P., Saleh, C., Andayani, N., Prasetyo, D. and Atmoko, S.S.U. 2007. Guidelines for the Better Management Practices on Avoidance, Mitigation and Management of Human-Orangutan Conflict In and Around Oil Palm Plantations. WWF-Indonesia.

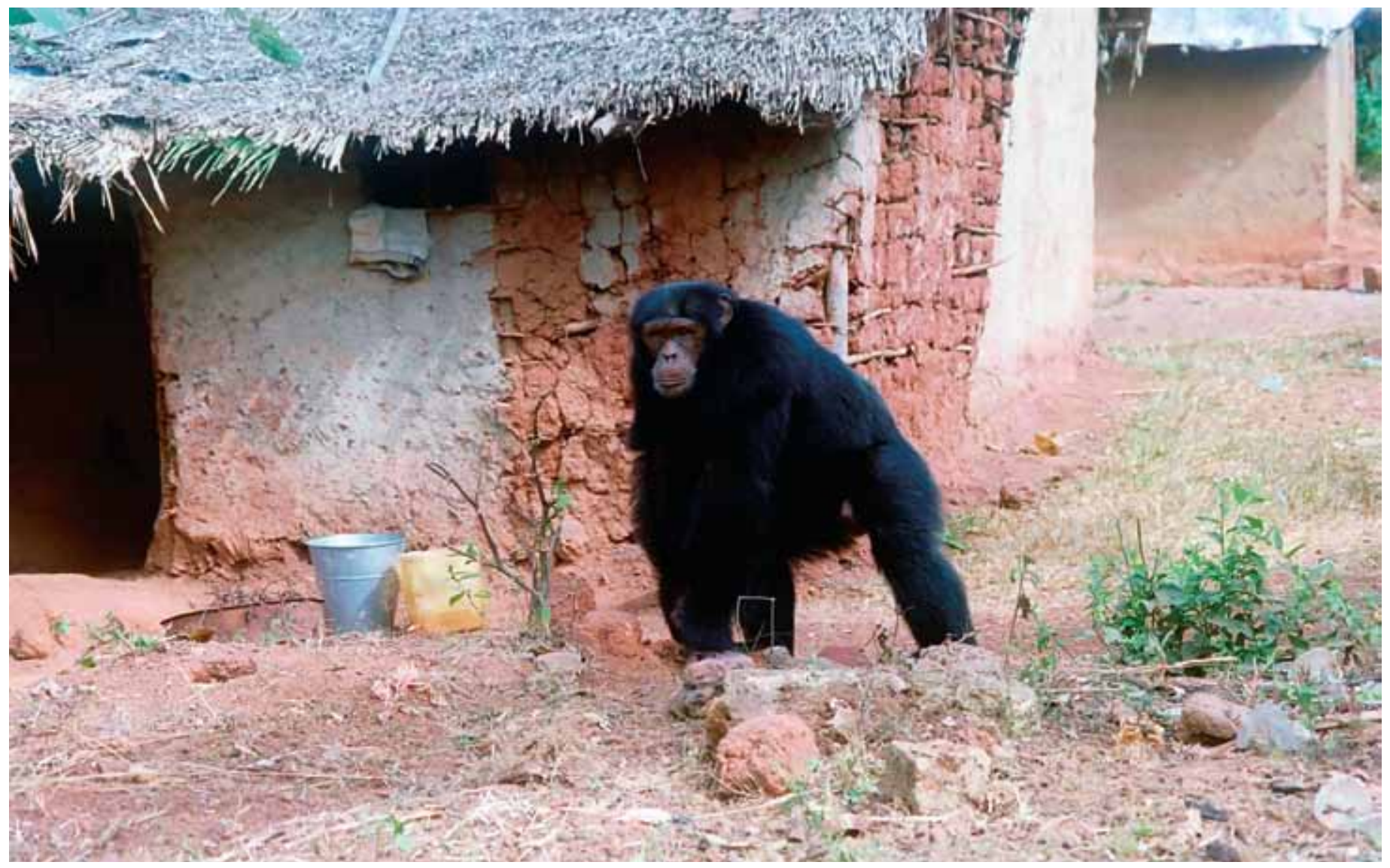

Adult male chimpanzee passes by a house in Bossou village. Such bold crop-raiding behaviour can lead to conflict between chimpanzees and local people. Photo: @ Tatyana Humle 


\section{Gorillas}

One-quarter of mountain gorillas (Gorilla beringei) in Uganda's Bwindi Impenetrable National Park are reported to visit farms and plantations abutting the park - four groups habituated for tourism and two unhabituated groups (75 individuals out of a total 300 gorillas, S. Asuma pers. comm. 2008). Bwindi gorillas raided crops before habituation for tourism began; conservationists believe, however, that the loss of fear of humans has heightened the gorillas' assertiveness when raiding crops.

Prior to the gazetting of the national park, gorillas ventured outside the park infrequently and were easily chased away. Post-gazetting, people were no longer allowed to chase the gorillas, which resulted in higher levels of crop-raiding of bananas, coffee and eucalyptus trees in particular, and more recently they have also been feeding on maize and beans. Since the latter are major subsistence crops, this situation is likely to aggravate levels of HuGo conflict (J. Byamukama pers. comm. 2008) and farmers now perceive gorillas to be a problem species. In addition to fear levels towards humans, vegetation structure and composition affect the gorillas' tendencies to crop-raid. In some areas adjacent to the park, farmers leave land to regenerate for up to five years due to poor soil quality. This fallow period encourages the growth of herbs preferred by gorillas, often at densities and heights that provide concealment. Likewise, poor maintenance of cultivated areas, especially banana plantations, allows the growth of secondary vegetation that provides food and cover for the gorillas (S. Asuma pers. comm. 2008). Gorillas travel between fields and orchards using uncultivated ravines (shrub trees and bushes) that offer attractive passageways and may provide access routes to several kilometres from the park boundary (Macfie 2000; Madden 2006). Remnant forest patches created by land-clearance also provide cover to which gorillas can retreat when raiding crops and for constructing night nests. Gorillas continue to frequent some of these patches, which constituted part of their historical home range (Macfie 2000).

To date, crop-raiding gorillas do not present a problem at Mgahinga Gorilla National Park (MGNP) in Uganda, because the crops being grown near the park boundary, mostly potatoes, sorghum and wheat, are not eaten by gorillas. There are no reports of crop raiding by gorillas in the higher altitudes of MGNP and Volcanoes National Park in Rwanda, where preferred crops such as bananas do not grow. However, around the Virunga National Park in the Democratic Republic of Congo, which extends to lower elevations, gorillas frequently enter fields along or near the forest edge where palatable crops such as bananas and maize are grown (Macfie 2000).

Unhabituated western gorillas (Gorilla gorilla) raid crops such as cassava (Lahm 1996; Hill 2005). Cross River gorillas (Gorilla g. diehli) in the Afi Mountain Wildlife Sanctuary, Nigeria, raid bananas and plantain, but such events are infrequent ( $<10$ times/yr) and therefore tolerated by humans (A. Dunn pers. comm. 2007). In the unprotected mid-elevation montane forests of Bechati-Fossimondi in Cameroon, Cross River gorillas raid fallow farms for plantain two to five times per month, and although local people often complain, such raids are also tolerated. In the Kagwene Gorilla Sanctuary, Cameroon, where there is a traditional ban on killing gorillas, reports of crop-raiding are rare (A. Nicholas pers. comm. 2008).

Although attacks on humans by western gorillas are extremely rare, there is a report from Kagwene of a solitary silverback male attacking an adult man whilst he was setting traps in the Sanctuary - the man attempted to run away and was attacked from behind (A. Nicholas pers. comm. 2008). Additionally, there have been documented cases of attacks on humans when Bwindi gorillas are ranging in areas outside park boundaries (L. Macfie pers. comm. 2008).

In summary, reports of crop-raiding by western gorillas are infrequent, while this behaviour in mountain gorillas appears to be influenced by two factors: (1) crop-raiding is common at altitudes where the most palatable crops, such as bananas, grow in proximity to park boundaries; and (2) gorillas in Bwindi can use corridors of dense secondary vegetation or remnant forest patches to range further from park boundaries (Macfie 2000).

\section{Orangutans}

Human-orangutan conflicts are a central issue in land-use management and conservation. Orangutans are wide-ranging across Borneo and northern parts of Sumatra (Delgado and van Schaik 2000; Singleton and van Schaik 2001). Orangutans are essentially forest dwellers and do not survive well in non-forested areas; however, the Bornean species Pongo pygmaeus does appear able to cope with a certain degree of habitat disturbance, by switching its diet away from fruit to fallback foods such as tree bark (LackmanAncrenaz et al. 2001; Ancrenaz et al. 2007). This behavioural flexibility is likely an adaptation to the generally less productive forests in Borneo and to periodic droughts and fruit abundances resulting from the El Niño effect, and has led to increased proximity with and exposure to human activities. On the other hand, the Sumatran species Pongo abelii is less able to cope with disturbance and habitat degradation. Even in forests that are selectively logged, Sumatran orangutan densities can fall by as much as $60-70 \%$ (Rao and van Schaik 1997). Unfortunately, human-orangutan conflicts often result in the displacement or disappearance of orangutan 
populations (Rijksen and Meijaard 1999; Rijksen 2001; Ancrenaz et al. 2007). Since they are lowland species and protected areas are in predominantly highland areas, $86 \%$ of orangutans live outside protected areas (Rijksen and Meijaard 1999). Orangutans tend to occur at their highest densities at the forest edges (i.e., the remaining lowlands), which are most affected by encroachment or conversion to plantations. Until 2002, less than $36 \%$ of orangutan habitats suffered some degree of human impact (Rijksen and Meijaard 1999; Nelleman and Newton 2002), but orangutans in both Borneo and Sumatra have since suffered extensive loss of their natural habitat to commercial resource extraction and large-scale agricultural conversion. Human-orangutan conflict is especially rife in commercial concessions (e.g., oil palm plantations, coal mines and logging concessions; Whitten and Ranger 1986; EIA 1999; Russon et al. 2001; Buckland 2005; Felton et al. 2003; CITES/Grasp 2006; Yuwono et al. 2007) and local, subsistence-level farms abutting the remaining forests (Salafsky 1993; Rijksen and Meijaard 1999; Lackman-Ancrenaz et al. 2001; Grundmann 2005; CITES/Grasp 2006; Ancrenaz et al. 2007).

The most serious threat to Bornean orangutans is the rapid expansion of oil palm plantations (Buckland 2005). The resulting forest destruction often causes isolation of orangutans, forcing them to live in and around oil palm plantations and to feed on young palms due to shortages of their native foods in remaining forest patches (Salafsky 1993; Goossens et al. 2006; Yuwono et al. 2007; M. Ancrenaz, A. Russon and I. Singleton pers. comms. 2008). Orangutans typically target young oil palms less than three years old and cause significant economic losses. Managers and employees at some plantations do not hesitate to attack and even kill orangutans to protect their palms (SOCP 2002; Yuwono et al. 2007; M. Ancrenaz pers. comm. 2008). Some plantation owners have gone so far as to offer bounties for the eradication of orangutans (Rijksen 1995). Others contact orangutan specialists, typically local rehabilitation projects, and request the capture and translocation of raiding orangutans out of conflict zones (A. Russon pers. comm. 2008). While this strategy may remove orangutans from immediate danger, translocation is not a long-term solution and should only be considered as a last resort (see Section 4.5). Habitat loss to encroachment and conversion to agriculture has similarly forced Sumatran orangutans to feed on cultivated fruits adjacent to their remaining forest habitat and on young oil palms in some regions.

Regarding commercial crops, orangutans also feed on the bark of rubber trees, Hevea brasiliensis, disrupting latex collection, and the bark of Acacia mangium, a quick-growing exotic used in reforestation and pulp production (M. Ancrenaz, G. Campbell-Smith and A. Russon pers. comm. 2008). This damage heightens conflict with plantation owners whose activities have exacerbated deforestation. At Sampan Getek in North Sumatra, an area dominated by cultivated fruit and rubber plantations, orangutans crop-raid on a daily basis; the five main crops include jackfruit, durian, jengkol (Archidendron pauciflorum), petai (Parkia speciosa) and rubber trees. The orangutans at this site have no alternative, being surrounded and isolated from pristine forest by large swathes of plantations that they will not cross (G. Campbell-Smith pers. comm. 2008). At Kinabatangan, East Bornean orangutans raid orchards for fruit (durians, mangosteens, mangoes) even when wild fruits are available in the forest (M. Ancrenaz pers. comm. 2008). Farmers in the area are known to shoot orangutans threatening their crops (Lackman-Ancrenaz et al. 2001). In both Sumatra and Borneo, some of the infants that survive and find their way into sanctuaries and rehabilitation centres have air rifle pellets embedded in their bodies or knife wounds, sustained during the killing of their mothers. Since seasoned 'hunters' typically use more powerful firearms, this situation supports the contention that many orangutans are killed opportunistically when raiding crops, by farmers or concession workers whose usual targets are crop-raiding monkeys, squirrels, and birds (I. Singleton pers. comm. 2008). In some areas of Borneo, subsistence farmers consider orangutans to be the most damaging crop-raider. This misperception is extremely serious as orangutans are being unfairly and indiscriminately persecuted, and the vast majority of orangutans entering sanctuaries in Borneo and Sumatra are victims of orangutan-human conflict (I. Singleton pers. comm. 2008).

Not only wild orangutans are involved in these conflicts, ex-captive orangutans are also increasingly coming into contact with humans under dangerous circumstances (Dellatore 2007). Rehabilitant orangutans do not fear humans as wild orangutans do and have been known to actively seek contact with humans (Aveling and Mitchell 1982; Russell 1995; Yeager 1997; Rijksen 2001; Grundmann 2005; Dellatore 2007). Although wild orangutans are rarely aggressive and reports of attacks on humans are rare (Yuwono et al. 2007; G. Campbell-Smith pers. comm. 2008), attacks on humans by rehabilitant orangutans are more common. Such attacks occur where tourism is permitted in areas where ex-captive rehabilitant orangutans range, specifically as a result of unfulfilled expectations of obtaining food carried by guides and tourists (Russell 1995; Yeager 1997; Dellatore 2007). Tourists should not be allowed to carry food while observing great apes and no contact with the great apes should occur. Furthermore, observation distances defined to prevent disease transmission between humans and great apes should be respected at all times (cf. Homsy 1999).

\section{Chimpanzees}

Chimpanzees (Pan troglodytes) have a highly flexible social system, an eclectic diet and seem able to adapt to areas of secondary vegetation bordering human habitation (Yamakoshi 2005). Chimpanzees bordering agricultural land and human settlements are frequently reported to raid crops and compete with humans over natural resources. For the most part, chimpanzees inhabiting large protected areas are less likely to raid crops, as they are generally not available within protected areas and the chimpanzees' sizeable home ranges provide sufficient wild food resources with fewer edge effects (cf. western lowland gorillas). However, 45-81\% of surviving chimpanzees exist outside designated protected areas, inhabiting smaller and more fragmented areas (Kormos et al. 2003). 
Eastern chimpanzees (P. t. schweinfurthii) at Budongo do not raid crops as much as other primates such as baboons, despite the introduction of schemes that have encouraged widespread planting of sugarcane - a cash crop of high monetary value (Reynolds 2005; Newton-Fisher et al. 2006; C.M. Hill pers. comm. 2008). However, different chimpanzee communities within the reserve vary in their crop-raiding propensities; individuals from the Sonso community feed on sugarcane in commercial plantations at the forest edge and mangoes in surrounding orchards (Reynolds 2005). Bates (2005) found that sugarcane was one of the most important foods in the Sonso chimpanzees' diet despite forest foods being plentiful, and suggested that the loss of food trees through human encroachment and illegal logging within the forest would exacerbate the problem of crop-raiding. However, the Nyakafunjo community, which lives closer to human settlements, raid crops more than their Sonso neighbours, possibly due to recent reductions in their home-range size due to the advance of human cultivation. Another small community, Kasokwa, inhabits a strip of riparian forest south of Budongo and subsists mainly on forest foods, but during occasional forest food shortages, the chimpanzees feed on papaya, mango and sugarcane (Reynolds 2005). Approximately $30 \mathrm{~km}$ south of Budongo, chimpanzees at Bulindi in the Hoima District live in a fragmented farm-forest-woodland mosaic and regularly raid sugarcane, mango, cocoa, papaya, banana, jackfruit, mangoes, pineapple, maize and pumpkin (McLennan 2008). Encounter rates between humans and chimpanzees at this site increased following extensive tree felling and encroachment within the chimpanzees' habitat. This disrupted their daily activities and the chimpanzees have started behaving more aggressively towards humans (McLennan 2008). In Bwindi, crop-raiding by chimpanzees is rare; however, conflicts are escalating as chimpanzees raid honey from beehives located in sectors of the park where apiculture is permitted (S. Asuma pers. comm. 2008).

Before the establishment of a buffer zone at Kibale, chimpanzees fed on maize and caused significant damage to banana plantations. They were thus viewed as a problem species by farmers, but a relatively small problem compared with elephants, baboons, bushpigs and redtail monkeys (Naughton-Treves et al. 1998), and feeding in abandoned banana fields was tolerated. A bigger problem was repeated chimpanzee attacks on human children. It was thought that one individual was responsible for these attacks, an adult male living largely alone in the affected area (Wrangham 2001). After deliberating the problem, researchers decided that this individual should be removed; however, the male chimpanzee was killed by local villagers before researchers could intervene. This example highlights the complex ethics of conflict issues, namely that the behaviour of one 'problem' individual may compromise the safety of other great apes sharing the habitat. This rare example also illustrates the value of establishing effective communication among all parties involved in and/or affected by HGAC.

Although quantitative data are lacking, the loss of forest habitat in southern Gombe has driven one community of chimpanzees to raid bananas, mango and palm fruits at the forest edge (Greengrass 2000). At Mahale, M-group used to feed on guava, mango, lemon, maize and sugarcane at the forest edge (Takahata et al. 1985; Nishida 2008), but since the creation of the National Park in 1980, the chimpanzees no longer raid crops because they are less available.

Yamagiwa et al. (1992) noted that although chimpanzees in the montane sector of Kahuzi-Biega exist at low densities, hostility among local people has worsened due to increased raiding of staple foods such as maize and plantain bananas by chimpanzees.

In Gabon, the central subspecies of chimpanzee (P. $t$. troglodytes) occasionally feeds on crops, but Lahm (1996) did not quantify this. Savanna-dwelling western chimpanzees (P. t. verus) overlap substantially with humans in their use of forest resources. Chimpanzees

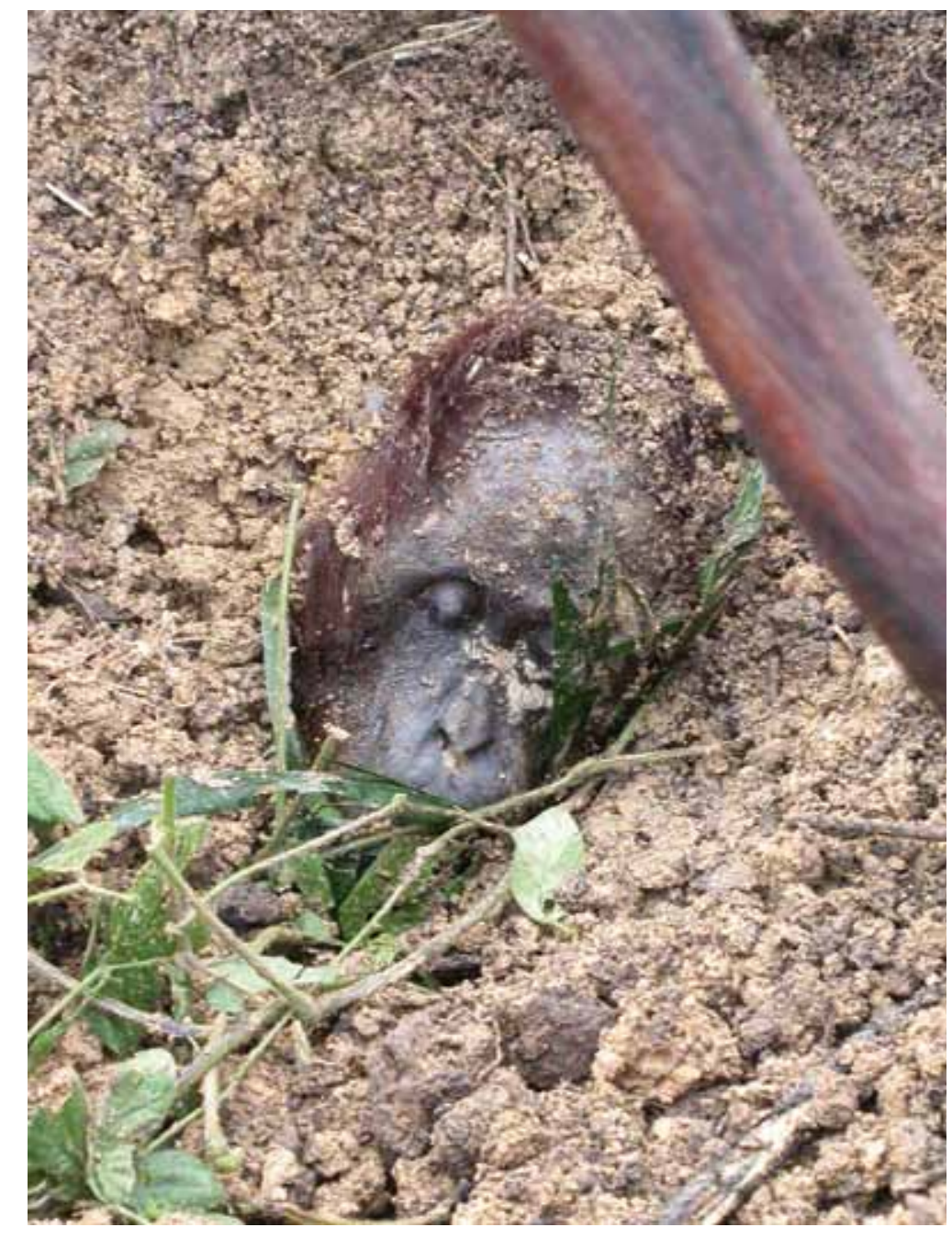

This adult female orangutan was uncovered in a newly-planted oil-palm plantation after a rescue team received a call about an orangutan in the vicinity. When they arrived on site, plantation workers denied seeing an orangutan, but they were nervous and one glanced at a freshly dug area. Only a few inches below the surface, the rescue workers found the orangutans still-warm body. A post mortem examination indicated she had been beaten unconscious and buried alive. Photo: () Borneo Orangutan Survival 
and humans in Fongoli generally coexist peacefully thanks to a cultural taboo against hunting chimpanzees, but concerns over rising levels of crop-raiding in the Tomboronkoto region threaten traditional tolerance. Pruetz (2002) found that 17 naturally occurring plant species were eaten by both humans and chimpanzees in this area. The fruit from the forest liana Saba senegalensis is important to the chimpanzees in the dry season and not exclusively during periods of wild fruit scarcity; this fruit also serves as a 'cash crop' for humans during times of hardship. The commercially exploited baobab fruit is a major wild food source for Fongoli chimpanzees. Unsustainable harvesting of these fruits by humans may reduce wild fruit availability to such an extent that chimpanzees will be forced to seek alternatives, perhaps increasing consumption of cultivated crops. Maize, peanuts, millet and other garden vegetables are grown locally, but at present chimpanzees do not raid these crops (P. Bertolani pers. comm. 2008); reasons for this are unknown but it is possible that chimpanzees are fearful of human presence.

In the village of Jeruberem, Guinea-Bissau, there is a similarly strong local taboo against hunting chimpanzees, which has allowed them to live in proximity to humans despite their regular raids of crops of oranges, pineapples and cashews (Gippoliti and Sousa 2004). Chimpanzees in this area also raid beehives and compete with local people for access to water wells in the dry season (C. Sousa pers. comm. 2008).

In drier habitats dominated by savanna grasslands, such as in the Fouta-Djallon region of Guinea, chimpanzees and humans also compete for access to water, leading to relatively high rates of encounter between chimpanzees and humans, with the risk of aggression, as well as disease transmission (J. Carter pers. comm. 2008; C. Sousa pers. comm. 2008). Dunnett et al. (1970) reported that chimpanzees in the Kanka Sili area of Guinea fed on rice and millet from subsistence farms, and grapefruit from commercial plantations, but we have no current information on this community. The chimpanzees of Bossou in south-eastern Guinea have been the subject of complaints by local farmers who report that they frequently raid an array of domestic crops, including cassava, maize, pineapple, orange and papaya (Hockings et al. 2006b). Humans and chimpanzees are not only neighbours in this area, but their coexistence is preserved by a delicate balance of wild and cultivated resource use (Yamakoshi 2005). These chimpanzees show specific behavioural adaptations to living with humans, such as increased vigilance and guarding behaviour (Hockings et al. 2006a; Hockings 2007). There have been several non-fatal attacks on children by chimpanzees at Bossou, most of which occurred within the forest or on the road-side. Papaya trees in the village bring chimpanzees close to people's houses, and this is thought to increase the likelihood of chimpanzee attacks on humans, especially children, and has motivated some people to cut down papaya trees near the forest edge in attempts to reduce human-chimpanzee contact (Hockings 2007). Although this approach is not appropriate for all cultivated foods, such as rice fields, it demonstrates that in some situations local people can take simple measures to reduce humanape contact and potential conflict situations. In the village of Yealé in the Nimba Mountains, Côte d'Ivoire, chimpanzees occasionally raid cocoa plantations and eat papaya, pineapple, orange, rice, maize and cassava growing close to the forest edge (N. Granier pers. comm. 2008). Incidence of crop-raiding seems to correlate with low natural fruit availability, as when fruits are abundant within the reserve chimpanzees are rarely seen close to the village (Humle 2003). In the Taï National Park, Côte d'Ivoire, only unhabituated chimpanzee communities at the periphery of the park have been known to raid crops (I. Herbinger pers. comm. 2007).

\section{Bonobos}

Bonobos (Pan paniscus) at Kokolopori live close to villages where they feed on pineapple, sugarcane, palm pith and bananas (A. Georgiev pers. comm. 2007). Throughout the Lukuru Wildlife Research Project, an area of 23,908km², bonobos feed in secondary vegetation created by clearing for cassava and rice; there are, however, no reports of bonobos eating these crops. Although bonobos occur near agricultural fields, people do not describe the situation as one of conflict, although when encountered in fields, humans chase them away. Humans in this region are nonetheless scared of the bonobos that they sometimes meet on the roadside, resulting in human travel restrictions (J. Thompson pers. comm. 2008). Thompson highlights that during a socio-economic study that included eight villages within the Salonga National Park, the local Lyaelima people (who coexist with bonobos due to ancient traditions and beliefs) did not identify them as a problem species. Few data are currently available on human-bonobo conflicts; crop-raiding by bonobos is likely to increase, however, as primary forests are lost and fragmented (Dupain and van Elsacker 2001; Myers-Thompson 2001). 
Appendix B: Preparatory Questions

B1. What are the sources of information about the human-great ape conflict (HGAC) problem and how reliable is the information?

- How did you or do you hear about HGAC in your area?

- From the affected people themselves?

- From a local leader or community representative?

- From a previous wildlife manager?

- From a researcher or technical expert?

- From a written report or via the media?

- Other?

How reliable is your present information on HGAC?

- Is your information from a direct observer of HGAC, or is it a second-hand report of HGAC?

- Have you received multiple direct or indirect reports on any specific incidents of HGAC?

- How recent is your information?

- Have you received any information that can be used as a direct measurement of damage levels by great apes to people or their livelihoods?

- Are there reasons why your informants may have exaggerated, understated, fabricated, or concealed reports of great-ape caused damage?

- Are there other animal species in the area that also damage crops? Which species?

Notes: 
Do you know if there are temporal patterns of HGAC?

- Do you know how frequently HGAC incidents occur?

- Do you know if incidents vary with time of day?

- Do you know if incidents vary with season or crop availability?

- Do you have information for one season/multiple seasons?

- Do you have this information for one year/multiple years?

- Do the apes have alternative resources, i.e. fallback foods, water sources?

- Do you know if there is any spatial pattern to HGAC?

- Do you know the geographic location of incidents in your area?

- Do you know if some places are more affected than others?

- Do you really know how serious the HGAC problem is?

- Do you judge the severity of incidents subjectively?

- Do you have a system for judging how serious an incident is?

- Can you distinguish between people directly and indirectly affected?

- Do you really know how serious the crop-raiding problem is?

- Do you know what resources (crops, wild foods, water) are involved?

- Do you know the extent of the damage?

(Do you have a quantitative measure of damage?)

- Do you really know how serious the threat of great ape attack is?

- Have people been injured by great apes?

- Where was the person when attacked?

- What was the person doing when attacked? e.g., harvesting wild foods, crop guarding, travelling on foot

- Do you know if great apes have been injured by humans?

- How were they injured by humans? e.g., snares, shotgun, slingshots

- For humans or great apes, were the attacks provoked or unprovoked?

- What great apes are involved in HGAC in your area?

- Do you know the group sizes of the great apes involved?

- Are only males involved?

- Are only females and young involved?

- Are mixed-groups (males, females and young) involved?

- Are any of these great apes individually identifiable?

- Does it appear that identifiable individuals are regular raiders or attackers?

- Are these wild, reintroduced, or rehabilitated individuals?

- Are the movements of raiders or attackers known?

- Do they show any specific behavioural adaptations?

Notes: 
- Do you think you understand the attitude of people affected?

- Do you think people exaggerate HGAC problems (perceived vs. actual)?

(Do they report more incidents than actually take place?)

(Do people conceal incidents of HGAC?)

(Do they report more serious damage than actually occurs?)

(Do people understate damages caused by great apes?)

(Do you think other wild and domestic species are a worse problem than great apes?)

- Do you think great apes restrict peoples' foot travel/farming/activities?

- Do you think great apes restrict peoples' access to water sources?

- Do you think great apes indirectly cause wider social problems?

(Job opportunities are decreased through increased crop guarding?)

- Do local people have traditional beliefs or stories about great apes?

- Do you think that traditional beliefs about great apes affect peoples' behaviour towards them?

- Do you think that people want to kill great apes?

(What reasons do people have for killing great apes?)

- Do you think that traditional beliefs in the area are changing or declining?

(Why?)

Who is most affected by the losses caused by great apes?

- A whole community of villages over a wide area?

- The village where damage occurred?

- A household whose property is damaged?

- The company/organisation that owns the damaged property?

- An individual who owns the damaged property?

Notes: 
- Do you need to collect more data on HGAC in your area?

- About damage incidents?

- About the people affected?

- About the individual great apes implicated?

- About great ape populations in the area?

- About other wildlife conflicts?

- About measures which people currently use in HGAC situations?

- About measures which could be used in HGAC situations?

- What human, financial and technical resources are available to you?

- Able to discuss issues with individual complainants only

- Able to discuss issues at meetings of complainants/representatives

- Able to delegate staff to attend complainant meetings

- Have someone available to collect incident data in the field ('enumerator or reporter')

- Able to organise training of enumerators ('training enumerator')

- Have someone to analyse incident data

- Have someone to research issues associated with HGAC in the area

- Have long-term financial support

- Do you have a strategy to address the HGAC problem?

- Will you address the problem through management action?

- Will you use only the information you have already?

- Will you collect more data/conduct research?

- Do you need more data before attempting to develop a strategy?

- Is this strategy based on any of the following?

(Previous experience of HGAC in another area?)

(Formal training of other professionals?)

(Knowledge of great ape behaviour?)

(Intuition?)

- Can you plan and direct this strategy yourself?

(Does this mean limited consultation with anyone else?)

- Do you think your strategy will diminish the level of HGAC in your area?

- Is there a way to measure the success of your strategy?

(Will you personally measure the degree of success?)

(Will someone else measure the degree of success?)

Notes: 
- What is your motivation for getting involved with HGAC?

- Obligation through formal employment?

(To protect wildlife?)

(To manage wildlife?)

(To enhance agricultural development?)

(To improve rural people's livelihoods?)

- Required to research the problem - from what perspective?

(Wildlife conservation?)

(Agricultural?)

(Effects on humans e.g., welfare/livelihoods or safety?)

- Under what policy constraints do you have to operate?

- Do great apes in your area have economic value to hunters?

- Do great apes in your area have economic value as pets?

- Do great apes in your area have economic value for tourism?

- Do people in your area derive any legal benefits from wildlife?

- Do people in your area derive illegal benefits from wildlife?

- Is there a tenure system governing land occupation and use?

(Freehold)

(Leasehold)

(Communal/occupancy only)

(Other e.g., protected area)

- Is there any planning process to develop human settlement?

- Is there a functioning land-use planning authority?

(Part of central government)

(Part of local government)

(A traditional leader)

- Do wildlife issues have any recognition in land-use planning?

- Do options exist for developing new 'local' regulations/laws that might help mitigate conflicts?

Notes: 
Ancrenaz, M., Dabek, L. and O'Neil, S. 2007. The costs of exclusion: recognizing a role for local communities in biodiversity conservation. PLoS Biol 5:e289.

Aveling, R. and Mitchell, A. 1982. Is rehabilitating orang utans worth while? Oryx 16:263-271.

Bates, L. 2005. "Cognitive aspects of travel and food location by chimpanzees (Pan troglodytes schweinfurthii) of the Budongo Forest Reserve, Uganda". PhD thesis, University of St Andrews, St Andrews.

Buckland, H. 2005. The oil for ape scandal: How palm oil is threatening orang-utan survival. Friends of the Earth Trust, London.

CITES/GRASP. 2006. CITES/GRASP Orang-Utan Technical Mission: Indonesia, 8-12 May 2006. CITES Secretariat, Geneva.

Delgado, R. and van Schaik, C.P. 2000. The behavioural ecology and conservation of the orangutan (Pongo pygmaeus): a tale of two islands. Evolutionary Anthropology 9:201-218.

Dellatore, D.F. 2007. "Behavioural health of reintroduced orangutans (Pongo abelii) in Bukit Lawang, Sumatra Indonesia". MSc thesis, Oxford Brookes University, Oxford.

Dunnet, S., Orshoven, J.V. and Albrecht, H. 1970. Peaceful coexistence between chimpanzee and man in West Africa. Bijdragen Tot De Dierkunde 40:148-153.

Dupain, J. and van Elsacker, L. 2001. The status of the bonobo (Pan paniscus) in the Democratic Republic of Congo. In: B.M.F. Galdikas, N. Erickson Briggs, L.K. Sheeran, G.L. Shapiro and J. Goodall (eds.), All Apes Great and Small. Vol 1: African Apes, pp.75-82. Kluwer Academic/Plenum Publishers, New York.

EIA. 1999. The final cut: Illegal logging in Indonesia's orangutan parks. Environmental Investigation Agency (EIA). Website: www.eia-international.org/old-reports/ Forests/Indonesia/FinalCut/

Felton, A.M., Engstrom, L.M., Felton, A. and Knott, C.D. 2003. Orangutan population density, forest structure and fruit availability in hand-logged and unlogged peat swamp forests in West Kalimantan, Indonesia. Biological Conservation 114:91-101.

Gippoliti, S. and Sousa, C. 2004. The chimpanzee, Pan troglodytes, as an 'umbrella' species for conservation in Guinea-Bissau, West Africa: Opportunities and Constraints. Folia Primatologica 75:386. (Abstract).

Goossens, B., Chikhi, L., Ancrenaz, M., Lackman-Ancrenaz, I., Andau, P. and Bruford, M.W. 2006. Genetic signature of anthropogenic population collapse in orang-utans. PLoS Biology 4:285-291.

Greengrass, E. 2000. The sudden decline of a community of chimpanzees at Gombe National Park: A supplement. Pan Africa News 7:25-26.

Grundmann, E. 2005. Will re-introduction and rehabilitation help the long-term conservation of orangutans in Indonesia? Re-Introduction News 24:25-27.

Hill, C.M. 2005. People, crops and primates: A conflict of interests. In: J.D. Paterson and J. Wallis (eds.), Commensalism and Conflict, pp.40-59. American Society of Primatologists, Norman, Oklahoma.

Hockings, K.J. 2007. "Human-Chimpanzee Coexistence at Bossou, the Republic of Guinea: A Chimpanzee Perspective". PhD thesis, University of Stirling, Stirling.

Hockings, K.J., Anderson, J.R. and Matsuzawa, T. 2006a. Road-crossing in chimpanzees: A risky business. Current Biology 16:668-670.

Hockings, K.J., Anderson, J.R. and Matsuzawa, T. 2006b. Temporal patterns of crop-raiding in the Bossou chimpanzees, Guinea, West Africa (Pan troglodytes verus): Relation to wild food availability. International Journal of Primatology 27(S1):304. (Abstract).

Homsy, J. 1999. Ape Tourism and Human Diseases: How Close Should We Get? International Gorilla Conservation Programme (IGCP), Nairobi. Website: www.igcp. org/files/ourwork/Homsy_rev.pdf

Humle, T. 2003. Chimpanzees and crop raiding in West Africa. In: R. Kormos, C. Boesch, M.I. Bakarr and T.M. Butynski (eds.), West African Chimpanzees. Status Survey and Conservation Action Plan, pp.147-155. IUCN, Gland, Switzerland.

Kormos, R., Boesch, C., Bakarr, M.I. and Butynski, T. 2003. West African Chimpanzees. Status Survey and Conservation Action Plan. IUCN, Gland, Switzerland. www.primate-sg.org/action.plans.htm

Lackman-Ancrenaz, I., Ancrenaz, M. and Saburi, R. 2001. The Kinabatangan Orangutan Conservation Project. In: B. Zoo (ed.), The Apes: Challenges for the 21st Century, pp.262-265. Brookfield Zoo, Chicago.

Lahm, S.A. 1996. A nationwide survey of crop-raiding by elephants and other species in Gabon. Pachyderm 21:69-77.

Macfie, L. 2000. Human-Gorilla Conflict Resolution: Recommendations for Component within IGCP Uganda Programming. International Gorilla Conservation Programme, Nairobi.

Madden, F. 2006. Gorillas in the garden - Human-wildlife conflict at Bwindi Impenetrable National Park. Policy Matters 14:180-190.

McLennan, M.R. 2008. Beleaguered chimpanzees in the agricultural district of Hoima, western Uganda. Primate Conservation (23):45-54.

Myers-Thompson, J.A. 2001. The status of bonobos in their southernmost geographic range. In: B.M.F. Galdikas, N. Erickson Briggs, L.K. Sheeran, G.L. Shapiro and J. Goodall (eds.), All Apes Great and Small. Volume 1: African Apes, pp.75-82. Kluwer Academic/Plenum Publishers, New York.

Naughton-Treves, L., Treves, A., Chapman, C. and Wrangham, R. 1998. Temporal patterns of crop-raiding by primates: Linking food availability in croplands and adjacent forest. Journal of Applied Ecology 35:596-606.

Nelleman, C. and Newton, A. 2002. Great Apes - the Road Ahead. An analysis of great ape habitat, using GLOBIO methodology. United Nations Environment Programme (UNEP), Nairobi.

Newton-Fisher, N.E., Notman, H., Paterson, J.D. and Reynolds, V. 2006. Primates of Western Uganda. Kluwer Academic Publishers, Dordrecht, The Netherlands.

Nishida, T. 2008. Why were guava trees cut down in Mahale park? The question of exterminating all introduced plants. Pan Africa News 15:12-14.

Pruetz, J.D. 2002. Competition between savanna chimpanzees and humans in southeastern Senegal. American Journal of Physical Anthropology $34: 128$. (Abstract).

Rao, M. and van Schaik, C.P. 1997. The behavioural ecology of Sumatran orangutans in logged and unlogged forest. Tropical Biodiversity 4:173-185.

Reynolds, V. 2005. The Chimpanzees of the Budongo Forest: Ecology, Behaviour, and Conservation. Oxford University Press, Oxford.

Rijksen, H.D. 1995. The neglected ape? NATO and the imminent extinction of our close relative. In: R.D. Nadler, B.M.F. Galdikas, L.K. Sheeran and N. Rosen (eds.), The Neglected Ape, pp.13-21. Plenum Press, New York.

Rijksen, H.D. 2001. The orangutan and the conservation battle in Indonesia. In: B.B. Beck, T.S. Stoinski, M. Hutchins, T.L. Maple, B. Norton, A. Rowan, E.F. Stevens and A. Arluke (eds.), Great Apes and Humans: The Ethics of Coexistence, pp.57-70. Smithsonian Institution Press, Washington, DC

Rijksen, H.D. and Meijaard, E. 1999. Our Vanishing Relative: The Status of Wild Orang-utans at the Close of the Twentieth Century. Dordrecht: Kluwer Academic Publishers, Dordrecht, The Netherlands.

Russell, C.L. 1995. The social construction of orangutans: An ecotourist experience. Society and Animals 3(2):151-170.

Russon, A.E., Erman, A. and Dennis, R. 2001. The population and distribution of orangutans (Pongo pygmaeus pygmaeus) in and around the Danau Sentarum Wildlife Reserve, W. Kalimantan, Indonesia. Biological Conservation 97:21-28.

Salafsky, N. 1993. Mammalian use of a buffer zone agroforestry system bordering Gunung Palung National Park, West Kalimantan, Indonesia. Conservation Biology 7:928-933.

Singleton, I. and van Schaik, C.P. 2001. Orangutan home range size and its determinants in a Sumatran swamp forest. International Journal of Primatology 22:877-911. SOCP. 2002. News from the field. Sumatran Orangutan Conservation Programme News 2.

Takahata, Y., Hiraiwa-Hasegawa, M., Takasaki, H. and Nyundo, R. 1985. Newly acquired feeding habits among the chimpanzees of the Mahale Mountains National Park, Tanzania. Human Evolution 1:277-284.

Whitten, A.J. and Ranger, J. 1986. Logging at Bohorok. Oryx 20:246-248.

Wrangham, R. 2001. Moral decisions about wild chimpanzees. In: B.B. Beck, T.S. Stoinski, M. Hutchins, T.L. Maple, B. Norton, A. Rowan, E.F. Stevens and A. Arluke (eds.), Great Apes and Humans: The Ethics of Coexistence, pp.230-244. Smithsonian Institutional Press, Washington, DC.

Yamagiwa, J., Mwanza, N., Spangenberg, A., Maruhashi, T., Yumoto, T., Fischer, A., Steinhauer-Burkart, B. and Refisch, J. 1992. Population density and ranging pattern of chimpanzees in Kahuzi-Biega National Park, Zaire: a comparison with a sympatric population of gorillas. African Study Monographs 13:217-230.

Yamakoshi, G. 2005. What is happening on the border between humans and chimpanzees? Wildlife conservation in West African rural landscapes. In: K. Hiramatsu (ed.), Coexistence with Nature in a 'Globalising' World: Field Science Perspectives, pp.91-97. Proceedings of the 7th Kyoto University International Symposium, 2005. Kyoto University, Kyoto.

Yeager, C.P. 1997. Orangutan rehabilitation in Tanjung Puting National Park, Indonesia. Conservation Biology 11:802-805.

Yuwono, E.H., Susanto, P., Saleh, C., Andayani, N., Prasetyo, D. and Atmoko, S.S.U. 2007. Guidelines for the Better Management Practices on Avoidance, Mitigation and Management of Human-Orangutan Conflict In and Around Oil Palm Plantations. WWF-Indonesia. 


\section{Occasional Papers of the IUCN Species Survival Commission}

1. Species Conservation Priorities in the Tropical Forests of Southeast Asia. Edited by R.A. Mittermeier and W.R. Konstant, 1985, 58pp.

2. Priorités en matière de conservation des espèces à Madagascar. Edited by R.A. Mittermeier, L.H. Rakotovao, V. Randrianasolo, E.J. Sterling and D. Devitre, 1987, 167pp.

3. Biology and Conservation of River Dolphins. Edited by W.F. Perrin, R.K. Brownell, Zhou Kaiya and Liu Jiankang, 1989, 173pp.

4. Rodents. A World Survey of Species of Conservation Concern. Edited by W.Z. Lidicker, Jr., 1989, 60pp.

5. The Conservation Biology of Tortoises. Edited by I.R. Swingland and M.W. Klemens, 1989, 202pp.

6. Biodiversity in Sub-Saharan Africa and its Islands: Conservation, Management, and Sustainable Use. Compiled by S.N. Stuart and R.J. Adams, with a contribution from M.D. Jenkins, 1991, 242pp.

7. Polar Bears: Proceedings of the Tenth Working Meeting of the IUCN/SSC Polar Bear Specialist Group, 1991, 107pp.

8. Conservation Biology of Lycaenidae (Butterflies). Edited by T.R. New, 1993, 173pp.

9. The Conservation Biology of Molluscs: Proceedings of a Symposium held at the 9th International Malacological Congress, Edinburgh, Scotland, 1986. Edited by A. Kay. Including a Status Report on Molluscan Diversity, by A. Kay, 1995, 81pp.

10. Polar Bears: Proceedings of the Eleventh Working Meeting of the IUCN/SSC Polar Bear Specialist Group, January 25-28 1993, Copenhagen, Denmark. Compiled by Ø. Wiig, E.W. Born and G.W. Garner, 1995, 192pp.

11. African Elephant Database 1995. M.Y. Said, R.N. Chunge, G.C. Craig, C.R. Thouless, R.F.W. Barnes and H.T. Dublin, 1995, 225pp.

12. Assessing the Sustainability of Uses of Wild Species: Case Studies and Initial Assessment Procedure. Edited by R. and C. PrescottAllen, 1996, 135pp.

13. Tecnicas para el Manejo del Guanaco [Techniques for the Management of the Guanaco]. Edited by S. Puig, South American Camelid Specialist Group, 1995, 231 pp.

14. Tourist Hunting in Tanzania. Edited by N. Leader-Williams, J.A. Kayera and G.L. Overton, 1996, 138pp.

15. Community-based Conservation in Tanzania. Edited by N. Leader-Williams, J.A. Kayera and G.L. Overton, 1996, 226pp.

16. The Live Bird Trade in Tanzania. Edited by N. Leader-Williams and R.K. Tibanyenda, 1996, 129pp.

17. Sturgeon Stocks and Caviar Trade Workshop: Proceedings of a Workshop, 9-10 October 1995 Bonn, Germany. Federal Ministry for the Environment, Nature Conservation and Nuclear Safety and the Federal Agency for Nature Conservation. Edited by V.J. Birstein,

A. Bauer and A. Kaiser-Pohlmann, 1997, 88pp.

18. Manejo y Uso Sustentable de Pecaries en la Amazonia Peruana. R. Bodmer, R. Aquino, P. Puertas, C. Reyes, T. Fang and N. Gottdenker, 1997, 102pp.

19. Proceedings of the Twelfth Working Meeting of the IUCN/SSC Polar Bear Specialist Group, 3-7 February 1997, Oslo, Norway. Compiled by A.E. Derocher, G.W. Garner, N.J. Lunn and Ø. Wiig, 1998, 159pp.

20. Sharks and their Relatives - Ecology and Conservation. Compiled by M. Camhi, S. Fowler, J. Musick, A. Bräutigam and S. Fordham, 1998, 39pp. (Also in French)

21. African Antelope Database 1998. Compiled by R. East and the IUCN/SSC Antelope Specialist Group, 1999, 434pp.

22. African Elephant Database 1998. R.F.W. Barnes, G.C. Craig, H.T. Dublin, G. Overton, W. Simons and C.R. Thouless, 1999, 249pp.

23. Biology and Conservation of Freshwater Cetaceans in Asia. Edited by R.R. Reeves, B.D. Smith and T. Kasuya, 2000, 152pp.

24. Links between Biodiversity Conservation, Livelihoods and Food Security: The Sustainable Use of Wild Species for Meat. Edited by S.A. Mainka and M. Trivedi, 2002, 137pp. (Also in French)

25. Elasmobranch Biodiversity, Conservation and Management. Proceedings of the International Seminar and Workshop, Sabah, Malaysia, July 1997. Edited by S.L. Fowler, T.M. Reed and F.A. Dipper, 2002, 258pp.

26. Polar Bears: Proceedings of the Thirteenth Working Meeting of the IUCN/SSC Polar Bear Specialist Group, 23-28 June 2001, Nuuk, Greenland. Compiled by N.J. Lunn, S. Schliebe and E.W. Born, 2002, 153pp.

27. Guidance for CITES Scientific Authorities: Checklist to Assist in Making Non-detriment Findings for Appendix II Exports. Compiled by A.R. Rosser and M.J. Haywood, 2002, 146pp.

28. Turning the Tide: The Eradication of Invasive Species. Proceedings of the International Conference on Eradication of Island Invasives. Edited by C.R. Veitch and M.N. Clout, 2002, 414pp.

29. African Elephant Status Report 2002: An Update from the African Elephant Database. J.J. Blanc, C.R. Thouless, J.A. Hart, H.T. Dublin, I. Douglas-Hamilton, C.G. Craig and R.F.W. Barnes, 2003, 302pp.

30. Conservation and Development Interventions at the Wildlife/Livestock Interface: Implications for Wildlife, Livestock and Human Health. Compiled by S.A. Osofsky and S. Cleaveland, W.B. Karesh, M.D. Kock, P.J. Nyhus, L. Starr and A. Yang, 2005, 220pp.

31. The Status and Distribution of Freshwater Biodiversity in Eastern Africa. Compiled by W. Darwall, K. Smith, T. Lower and J.-C. Vié, 2005, 36pp.

32. Polar Bears: Proceedings of the 14th Working Meeting of the IUCN/SSC Polar Bear Specialist Group, 20-24 June 2005, Seattle, Washington, USA. Compiled by J. Aars, N.J. Lunn and A.E. Derocher, 2006, 189pp.

33. African Elephant Status Report 2007: An Update from the African Elephant Database. Compiled by J.J. Blanc, R.F.W. Barnes, C.G. Craig, H.T. Dublin, C.R. Thouless, I. Douglas-Hamilton and J.A. Hart, 2007, 275pp.

34. Best Practice Guidelines for Reducing the Impact of Commercial Logging on Great Apes in Western Equatorial Africa. D. Morgan and C. Sanz, 2007, 32pp. (Also in French)

35. Best Practice Guidelines for the Re-introduction of Great Apes. B. Beck K. Walkup, M. Rodrigues, S. Unwin, D. Travis, and T. Stoinski, 2007, 48pp. (Also in French at http://www.primate-sg.org/BP.reintro.htm)

36. Best Practice Guidelines for Surveys and Monitoring of Great Ape Populations. H. Kühl, F. Maisels, M. Ancrenaz and E.A. Williamson, 2008, 32 pp. (Also in French) 


\section{IUCN}

INTERNATIONAL UNION

FOR CONSERVATION OF NATURE

WORLD HEADQUARTERS

Rue Mauverney 28

1196 Gland, Switzerland

mail@iucn.org

Tel +41229990000

Fax +41229990002

www.iucn.org 